San Jose State University

SJSU ScholarWorks

Master's Theses

Master's Theses and Graduate Research

Spring 2020

\title{
An Examination of Garden-Based Education Impacts on Title 1 Elementary School Students' Environmental Literacy in San José, California
}

Alexandra Dahl

San Jose State University

Follow this and additional works at: https://scholarworks.sjsu.edu/etd_theses

\section{Recommended Citation}

Dahl, Alexandra, "An Examination of Garden-Based Education Impacts on Title 1 Elementary School Students' Environmental Literacy in San José, California" (2020). Master's Theses. 5093.

DOI: https://doi.org/10.31979/etd.jc6k-7xjb

https://scholarworks.sjsu.edu/etd_theses/5093

This Thesis is brought to you for free and open access by the Master's Theses and Graduate Research at SJSU ScholarWorks. It has been accepted for inclusion in Master's Theses by an authorized administrator of SJSU ScholarWorks. For more information, please contact scholarworks@sjsu.edu. 


\title{
AN EXAMINATION OF GARDEN-BASED EDUCATION IMPACTS ON TITLE 1 ELEMENTARY SCHOOL STUDENTS' ENVIRONMENTAL LITERACY IN SAN JOSÉ, CALIFORNIA
}

\author{
A Thesis \\ Presented to \\ The Faculty of the Department of Environmental Studies \\ San José State University \\ In Partial Fulfillment \\ of the Requirements for the Degree \\ Master of Science
}

by

Alexandra Dahl

May 2020 
(C) 2020

Alexandra Dahl

ALL RIGHTS RESERVED 
The Designated Thesis Committee Approves the Thesis Titled

\begin{abstract}
AN EXAMINATION OF GARDEN-BASED EDUCATION IMPACTS ON TITLE 1 ELEMENTARY SCHOOL STUDENTS' ENVIRONMENTAL LITERACY IN SAN JOSÉ, CALIFORNIA
\end{abstract}

by

Alexandra Dahl

APPROVED FOR THE DEPARTMENT OF ENVIRONMENTAL STUDIES

SAN JOSÉ STATE UNIVERSITY

May 2020

Katherine Cushing, Ph.D.

Department of Environmental Studies

Carolina Prado, Ph.D.

Department of Environmental Studies

Mera Burton, M.A.

Education Outreach Program Manager

Santa Clara Valley Water District 


\section{ABSTRACT \\ AN EXAMINATION OF GARDEN-BASED EDUCATION IMPACTS ON TITLE 1 ELEMENTARY SCHOOL STUDENTS' ENVIRONMENTAL LITERACY IN SAN JOSÉ, CALIFORNIA \\ by Alexandra Dahl}

The objective of this research was to assess garden-based pedagogy as an effective strategy to increase environmental literacy in elementary-aged students. With severe environmental issues facing children today and into the future, environmental literacy is a desired outcome of environmental education programs. Such interventions create environmentally responsible citizens who understand how humans impact the natural environment and thereby act sustainably. Currently, little research exists on garden education's influence on students' environmental literacy, especially in underrepresented communities. Using a nonequivalent control group study design, this project investigated the impact of a garden education program in Central San José, CA in an underserved, mostly Latinx population. This seven-week program included learning in an on-site raised bed garden and a field trip to an urban farm. The study employed pre- and postsurveys modeled after the Children's Environmental Attitude and Knowledge Scale, participant journaling, and researcher observation to assess changes in environmental literacy in two treatment and two control classes of fourth graders living in underrepresented communities. Data were analyzed using t-tests, participant observation, and document review. Mean environmental literacy scores of students participating in the garden education program increased significantly over the control group, especially in categories of pro-environmental awareness and attitude. 


\section{ACKNOWLEDGMENTS}

This research would not have been possible without the support of many people.

I would first like to thank my thesis advisor, Dr. Katherine Cushing, for her endless guidance, patience, and input. I would also like to express sincere gratitude to Dr. Carolina Prado and Mera Burton, who make up my all female, interdisciplinary thesis committee, for dedicating their time to share their feedback and expertise.

I am grateful to the McKinley and Olinder Elementary School principals and fourth grade teachers for welcoming both the Growing Sustainably program and my research, as well as their support through the IRB approval processes.

I would also like to thank my managers and peers at CommUniverCity, for allowing me to showcase my passions in the Growing Sustainably program, as well as collect data among its participants. Likewise, I need to thank Santa Clara County Open Space Authority, for funding the Growing Sustainably program, without which this research would not have been possible.

To my friends - I thank you for always being in my corner and for listening to me speak endlessly about both my stresses and my successes.

Last, I'd like to thank my family for their unwavering encouragement and most importantly, for providing me with many outdoor experiences that eventually inspired this very research. I am forever changed by my time spent sailing in Monterey Bay, skiing and swimming in Lake Tahoe, and, of course, in the front yard gardening. 


\section{TABLE OF CONTENTS}

List of Tables ............................................................. viii

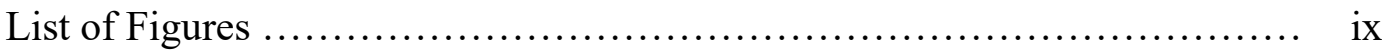

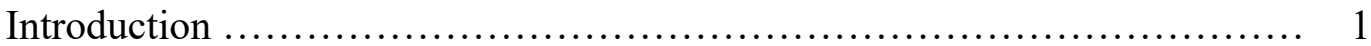

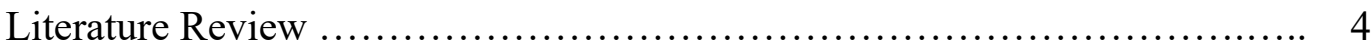

Environmental Literacy ........................................... 4

Garden Education as a Vehicle for Developing Environmental Literacy ... 10

Outdoor Experiences in Childhood ................................. 13

Outdoor Experiences \& Equity .................................... 17

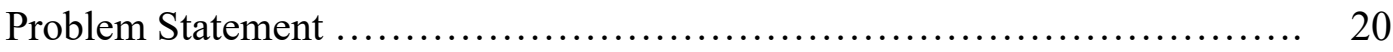

Objectives \& Research Questions .................................... 21

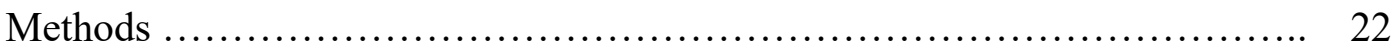

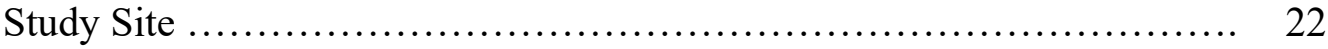

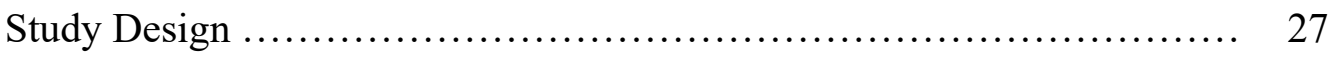

Data Collection ................................................... 29

Data Analysis .................................................. 34

Limitations ........................................................... 35

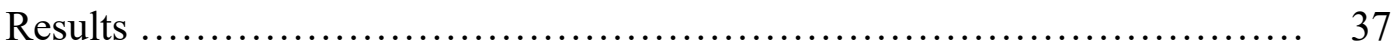

Response Rate \& Demographics ................................... 37

RQ1: What is the level of environmental literacy among elementary-age students in an underserved Central San José community? ................. 39

Environmental literacy scores ................................... 39

Environmental literacy scores by student group .................... 39

RQ2: What impact, if any, does a garden-based environmental education program have on environmental literacy? ........................... 42

RQ3: If there is a change in the level of environmental literacy, which of the five aspects of EL changes most? ................................. 45

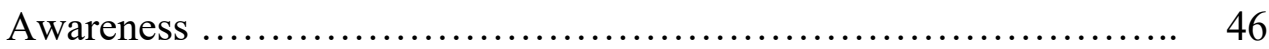

Awareness: Survey results ............................... 46

Awareness: Journal entry results ............................. 49 
Awareness: Observation results .......................... 52

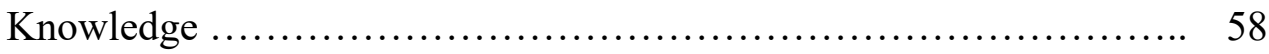

Knowledge: Survey results .............................. 53

Knowledge: Journal entry results ......................... 56

Knowledge: Observation results ............................. 58

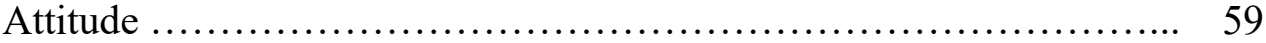

Attitude: Survey results ................................... 59

Attitude: Journal entry results ............................ 63

Attitude: Observation results ................................. 65

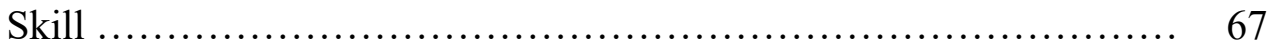

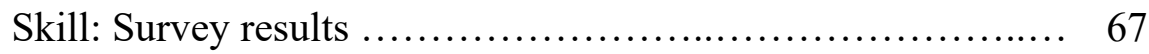

Skill: Journal entry results ................................... 70

Skill: Observation results ..................................... 72

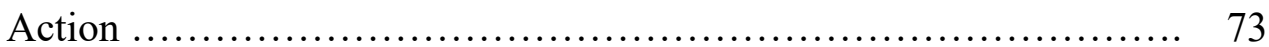

Action: Survey results .................................... 73

Action: Journal entry results ............................. 76

Action: Observation results .............................. 77

Discussion ........................................................ 80

Implications \& Recommendations .................................... 94

Recommendation 1: Lengthen EE Program \& Integrate with Existing

Curriculum ...................................................... 94

Recommendation 2: Collect Data Outside the EE Workshops \& Create More Nuanced Assessment Mechanism for Reflection ................... 97

Recommendation 3: Further Develop Holistic Assessment Measures

Method Beyond the Traditional Written Survey ......................... 98

Conclusion ......................................................... 101

References ...................................................... 105

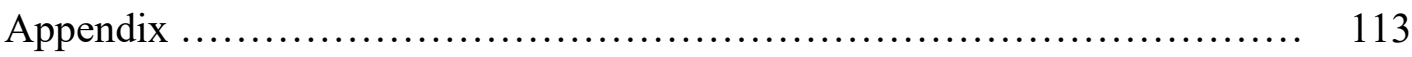




\section{LIST OF TABLES}

Table 1. Components of Environmental Literacy .......................... 6

Table 2. Impacts of Childhood Outdoor Experiences on Environmental Attitudes ................................................. 16

Table 3. Study Site Demographics ......................................... 24

Table 4. CommUniverCity Core Pillars ..................................... 25

Table 5. Environmental Literacy Pre-Test Scores by Category .............. 39

Table 6. Pre-Survey and Post-Survey EL Score Descriptions .............. 42

Table 7. EL Component Mean Changes by School ......................... 45

Table 8. McKinley Students' Pre-Survey and Post-Survey Score Descriptions ..................................................... 46

Table 9. Changes in McKinley Students' Awareness Scores, per EL Survey. 48

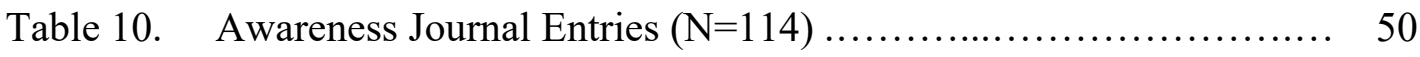

Table 11. Count of Awareness-Coded Journal Entries, by Week .............. 52

Table 12. Number of Knowledge Questions Answered Correctly $(\mathrm{N}=27) \ldots . .56$

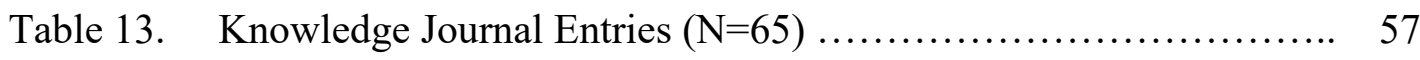

Table 14. Changes in McKinley Students' Attitude Scores, per EL Survey ... 62

Table 15. Attitudes Recorded in Participant Journal Entries .................. 64

Table 16. Changes in McKinley Students' Skill Scores, per EL Survey ....... 69

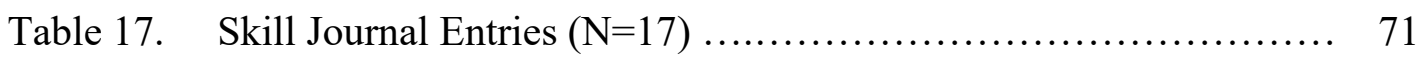

Table 18. Changes in McKinley Students' Action Scores, per EL Survey

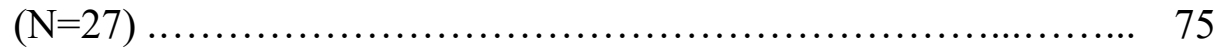

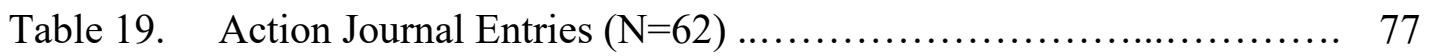




\section{LIST OF FIGURES}

Figure 1. Early model of pro-environmental behavior. Adapted from Kollmuss

\& Ageyman, 2002 5

Figure 2. EL components. Adapted from Coyle, 2005; Hungerford \& Volk, 1990; Marcinkowski, 1991; Roth, 1992; Stevenson et al., 2013;

UNESCO, 1997

Figure 3. Map of San José - McKinley Elementary (green) and Olinder

Elementary (orange). Source: Google Earth, n.d.

Figure 4. Garden educator (SJSU student intern) passes out seed packets to GS participants, April 2019 26

Figure 5. GS participants observe peacock at Veggielution Community Farm field trip, May 2019

Figure 6. Nonequivalent control group design. Adapted from Portney, 2020 28

Figure 7. Students completing journal entries after garden workshop, April 2019

Figure 8. McKinley and Olinder fourth grade students self-reported demographic information (McKinley $\mathrm{N}=27$, Olinder $\mathrm{N}=42$ ) 38

Figure 9. Percentage of EL scores received on pre-survey $(\mathrm{N}=69) \ldots \ldots \ldots \ldots \ldots .40$

Figure 10. Percentage of EL scores received on post-survey $(\mathrm{N}=69) \ldots \ldots \ldots \ldots \ldots .41$

Figure 11. Change in EL mean scores for McKinley students $(\mathrm{N}=27) \ldots \ldots \ldots \ldots .43$

Figure 12. EL mean scores for Olinder students $(\mathrm{N}=42) \ldots \ldots \ldots \ldots \ldots \ldots \ldots \ldots \ldots \ldots$

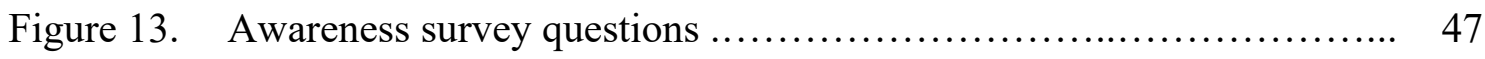

Figure 14. McKinley Elementary awareness survey scores $(\mathrm{N}=27) \ldots \ldots \ldots \ldots \ldots .49$

Figure 15. Students exploring garden bed, March 2019 .................... 53

Figure 16. Knowledge survey questions............................... 54

Figure 17. McKinley Elementary knowledge survey scores $(\mathrm{N}=27) \ldots \ldots \ldots \ldots \ldots . \quad 55$ 
Figure 18. Students working together in garden beds, May 2019 ............... 59

Figure 19. Attitude survey questions ................................. 60

Figure 20. McKinley Elementary attitude survey scores $(\mathrm{N}=27) \ldots \ldots \ldots \ldots \ldots \ldots .63$

Figure 21. GS participant shows off worms found in garden, April $2019 \ldots \ldots \ldots .65$

Figure 22. Student holds up weeds picked from garden, April 2019 ............. 67

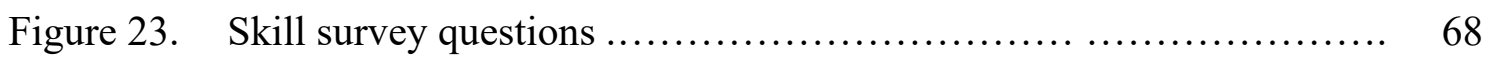

Figure 24. McKinley Elementary skill survey scores $(\mathrm{N}=27) \ldots \ldots \ldots \ldots \ldots \ldots \ldots . \ldots$

Figure 25. Students watering raised bed, May $2019 \ldots \ldots \ldots \ldots \ldots \ldots \ldots \ldots \ldots \ldots \ldots \ldots$

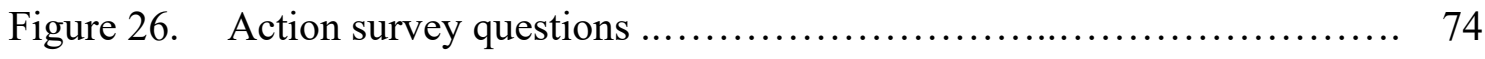

Figure 27. McKinley Elementary action survey scores $(\mathrm{N}=27) \ldots \ldots \ldots \ldots \ldots \ldots \ldots$

Figure 28. Student transferring germinated seedling to garden bed, May $2019 \ldots 79$

Figure 29. EL components ........................................... 92 


\section{Introduction}

Human-caused environmental degradation today contributes to global climate change as well as to localized issues such as water pollution. In an effort to reduce consequences of environmental destruction, such as biodiversity loss, greenhouse gas emissions, and habitat destruction, environmental education (EE) has increased in importance as a method to inform citizens about the consequences of their daily actions and encourage engagement in pro-environmental behavior. EE is education geared toward changing a broad scope of responsible environmental actions and citizenship behavior (Hungerford \& Volk, 1990). Developing effective EE is a necessary step toward creating global citizens who are knowledgeable about environmental problems and equipped with the ability to create realistic solutions.

EE originally gained popularity alongside the modern environmental movement with the publication of Rachel Carson's Silent Spring in 1962 (Sanera, 2008). While much advancement has been made in the field since the 1960s, EE still greatly lacks the ability to create citizens who demonstrate pro-environmental behavior. Although many can agree with the importance of EE, programs still are not equipped to address the goals and motivators to impact pro-environmental behavior (Marcinkowski, 1991). Hungerford and Volk (1990) cite three dominant concerns with current EE practices: the enormity of environmental issues that still exist and continue to grow; the lack of nationwide, equitably available EE programs; and the inability of current EE methods to produce skills needed to make general positive environmental behavior change, as many EE methods focus on one-off issues, leaving students ill equipped to act pro-environmentally 
on a day-to-day basis. Many issues with EE's implementation exist-particularly in integrating constantly updating information, effective communication of big-picture problems, and adapting to changing student demographics and learning styles (Hudson, 2001).

Many educators look to the No Child Left Behind Act (NCLB, 2002) as a turning point for the pressure of standardized test scores, which in many ways is ultimately a hindrance to the spread of EE. NCLB's primary goal was to shrink the gap between highachieving and low-achieving students, with a specific note given to these same discrepancies between students from disadvantaged communities and similar aged students from an advantaged background (NCLB, 2002). Although NCLB's critics do agree with the overall goal of improving the knowledge and test scores of lower-income students, these critics also recognize that this test-driven policy decreases the importance of subjects not recognized in these national reports (Griffith \& Scharmann, 2008). James Elder, Director for the North American Association for EE, recognizes the threat NCLB poses to EE efforts, due to the fact that it is not a focus in such testing or curriculum (2003). Among underperforming schools, particularly for students who are still learning English or speak a second language at home, this is even more increasingly true, as efforts to study EE, or even science in general, are thwarted by English Language Arts/Literacy (ELA) and Mathematics classes (Gruenewald \& Manteaw, 2007).

In an effort to increase rankings and test scores, non-essential classes and programs are cut and swapped out with increased study time for the core NCLB curriculum. Outdoor time in science, or even in recess, is cut down during the school day to focus on 
test preparation (Gruenewald \& Manteaw, 2007). With long school days acting as one of the largest impediments to outdoor playtime, it is important that the shift occurs toward outdoor experiences, hands-on projects, and unique subjects such as EE.

To prepare civilians with the ability to make decisions to tackle current and future environmental problems, effective EE must be addressed on a large scale. Despite EE's decades-long history, it has still failed to gain traction in integrating with U.S. curriculum (Moroye \& Ingman, 2013). With recognition that EE needs to do more in order to successfully change behavior in its students, there exists a mission of environmental educators to develop the subject as its own field and assess the environmental literacy (EL) of students. Throughout the exploration of EE as a field, EL developed as a term to describe its goals: EL encompasses the steps from, and including, knowledge to behavior. The Vice President of Education at the National Wildlife Federation claims that only roughly $1-2 \%$ of American adults can be considered environmentally literate (Coyle, 2005). With the necessity for EE programs established, it is important to shift research focus toward ensuring these programs impacting EL. 


\section{Literature Review}

\section{Environmental Literacy}

Despite a variety of application and measurement, the goals of EE are constant: creating citizens who can act appropriately toward the environment by using critical thinking, problem solving, and knowledge-backed decisions. Thus, the environmental educators in the 1990s produced a framework of EL as the EE field developed to incorporate additional necessary steps to change learner behavior (McBeth \& Volk, 2010). Developing environmentally literate learners is the end goal of EE, as EL ultimately culminates in pro-environmental behavior.

Despite the goals of EE generally being agreed upon, there still remains a lack of guidelines on effective EE opportunities and strategies. In a recent EE survey, it was found that $95 \%$ of Americans believe that EE should be taught in schools (Coyle, 2005). In California, the Environmental Literacy Task Force (2015) found that only 13\% of schools integrate EE practices into their curriculum and that students do not have regular access to appropriately funded and high-quality opportunities, both in and out of the classroom setting, to develop EL. Thus, the ensuing Senate Bill 720 (SB720) enforced the opportunity for all students to develop EL by embedding environmental principles into state-standard curriculum (CA, 2018).

One of the largest challenges adults face today is fostering future generations with the knowledge, affect, and skills to create change, hence the importance of early childhood EE (Davis, 1998). Achieving pro-environmental behavior in learners was a task once thought of as a linear trajectory from environmental knowledge to corresponding 
behavior; thus, investment was spent on education, assuming traditional education techniques would promote pro-environmental behavior in students. Now, it is realized this is not fully explanatory: increases in knowledge alone do not necessarily lead to increases in environmentally favorable behavior (Hungerford \& Volk, 1990). An early model of EE is shown in Figure 1.

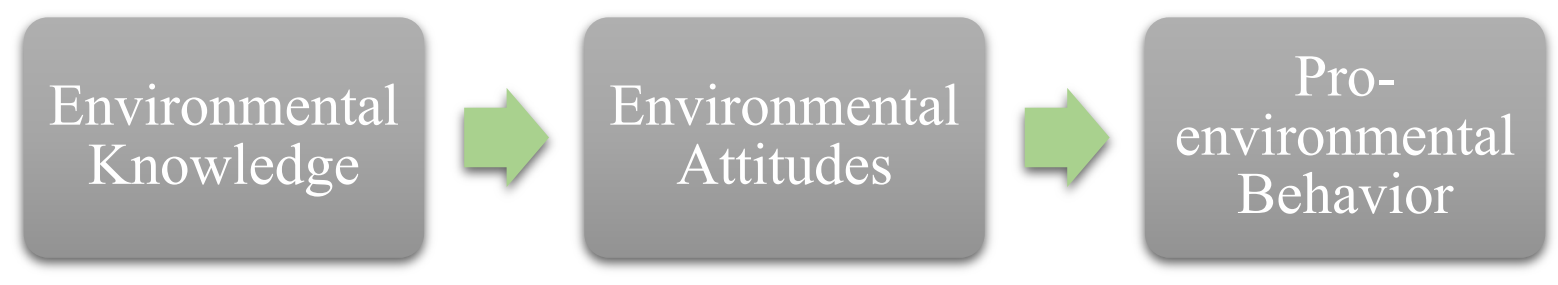

Figure 1. Early model of pro-environmental behavior. Adapted from Kollmuss \& Ageyman, 2002.

The term $E L$ was first introduced by Charles Roth in 1968 when he asked, "How shall we know an environmentally literate citizen?" in response to media coverage referring to polluters as "illiterate" (Roth, 1968). Roth's first writings on EL were reprinted in the New York Times in 1969 and then resurfaced in speeches by President Richard Nixon related to passing the National Environmental Education Act in 1970 (Roth, 1992). Since then, EL has been introduced, reused, and redefined as it lacked a proper definition, although it crept closer to becoming a common term in EE (Roth, 1992).

In 1977, the United Nations Educational, Scientific, and Cultural Organization (UNESCO) held the first international conference on EE. At its conclusion, the Tbilisi Declaration was adopted, proving the global need for effective EE. UNESCO's 1997 expansion of the declaration defined EL as "a basic functional education for all people, which provides them with the elementary knowledge, skills, and motives to cope with 
environmental needs and contribute to sustainable development" (UNESCO, 1997). EE objectives set forward at this conference outline the general guiding principles of EL today and demonstrate the link from awareness to action (see Table 1).

Table 1

Components of Environmental Literacy

\section{Component Description}

Awareness Developing a consciousness and sensitivity to the environment and its associated problems.

Knowledge Acquiring a basic understanding of the environment and its associated problems.

Attitude Developing a set of values and feelings of concern for the environment and the motivation for pro-environmental behavior.

Skill Gaining the ability to identify and solve environmental problems.

Participation Involvement at all levels in working toward resolution of environmental problems.

Note: Adapted from UNESCO, 1997, pages 26-27.

Marcinkowski (1991) adapted the widely-used overview provided by the Tbilsi

Declaration to declare that EL includes: awareness and sensitivity toward the

environment; knowledge and understanding of how natural systems work as well as how

social systems interact with natural systems; a sense of personal investment in and responsibility for work individually and collectively taken toward the resolution of environmental issues; the skills required to develop and implement strategies for remediating environmental problems; and active involvement at all levels in working toward solutions. 
Each category of EL is important in successfully achieving its goal of equipping citizens to take on environmental issues (Stevenson, Peterson, Bondell, Mertig, \& Moore, 2013). These categories are the same categories of objectives as outlined at UNESCO's Tbilisi Conference (1997) and by Marcinkowski's (1991) definition: awareness, knowledge, attitudes, skills, and participation. Someone who is considered environmentally literate demonstrates both awareness and sensitivity toward ecosystems and their issues, proficiency in understanding of the environment, concern toward environmental issues and desire to confront them, competence to recognize problems, and actively works toward solutions (Hungerford \& Volk, 1990). In Coyle's review of EE in America, he describes EL as the ultimate goal of such education programs, pointing out that literacy develops in a series of steps from knowledge, to skill growth, to application of actions (2005).

Each of the EL steps contributes to developing an environmentally literate citizen, so having all five is crucial to promoting the overall goals of EE. Roth (1992) demands that EL is a continuum from inability to having advanced abilities, contradicting what many educators suggested about the definition of literate as being something that you are or are not. As a part of this spectrum, he indicates stages of progression that successfully combine to create environmentally literate individuals (Roth, 1992). As a continuum, there are achievement levels obtained across particular stages that also touch upon the aspects of aforementioned EL definitions: understanding of human and nature interactions and accompanying consequences; a feeling that the negative consequences of these interactions need to change; an understanding of information about the present and 
future implications of human and nature interactions; insight into decision-making skills and their use in these interactions; and application of these insights into behavior changes (Roth, 1992). Figure 2 outlines the categories of EL named in this study: the color grading indicates sequencing among EL aspects to develop an environmentally literate citizen, while all five play a part in contributing.

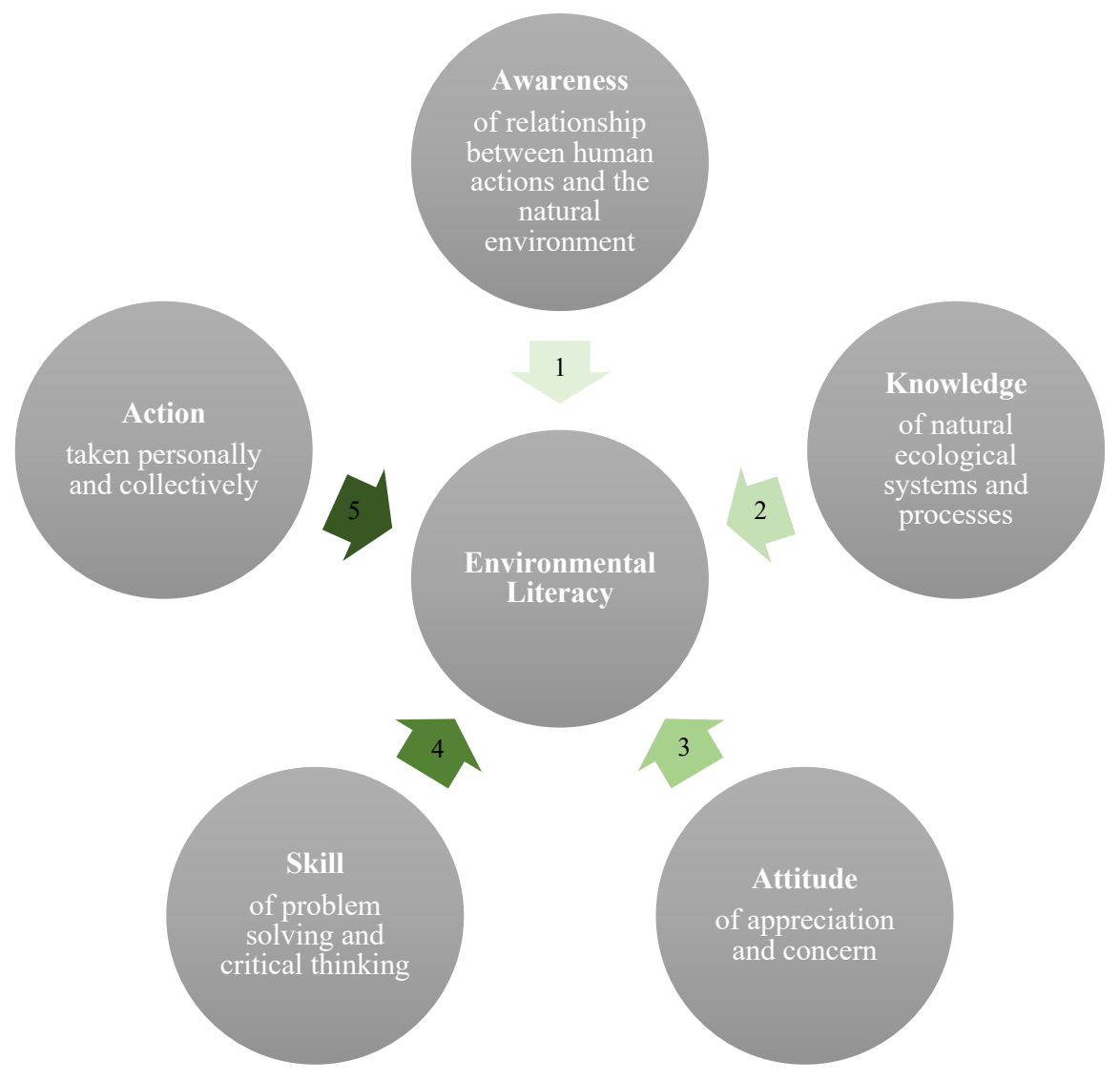

Figure 2. EL components. Adapted from Coyle, 2005; Hungerford \& Volk, 1990; Marcinkowski, 1991; Roth, 1992; Stevenson et al., 2013; UNESCO, 1997.

Roth expanded on his definition of EL by introducing a spectrum: nominal, functional, and operational levels of literacy (1992). Nominal EL refers to the ability to communicate basic knowledge of the environment, but has no connection to understanding or motivation to address problems; functional EL indicates the ability to 
understand and communicate actions that can be taken in general in regard to environmental concerns; and operational EL expresses the ability to use questioning and deductive reasoning to gather information on and make decisions resolving environmental issues (Moselely, 2000). He suggests further that one cannot demonstrate operational EL by mastering one of the phases (for example just by being environmentally aware or exhibiting pro-environmental attitudes), but rather when all of the components come together (Roth, 1992). Roth proposes that everyone sits somewhere on the EL spectrum when they have included all of the aspects of EL in their actions and decision-making. Moseley (2000) acknowledges that operational EL is the ultimate goal of EE, while also pointing out that past EE programs have focused on knowledge and awareness, implying their insufficiency in producing operationally environmentally literate students.

Within approaches for EE, many researchers recognize three separate foci: education about, in, and for the environment. The education system we are most familiar with today encompasses about the environment—in-classroom education about the Earth's natural cycles, science-based foundations, and global human-caused problems all through literature, theory, and controlled experiments. Teaching in the environment indicates the need to include exposure and subject enrichment by exiting the traditional classroom setting. As previous research shows that continuous exposure to nature is the key to increasing environmental understanding, school programs that require excursions to "pristine" nature may not prove to be incredibly effective (Fisman, 2005). These two, however, can even be intertwined—in that teaching about the environment while 
simultaneously being in the environment can really impact the student learning experience (Gough, 1990). Lastly, teaching for the environment incorporates social, political, and cultural impacts of the subject. In other words, for advocacy, the most strategically important of the EE strategies, teaching for the environment means taking ownership for human involvement in environmental degradation and understanding the underlying causes of these issues. On the importance of educating students about environmental consequences of actions, Russell and Bell (1996, p. 7) explain, "It is not a case of indoctrinating students; quite the contrary, it requires bringing to their attention choices and possibilities which are otherwise hidden." EE that falls under the for the environment category may be the most effective in changing these aforementioned categories in learners and is the focus of this research.

Experiential learning opportunities can be an effective way to foster behavior and attitude change in students. The Educational Resources Information Center defines experiential education as "learning by doing" and also denotes its shared focus and purpose as being consistent with and supporting goals of EE (Adkins \& Simmons, 2002). Garden education programs may be one of the most school campus-friendly ways to administer EE that allows growth in each of EL's five contributing pieces.

\section{Garden Education as a Vehicle for Developing Environmental Literacy}

Garden education programs in elementary schools consist of hands-on experience, increased garden knowledge, and grade-level appropriate science lessons. In such a program, students learn gardening basics such as reading seed packets, germination, and harvest times, while also participating in activities such as watering, weeding, mulching, 
planting, and harvesting. While school gardens are far from a new concept in the U.S., their purpose and intentional and unintentional consequences have evolved over time.

While the initial popularity of on-campus gardens may have developed from the desire to beautify schoolyards and encourage learning of real-world skills, today they are implemented across the country because of their impacts on public health, hands-on interdisciplinary education, and ability to provide a nature-based outlet for children Kohlstedt, 2008). Via his push for more progressive education techniques, education philosopher John Dewey supported garden education as an effective way to curate science knowledge in lieu of simple lectures (Dewey, 1923). During World War I, school gardens rose in popularity due to the encouragement of children becoming beneficial community members as well as educating on how to produce food on the home front during wartime (Kohlstedt, 2008). First Lady Michelle Obama implemented a White House raised-bed garden which was tended to by local school children, and in an interview at its opening explained, "My hope is that through children, they will begin to educate their families and that will, in turn, begin to educate our communities" (Burros, 2009).

The importance of school gardens is already largely recognized as several pieces of legislation in California alone promote their importance. In 1995, California's Department of Education enacted the Garden in Every School Initiative with the goal to encourage widespread school gardens and followed this up with several bills supporting school gardens over the next decade (Agee, 2002). In 2010, the California State Superintendent of Public Instruction publicly asked for increase prevalence of gardens in 
elementary schools as well as further research into their benefits (Steward, Purner, \& Guzmán, 2013).

Previous research supports garden education as an effective learning tool in partnership with typical classrooms. Academic performance may be directly impacted from participation in a garden program in science, math, and social sciences (Klemmer, Waliczek, \& Zajicek, 2005; Ozer, 2007). Research indicates school garden programs also lead to increase in consumption (Lautenschlager \& Smith, 2007), willingness to taste (Morgan et al., 2010) and positive attitudes toward (Linebarger \& Zajiceck, 2000) fruits and vegetables. Yet another study found that students who had gardens at their schools were more likely to try new vegetables than students who did not have a garden education program (Morris, Neustadter, \& Zidenberg-Cherr, 2001). Beyond the classroom, school gardens give students a sense of communal belonging and an appreciation for their environment along with a connection with nature (Desmond, Grieshop, \& Subramaniam, 2004) as well as improved inter-personal relationships (Cammack, Waliczek, \& Zajicek, 2002). Additionally, garden education increases time spent playing outside (Ozer, 2007). Garden education has the ability to impact students' intake of academic information, as well as positively influence interpersonal skills, life skills, and professional skills.

Some work in school gardens and hands-on EE already exists in San José. Not far from the study site itself, the California Native Garden Foundation has a goal of being a model of sustainable land use and is a space for school field trips, camps, and research training (2018). Nearby Emma Prusch Farm Park Foundation is home to seventeen 
garden plots for heirloom tomatoes, as well as an apple, cherry, pear, and persimmon orchard and a large animal barn tended to by $4 \mathrm{~K}$ students (n.d.). Saint Victor School, a private Catholic elementary school in San José, began a school garden a decade ago as an elective class and now grows so much food that leftovers are donated to the Second Harvest Food Bank (2019). Although garden opportunities are available for some children in San José, $67 \%$ of local school gardens are found in neighborhoods with less than 10\% low income households (Steward et al., 2013). Within District 3, where this study occurs, only two of San José's seventeen community gardens lie (Parks, Recreation, and Neighborhood Services, n.d). In addition, in areas of Santa Clara County where $60 \%$ of residents identified as nonwhite (were mostly Hispanic), only $15 \%$ of all county's school gardens exist (Steward et al., 2013).

\section{Outdoor Experiences in Childhood}

While in general, garden education has shown a variety of positive impacts on participants, the outdoor experience component may specifically address many of the learner changes needed to create environmentally literate citizens. Many studies have also assessed the importance of childhood exposure to nature in social, cognitive, and emotional development, on top of general awareness of and appreciation for their environment. Thomas Tanner (1980) tested a nature-exposure hypothesis through his work with active conservationists in assessing which life experiences shaped these people into pro-environmental adults. By surveying professional staff at green organizations such as the Sierra Club and the National Wildlife Foundation, he found that the dominant influence was childhood experiences in the pristine outdoors. 
Even among the general population, not simply environmental activists or professionals as many researchers have studied, exposure to natural environments before age eleven correlates to expressing pro-environmental behavior (Wells \& Lekies, 2006). Outdoor education specifically has been linked to changing student attitudes, one of the critical steps to changing environmental behavior. Elementary-aged students show significant changes in environmental knowledge and attitudes when experiencing EE within an outdoor context that is familiar to them (Cronin-Jones, 2000; Fisman, 2005; Martin, 2003). For these reasons, conducting an EE experience at an on-site garden may be an effective way of increasing pro-environmental behavior and attitudes.

With increases in built environment and decreases in natural spaces, children's reduced exposure to the outdoors is of concern to many researchers (Louv, 2005; Strife \& Downey, 2009). Garden education programs may overcome barriers to outdoor experiences such as limited access to green recreation space; schedules filled with structured programs; availability of the Internet, televisions, and video games; or concerns about safety and violence outside (Louv, 2005; Rosenfeld \& Wise, 2010; Strife \& Downey, 2009; Valentine \& McKendrck, 1997). Many studies show that how children view their natural environment proves to be a large factor in their appreciation, concern, and conservation as an adult, for example in feelings of responsibility, such as choosing to live in a smaller house even if you can afford a larger one (Bixler, Floyd, \& Hammitt 2002; Duerden \& Witt, 2010; Kollmuss \& Agyeman, 2002). The research tells us it is imperative for development of global citizens, particularly of those who go on to exhibit pro-environmental behavior, that there are outdoor opportunities available as children. 
Richard Louv coined the term "nature deficit disorder" after assessing that children are spending less time outdoors and are thus experiencing consequences in behavior and development (2005). He attests that lack of time spent in the outdoors during childhood development lead to a decreased use of the five senses, an increase in attention deficit disorders, and development of emotional and physical illnesses. Louv attributes decreased time spent outside to several societal factors, including fear of being outside from parents and the media, decreasing open space, increased street traffic, access and desire to use technology over playing outside, and a lack of importance of nature presented to children (2005). Table 2 highlights additional implications in attitudinal changes as a result of outdoor exposure for children. 
Table 2

Impacts of Childhood Outdoor Experiences on Environmental Attitudes

\begin{tabular}{cccc}
\hline $\begin{array}{c}\text { Author(s) } \\
\text { Year }\end{array}$ & Article Title & Research Question(s) & Findings
\end{tabular}

David Sobel Beyond Ecophobia
(1996)

If education focused on saving the Earth does not work, what does?
Teaching children about environmental issues prior to their appreciation of the environment itself may result in developing fear of the issues instead of wanting to work toward solutions. First, children must be exposed to and appreciative of natural environments.

$\begin{array}{ll}\text { Sonja Skelly } & \text { The Effect of an } \\ \text { \& Jayne } & \text { Interdisciplinary } \\ \text { Zajicek } & \text { Garden Program on the } \\ \text { (1998) } & \text { Environmental } \\ & \text { Attitudes of Elementary } \\ & \text { School Students }\end{array}$

Can focusing on handson experiences create an interdisciplinary approach to EE?

Outdoor, hands-on education sets up positive environmental attitudes in children. The greater number of outdoor activities a child participates in, the larger positive environmental attitudes they displayed.

\begin{tabular}{lll}
\hline Louise & Life Paths into & What motivates people \\
Chawla & Effective & to take action to protect \\
(1999) & Environmental Action & the environment?
\end{tabular}

Childhood experiences in nature influence environmental concern and career choices as adults, if the experiences are positive and frequent.

\begin{tabular}{ll}
\hline Robert D. & Environmental \\
Bixler, & Socialization: \\
Myron F. & Quantitative Tests of \\
Floyd, \& & the Childhood Play \\
William E. & Hypothesis \\
Hammitt & \\
(2002) & \\
\hline
\end{tabular}

Nancy M. Nature and the Life Wells \& Course: Pathways from

Kristi S. Childhood Nature

Lekies Experiences to Adult

(2006) Environmentalism

$\begin{array}{ll}\begin{array}{l}\text { Does childhood } \\ \text { experience in natural } \\ \text { environments have } \\ \text { effects wider than } \\ \text { stimulating adulthood } \\ \text { environmentalism? }\end{array} & \begin{array}{l}\text { Playing in natural environments } \\ \text { as a child has significant effects } \\ \text { on environmental attitudes and } \\ \text { activity preferences, but not } \\ \text { necessarily on } \\ \text { environmentalism. }\end{array} \\ \begin{array}{l}\text { How might childhood } \\ \text { interaction with the } \\ \begin{array}{l}\text { natural environment } \\ \text { begin to shape a life }\end{array}\end{array} & \begin{array}{l}\text { Exposure to natural } \\ \text { environments prior to age eleven } \\ \text { correlates to expressions of pro- } \\ \text { environmental behavior. }\end{array}\end{array}$
course trajectory with respect to environmental concerns and ecological actions?
Exposure to natural
environments prior to age eleven
correlates to expressions of pro-
environmental behavior. 
Previous literature indicates that if the goal of EE programs is to create citizens who engage in positive environmental behavior, it is imperative that these programs encompass hands-on learning, exposure to nature, and availability for all student populations, to be successful. Sociologists recognize that there are constructs larger than education that explain differences in environmental behavior, and thus look at attitudes, values, and beliefs.

\section{Outdoor Experiences \& Equity}

In discussing outdoor experiences and experiential learning, it is simultaneously important to understand the barriers many students have to these types of opportunities. In particular, students from disadvantaged communities face larger barriers to getting outside than do their more well-off peers. While school gardens have many demonstrated positive academic and social impacts on students, they are more prevalent in wealthier and less diverse schools specifically in the San José area (Steward et al., 2013).

Additionally, the range of experiences in natural environments widens across race, ethnicity, and socioeconomic demographic variances (Strife \& Downey, 2009).

Stevenson et al. (2013) found that Hispanic and African American children spend less time outdoor than their White peers and are more often excluded from outdoor recreation activities. In their study on an outdoor education program, Aguilar, Waliczek, and Zajicek (2008) found significant differences between environmental attitudes of White and of Hispanic and African-American youth and is quick to point out that previous research has also indicated that White students typically report higher environmental attitude measures than their peers. 
Reasons for this discrepancy encompass many characteristics, including fears of violence or danger outside, distance of playing fields or hiking trails, or lack of available transportation. This disproportionately affects non-White populations: for example, the placement (or lack thereof) of parks for Latinx, African American, and Asian-Pacific Islander communities or low-income housing's distance to usable outdoor spaces (Byrne $\&$ Wolch, 2002; Frumkin, 2005). Fisman (2005) found that children who live in areas where they feel unsafe may not correlate environmental knowledge with their own neighborhoods. This same study also suggests that hands-on learning may be the effective connection to these students and their ecological awareness.

Aside from physical barriers alone, cultural and language barriers exist that interfere with underserved communities' access to outdoor spaces. For example, the cost of youth recreation programs, the lack of appropriate translation or language services, or the feeling of exclusion all impede on children of color participating in outdoor activities. Limited diversity among staff of environmental experiences or facilities also closes off an introduction to these outdoor activities. For example, Hong and Anderson (2006) found that when asking Latinx families why they did not use local nature centers, they responded that these places were for "White people with money" (p. 35). EE as a field struggles with typically being associated with middle-class and White populations (Gruenewald \& Manteaw, 2007). With the continuously growing Latinx and African American population, environmental experiences that cater to only White populations leave out an important demographic (Chavez, 2012; Hong \& Anderson, 2006). 
Despite many known barriers to outdoor access for Latinx populations, many recent polls indicate positive attitudes toward the environment and solutions to environmental problems from Latinx adults. According to a study by Cornell University, although environmentalist may be commonly a title given to White, well-educated individuals, there actually exists a large underestimation of how great environmental concerns are among Latinx populations (Pearson, Schuldt, Romero-Canyas, Ballew, \& Larson-Konar, 2018). In 2012, the California League of Conservation Voters polled California Latinx voters and found that an $56 \%$ consider themselves environmentalists while $69 \%$ strongly agree we can protect the environment while creating new jobs (California League of Conservation Voters, 2012). Five years earlier, the Public Policy Institute of California also ran a poll on conservation attitudes among California adults, finding that a large percentage of Latinx adults are concerned about localized and global environmental issues. Forty-five percent of Latinx responders consider air pollution a big problem, more than any other ethnic group, although among proposed solutions such as tougher policies surrounding commercial industry and transportation, Latinx responders showed the lowest support (Public Policy Institute of California, 2007). Nationwide, Latinx are particularly vulnerable to environmental impacts such as air and water pollution, and thus are more likely to prioritize pro-environmental policy; a Latinx-focused health and environment survey Nuestro Futuro reports that nine in ten Latinx responders want climate action (Natural Resources Defense Council, 2016). It is increasingly important to increase EL learning to continue to foster these existing pro-environmental attitudes. 


\section{Problem Statement}

Among research on school gardens, there is a gap in knowledge on research in minority populations (Aguilar et al., 2008). Stevenson et al. (2013) express a need for research on EL among minority student populations, specifically within the context of outdoor experiences. Although there is much research done in school gardens, more needs to be done, particularly on academic achievement (Ozer, 2007). Steward, Purner, and Guzmán (2013) also call for the need for further studies on the impacts of school gardens among elementary-aged children. Roberts (2013) mentions that almost nothing is known about outdoor experiential education impacts on biracial or multiracial populations. This study aims to fill understanding in EL research by fully capturing each of five aspects of EL alongside a better understanding of the role garden education can play in each of these areas. This research addresses the equity gap by assessing the impacts of a hands-on EE program within Title 1 elementary schools. 


\section{Objectives \& Research Questions}

The objective of this research is to assess a garden-based EE program in terms of its impact on participant EL for elementary-age students in Central San José. By first assessing the level of EL among fourth graders in this community, this study has the goal to gauge changes in environmental understanding, knowledge, attitudes, skills, and behaviors based on participation in CommUniverCity SJSU's Growing Sustainably garden education program. This research aims to address the following questions:

1. What is the baseline level of environmental literacy among elementary school-age students in an underserved Central San José community?

2. What impact, if any, does a garden-based environmental literacy program have on environmental literacy?

3. If there is a change in the level of environmental literacy, which of the five components of EL changes the most? 


\section{Methods}

\section{Study Site}

This study took place in four fourth grade classrooms among two elementary schools in San José, CA: McKinley Elementary School (Franklin-McKinley School District) and Selma Olinder Elementary School (San José Unified School District). Although these schools are in two different school districts, share similar demographic makeups and sit only a half mile apart (Figure 3). These are both Title I schools in San José's District 3, meaning that at least $40 \%$ of students come from low-income families (U.S. Department of Education).

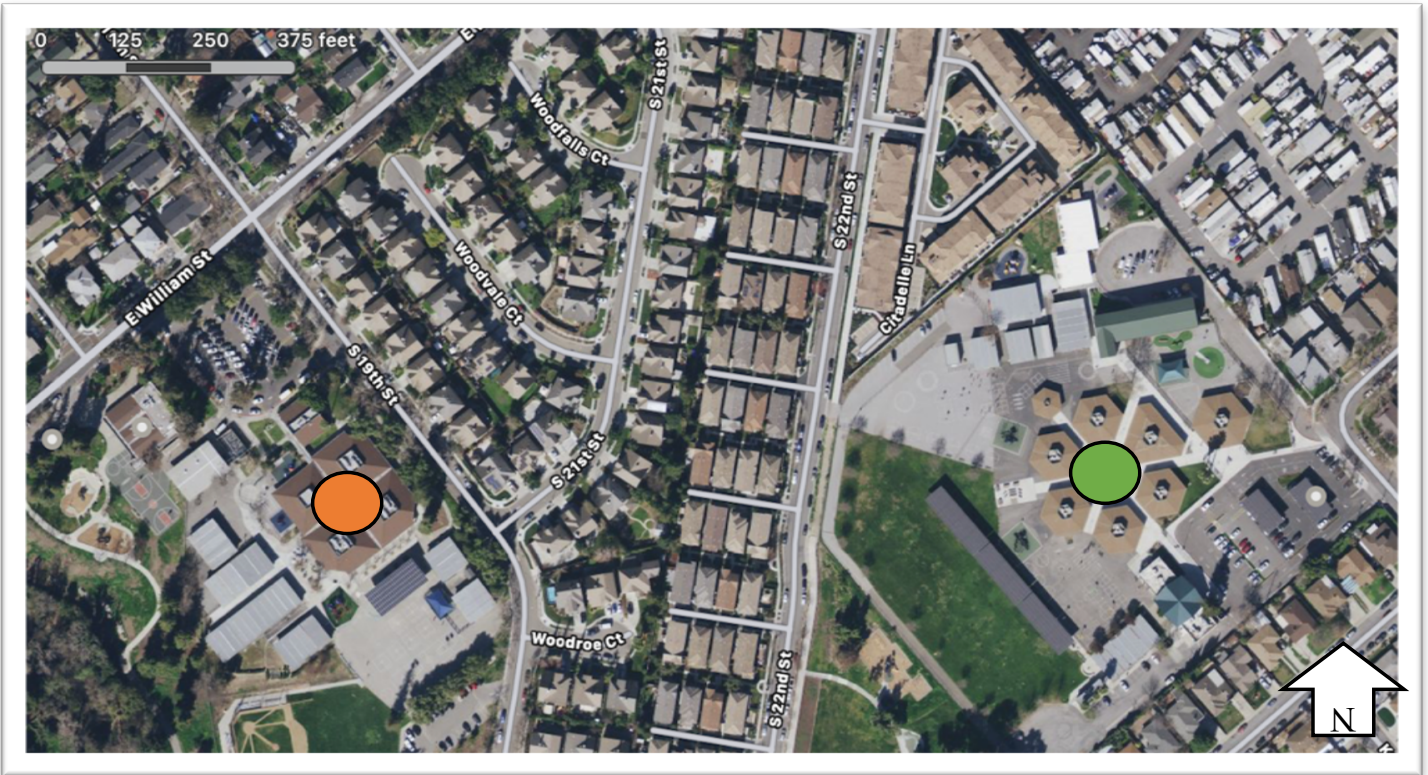

Figure 3. Map of San José - McKinley Elementary (green) and Olinder Elementary (orange). Source: Google, n.d.

McKinley Elementary is an urban, kindergarten-sixth grade elementary school with 315 enrolled students. According to the 2017-2018 School Accountability Report Card (SARC), $88.3 \%$ of McKinley students are Hispanic/Latino identifying, followed by $7.9 \%$ 
Asian, $1.6 \%$ Filipino, and $0.6 \%$ White. Additionally, only $22 \%$ of students meet or exceed state standards in ELA while 18\% meet or exceed state standards in Math. In comparison, $48 \%$ of students meet or exceed ELA standards and $43 \%$ meet or exceed Math standards for the district. Of the entire student body, $70.8 \%$ are English learners and $86.7 \%$ are socioeconomically disadvantaged (CA Department of Education). The McKinley Elementary fourth graders will receive the seven-week garden education program.

Nearby Selma Olinder Elementary enrolls 398 students in grades Kindergarten-fifth. According to the 2017-2018 SARC (prepared in the 2018-2019 school year), the student body is made up of $87.4 \%$ Hispanic/Latino, 6.5\% Asian, 3\% White, and 1.3\% Filipino identifying students. Twenty-six percent of students meet or exceed ELA state standards while $21 \%$ meet or exceed Math state standards. In contrast, for the district, $54 \%$ of students meet or exceed ELA and $43 \%$ meet or exceed Math standards. Furthermore, $61.3 \%$ are English learners and $87.9 \%$ are socioeconomically disadvantaged (CA Department of Education). The Olinder Elementary fourth graders will be used as the control measure in this research. All demographics are outlined further in Table 3. 
Table 3

Study Site Demographics

\begin{tabular}{|c|c|c|}
\hline Name & McKinley Elementary & Olinder Elementary \\
\hline Grades & $K-6^{\text {th }}$ & $\mathrm{K}-5^{\text {th }}$ \\
\hline Enrolled students & 315 & 398 \\
\hline Student population & $\begin{array}{l}88 \% \text { Hispanic/Latino, } 8 \% \\
\text { Asian, } 2 \% \text { Filipino, } 1 \% \\
\text { White }\end{array}$ & $\begin{array}{l}87 \% \text { Hispanic/Latino, } 7 \% \\
\text { Asian, 3\% White, and 1\% } \\
\text { Filipino }\end{array}$ \\
\hline $\begin{array}{l}\text { Students who } \\
\text { meet/exceed } \\
\text { English/Language } \\
\text { Arts (ELA) state } \\
\text { standards }\end{array}$ & $22 \%$ & $26 \%$ \\
\hline $\begin{array}{l}\text { Students who } \\
\text { meet/exceed } \\
\text { Mathematics state } \\
\text { standards }\end{array}$ & $18 \%$ & $21 \%$ \\
\hline English learners & $71 \%$ & $61 \%$ \\
\hline $\begin{array}{l}\text { Socioeconomically } \\
\text { disadvantaged } \\
\text { students }\end{array}$ & $87 \%$ & $88 \%$ \\
\hline
\end{tabular}

Note: Source: CA Department of Education.

CommUniverCity SJSU (CUC), a community-based organization that intertwines the needs of the local neighborhoods with support from city leaders and San José State University (SJSU) student leaders and faculty, oversees the garden education program. Each of CUC's 40 unique projects focus in three main areas: engagement, education, and neighborhood revitalization. These programs are developed specifically by requests and demands from SJSU's Central San José neighboring communities, and include financial literacy workshops, writing skill development, community fairs, preservation of safe outdoor spaces, and legal consultation for expungement law (CUC SJSU, n.d.). Inspired 
by locally high rates of diabetes, low overall science understanding, and a need for improved outdoor education, CUC's Growing Sustainably (GS) program provides lowincome, Title 1 elementary and middle schools with a raised-bed garden, SJSU student teachers, and all necessary gardening supplies. An overview of CUC project influences is found in Table 4.

Table 4

\section{CommUniverCity Core Pillars}

\begin{tabular}{l|ll}
\multicolumn{1}{c}{ Engage } & \multicolumn{1}{c}{ Learn } & \multicolumn{1}{c}{ Build } \\
& \multicolumn{1}{c}{. Education } & - Neighborhood \\
- Community health & - Service-learning & revitalization \\
- Skill building & experiences & - Community participation \\
- Leadership & "College-going" culture & - Community fairs \\
- Roles in community & - Civic engagement & \\
&
\end{tabular}

Note: Source: CommUniverCity SJSU, n.d.

The GS program has three main focus areas: in-class garden education, after-school garden clubs, and an after-school cooking club. Each of these workshop series is taught by a team of SJSU student interns from an interdisciplinary background of study fields: Environmental Studies, Urban Planning, Nutrition Sciences, or Child and Adolescent Development. The CUC Project Coordinator, based on need, demand, and ability to expand the program each academic year, recruits each school and class receiving the GS program. This Project Coordinator also recruits, hires, and trains interns each semester, who in turn work in pairs to develop each unique lesson plan. Topics taught include recycling, photosynthesis, seed germination, composting, soil components, pollinators, climate change, the plant life cycle, and the water cycle. Each lesson is taught by the 
interns, with the Project Coordinator overseeing, and is developed with an emphasis on connection to state standard curriculum and topics taught in students' various other subjects. This research focuses solely on the in-class garden education portion of the GS program because of its consistency of attendance and therefore ease of data gathering.

The seven-week long GS program begins at the start of each academic semester (August and January), creating two cycles per year to serve as many local classrooms as possible. Each week topics progress down the natural timeline of gardening-ranging from mulching, planting, watering, weeding, harvesting, all intertwined with observation, measurement, and maintenance. Lessons are comprised of lecture, worksheets, crafts and activities, and time outdoors in on-site raised bed gardens. Throughout the length of the seven weeks, each class is taught by the same pair of SJSU student interns as a way to develop rapport, comfort, and accountability. Figure 4 captures a student intern working closely with garden education participants.

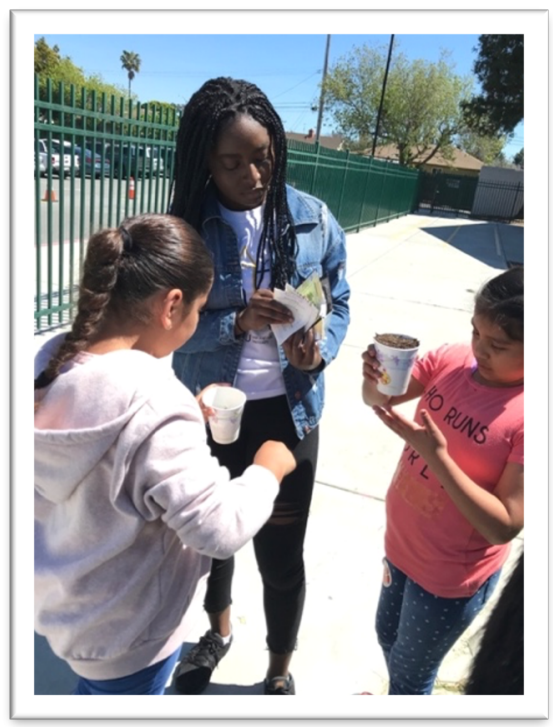

Figure 4. Garden educator (SJSU student intern) passes out seed packets to GS participants, April 2019. 
Culminating the six weeks of garden lessons, the students embark on a field trip to Veggielution Community Farm, just a few blocks from their school campus (Figure 5). Veggielution is a nonprofit 6-acre urban farm, founded by former SJSU students on land donated to the city, with the goals to connect community members through food, farming, and outdoor experiences (Veggielution, 2019). Field trip topics include natural resources, watersheds, agriculture, and nature's health benefits. Activities include planting, weeding, and harvesting, all with a focus on collaborative team efforts.

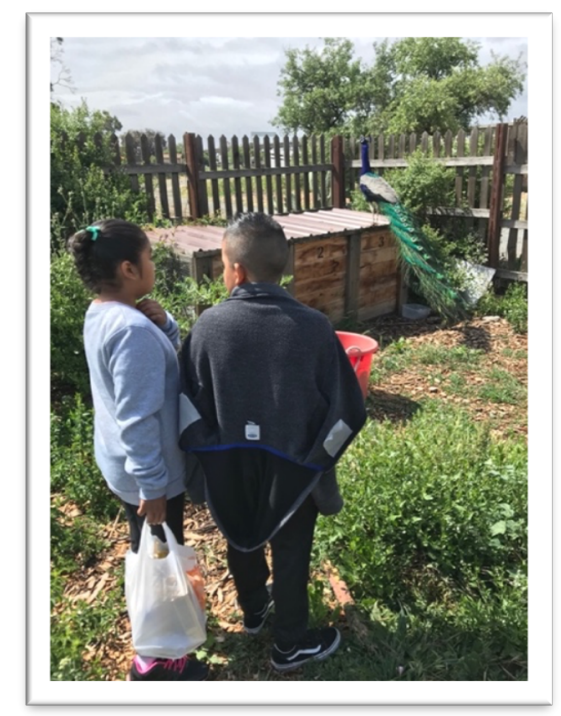

Figure 5. GS participants observe a peacock at Veggielution Community Farm field trip, May 2019.

\section{Study Design}

This research is a pretest-posttest nonequivalent control groups design with a sevenweek educational intervention. Due to the nature of pre-established classrooms and each school's availability to host raised-bed gardens, the participants for this study are not necessarily randomly selected and thus this study is denoted as a nonequivalent control group (Campbell \& Stanley, 1963). As these two elementary schools have comparable 
demographics, a baseline measure was taken of all four classrooms of each of the five areas of EL: awareness, knowledge, attitude, skill, and action.

The garden program intervention was given to the two fourth grade classrooms at McKinley Elementary School. During each weekly GS lesson, students were asked to complete a one-page journal entry reflecting on what they learned, did, and felt, during the garden workshop. After the seven-week program, another measure was taken of each of the five aspects of EL for all four classrooms (two different populations). Analysis was both between participants, the control in contrast to the experimental, and within participants, a change from the beginning to the end of the treatment (see Figure 6).

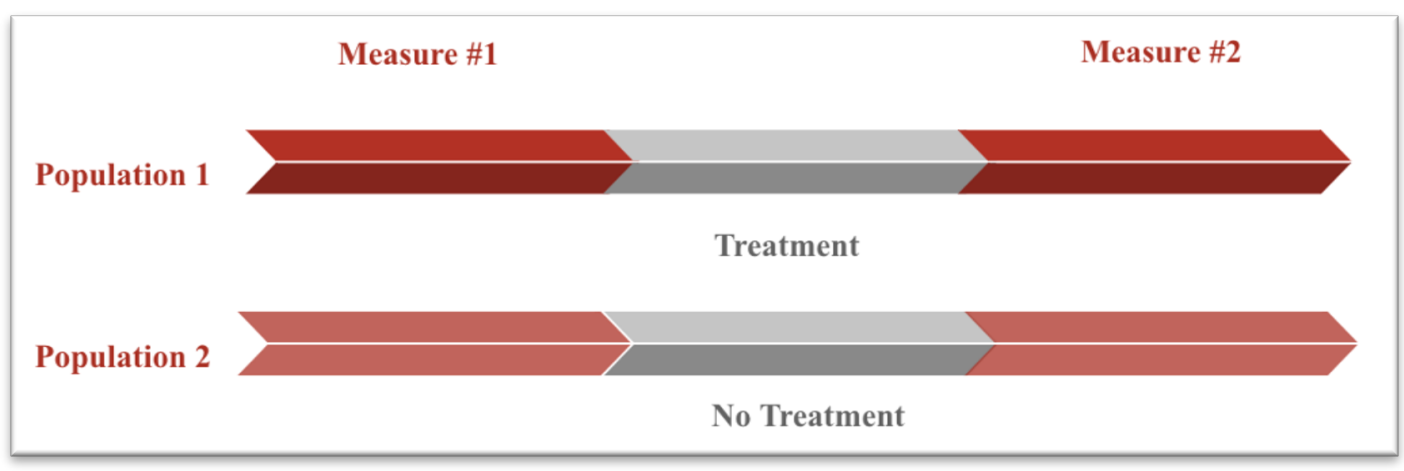

Figure 6. Nonequivalent control group design. Adapted from Portney, 2020.

Both fourth grade classes at each of these schools make up the subject population. Fourth grade is a popular target demographic for research due to the National Assessment of Educational Processes testing beginning in this grade nationwide. Thus, fourth grade is determined to be the point when literacy and reading comprehension must be established in order to move forward academically (Allington \& Johnson, 2000). Fourth grade has also been denoted the "slump," because this is the age in which the transition of reading comprehension and literacy become a challenge for many students (Chall, 1983). 
Additionally, fourth grade students are currently the oldest population of students at both McKinley Elementary and Olinder Elementary Schools who have not yet received the GS program. To fully capture the impact of this program, it is important that these students have never received a formal garden education program, but also that the organization has the ability to expand the program to include these students.

\section{Data Collection}

Data collection consisted of self-administered surveys, participant journaling, and researcher observations. By utilizing both quantitative and qualitative methods, a variety of participant experiences, literacy levels, and general abilities can be taken into account (Barker \& Weller, 2003).

EL measures were completed via Likert scale and multiple-choice option survey, which was chosen due to their frequent usage in capturing attitudes and opinions in children and is available in Appendix (Fisman, 2005; Mellor \& Moore, 2013; Miller, Giesbrecht, Müller, McInerney, \& Kerns 2012). When applicable, response options were emoticons, as appropriate to age and literacy level of participant demographic. Inspiration for use of emoticons came from Hall, Hume, and Tazzyman (2016), who used 5-point smiley face Likert scales with children age nine-11 and found it to be an effective tool. Additionally, Mellor and Moore (2013) found that children have difficulty responding to numeric Likert scale responses and instead respond better with words—specifically showing ease of use in categories of frequency. Thus, frequency responses are used in opportunities to track action, and all Likert scale response options are emoticons accompanied words. Benson and Hocevar's (1985) research on surveying children 
confirms previous studies that negatively phrased questions reduce the validity of the overall survey, so only positively phrased questions will be used. Lastly, Likert scale research in both adults and children indicates that participants are drawn to select the first responses given—often referred to as "Left-side bias" (Krosnick \& Alwin, 1987). To compensate for this potential bias, two surveys of identical questions are created with reversed response order: for example, survey A features responses transcribed as AngryExcited or Never-Always while survey B's responses are written as Excited-Angry and Always-Never. Both control and experimental groups receive each of these surveys, as one of each will be administered to each group.

The survey itself is modeled after Leeming, Dwyer, \& Bracken's (1993) Children's Environmental Attitude and Knowledge Scale (CHEAKS), the initial assessment tool for EL, after which several other surveys were modeled, such as the Middle School Environmental Literacy Survey (MSELS) (Ruggerio, 2016). CHEAKS consists of 29 knowledge and 36 attitude questions (12 verbal commitments, 12 actual commitments, and 12 affect) focusing on six different areas: animals, water, energy, recycling, pollution, and general issues. By administering CHEAKS to elementary through junior high school children, Leeming, Dwyer, \& Bracken found it to be a highly valid tool to assess knowledge, attitudes, and knowledge of the environment (1995). However, CHEAKS has been critiqued as lacking a theoretical framework (Johnson \& Manoli, 2010) as well as for its difficulty and inclusion of actions that are typically above a child's control (Evans et al., 2007), so modifications were taken to combine CHEAKS 
with fourth grade Next Generation Science Standards. In fifteen questions, this survey assesses awareness, knowledge, attitudes, skills, and actions.

Questions 1-3 measure awareness, defined as understanding of human impacts on the natural environment, both positively and negatively. The scores spread from (1) No! to (5) Yes!. A higher score (15) indicates someone with high environmental awareness, while a lower score (3) indicates someone with low environmental awareness.

Questions 4-6 measure knowledge, or specifically an understanding of the natural functions of the Earth. A higher score (3) indicates someone with high environmental knowledge, while a lower score (0) indicates someone with low environmental knowledge. Possible scores for each individual question were either zero or one, indicated by selecting the correct multiple-choice option; selecting the "I'm not sure" answer received zero points. Scores were recoded so that the total possible range of scores for knowledge was three to 15 to ensure all variables carried the same weight on the EL survey. To do this, students who did not answer any of the three questions correctly (score of 0 ) were given a baseline of a score of three, answering one question correctly became a score of seven, answering two questions correctly became a score of 11 , and answering all questions correctly became a score of 15 .

Questions 7-9 assess attitude, or personal feelings toward the environment and accompanying environmental issues. Scores range from (1) Angry to (5) Excited. After recoding, a higher score (15) indicates someone with favorable environmental attitudes while a lower score (3) indicates someone with unfavorable attitudes. 
Questions 10-12 evaluate skill, defined here as knowledge of what actions can be taken to manage environmental issues and each question asks of a specific task that can be done to reduce human-caused environmental destruction. A higher score (3) indicates someone with a high environmental skillset and a low score (0) indicates a lower environmental skillset. Possible scores for each individual question were either zero or one, indicated by selecting the correct multiple-choice option; selecting the "I'm not sure" answer received zero points. Scores were recoded so that the total possible range of scores for skill was three to 15 to ensure all variables carried the same weight on the EL survey. To do this, students who did not answer any of the three questions correctly (score of 0 ) were given a baseline of a score of three, answering one question correctly became a score of seven, answering two questions correctly became a score of 11, and answering all questions correctly became a score of 15 .

Questions 13-15 measure action, or the frequency with which a specific proenvironmental task has actually been performed. The scores range from (1) Never to (5) Always. A higher score (15) indicates someone with high pro-environmental behavior, while a lower score (3) indicates someone with low pro-environmental behavior.

Each survey included a front sheet asking for name and demographic information. This information was used to compare against consent forms and to recode student names. Surveys were administered by the researcher via paper during the regular school day after obtaining assent from participants and each question was read aloud to reduce confusion or literacy barriers. Students were encouraged to raise their hand if there was confusion. Pre-surveys were completed immediately before the beginning of the garden 
workshop program and post-surveys were administered immediately after the culminating lesson (a field trip to an urban farm). Surveys were administered to control classrooms within one week of each of these aforementioned project implementation milestones. Paper surveys were immediately collected and be transcribed via Google Forms by the researcher. Surveys were completed in English.

Additionally, participants were asked to record their thoughts on each garden workshop session via a journaling worksheet in order to capture further insight into their experiences in the program. For younger research participants, structured interviews may not be effective, so guided reading and writing activities can be used in substitution to gain insight (Mauthner, 1997). The researcher provided half-sheet paper worksheets at the end of each lesson consisting of prompts: "Today in garden workshop, I learned, I felt, and I did." Students were instructed to answer to all three prompts, as well as to add any additional thoughts they would like to share and return to the researcher at the end of each workshop. Due to the variety of literacy levels in this sample population, students were given the option to draw or write their responses. When asking children to record their answers, using drawings can be appropriate as contextually determined (Barker \& Weller, 2003). Thematic analysis of written thought may provide a better way to capture which aspects of the education program had an impact on students than surveys alone (Reissman, 1993). The researcher then collected, transcribed, and coded each weekly journal entry. Figure 7 captures students completing journal worksheets. 


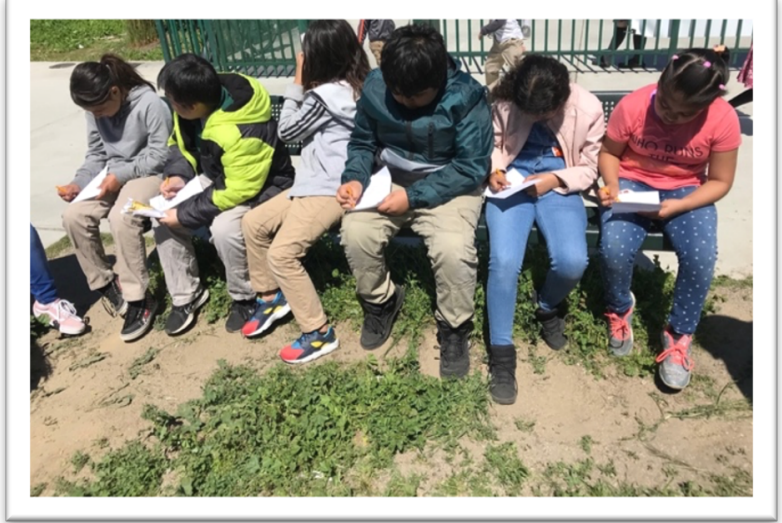

Figure 7. Students completing journal entries after garden workshop, April 2019.

Lastly, the researcher was present for all garden workshop lessons to act as a participant observer and recorded observations in conversation, behavior, attitudes, and awareness. As school grounds provide optimal field study opportunities on childhood play, cognitive and social development, and nature exposure in a built environment, adding observation to this study enhanced further qualitative data opportunities.

Observation sheets were inspired by Tranter and Malone's (2004) behavioral observation sheets of children's use of school grounds. Children were observed and both interaction and behavior were recorded: such as participation activities, involvement with nature, and number of students together. Details captured also included lesson topic, physical weather conditions, number of children present, time spent in garden, and date.

Observation sheets were later transcribed onto Word and recoded by the researcher based on previous similar work conducted by Creswell and Clark (2017).

\section{Data Analysis}

Mixed methods were used to analyze data; by combining both quantitative and qualitative methods, results are more diverse and encompassing (Creswell \& Clark, 
2017). First, survey data were analyzed using an independent samples t-test to assess differences between student groups and a paired t-test to assess changes in EL within individuals over time (Bhattacherjee, 2012). The researcher used SPSS version 25 software to complete statistical tests.

Additionally, both student journal entries and observation data were analyzed using thematic coding analysis. Emergent themes were hand-coded to identify patterns and changes (Reissman, 1993; Creswell \& Clark, 2017).

\section{Limitations}

There were several limitations to this study, particularly associated with methods. First, the length of this study was quite short. In a seven-week workshop series, it can be difficult to assess true changes in many of the categories collected here. Some of the more complicated topics are lost in such a short program. Additionally, data were only collected during the garden workshops themselves. It was difficult to assess some of these categories' changes when the researcher only had insight into the students for an hour a week. Another limitation surrounds the data collection method. Students may feel obligated to report to their teacher or an adult researcher present in the classroom the answer they believe the adult wants to hear, as opposed to what may be their actual thought or opinion. This can create an overexaggerated report of good behavior, proenvironmental attitudes, etc. Further, the EL survey used for this study used only three questions per EL category: using such specific parameters and so few questions for each category may not be an ideal representation of the true changes experienced by participants. Lastly, the children who participated in this study exhibited limited reading 
and writing discomfort, which made data collection via survey and written journal entries difficult. 


\section{Results}

\section{Response Rate \& Demographics}

In total, 87 pre-surveys and 89 post-surveys were collected for a total of 176 surveys. Some students were absent for either pre- or post-survey distribution, so in total 71 pairs of pre- and post-surveys were collected across both the control and treatment groups. To accommodate a few extreme outliers, all cases falling outside two standard deviations from the mean were removed. Therefore, 69 pairs of pre- and post- surveys were used in this data analysis.

Olinder Elementary has a larger fourth grade population; $42(60.8 \%)$ pairs of surveys were used while 27 (39.1\%) pairs of McKinley student surveys were used. Among all students (N=69), 55 (79.7\%) self-reported as Hispanic/Latino/a, 5 (7.2\%) as Asian/AsianAmerican, and $3(4.3 \%)$ as White. Students were given the option to select more than one ethnic option on the survey, but only $3(4.3 \%)$ of students chose to do this. Students were also asked what language(s) they spoke at home and were once again allowed to select more than one option. Among all students, 44 (63.8\%) speak both English and Spanish, $12(17.4 \%)$ speak only Spanish, 6 (8.7\%) speak only English, and 3 (4.3\%) speak both English and Vietnamese with their families outside of school. Thirty-four (49.3\%) were female and $32(46.4 \%)$ were male.

The survey data show that demographic information for these two separate populations of fourth graders is very similar. At McKinley Elementary, 23 (85.2\%) of students reported their ethnicity as Hispanic/Latino/a, three (11.1\%) reported as Asian/Asian-American, and one (3.7\%) reported as Black/African-American and 
Hispanic/Latino/a. Regarding languages spoken at home, 17 (63\%) reported English and Spanish, four (14.8\%) reported Spanish, three (11.1\%) reported English and two (7.4\%) reported English and Vietnamese. At Olinder Elementary, 32 (76.2\%) of students reported ethnicity as Hispanic/Latino/a, three (7.1\%) reported White, two (4.8\%) each reported Asian/Asian-American and Native American/Alaskan Native. Regarding languages spoken at home, 27 (64.3\%) reported English and Spanish, eight (19\%) reported Spanish, and three (7.1\%) reported English. These comparisons are outlined side-by-side in Figure 8.

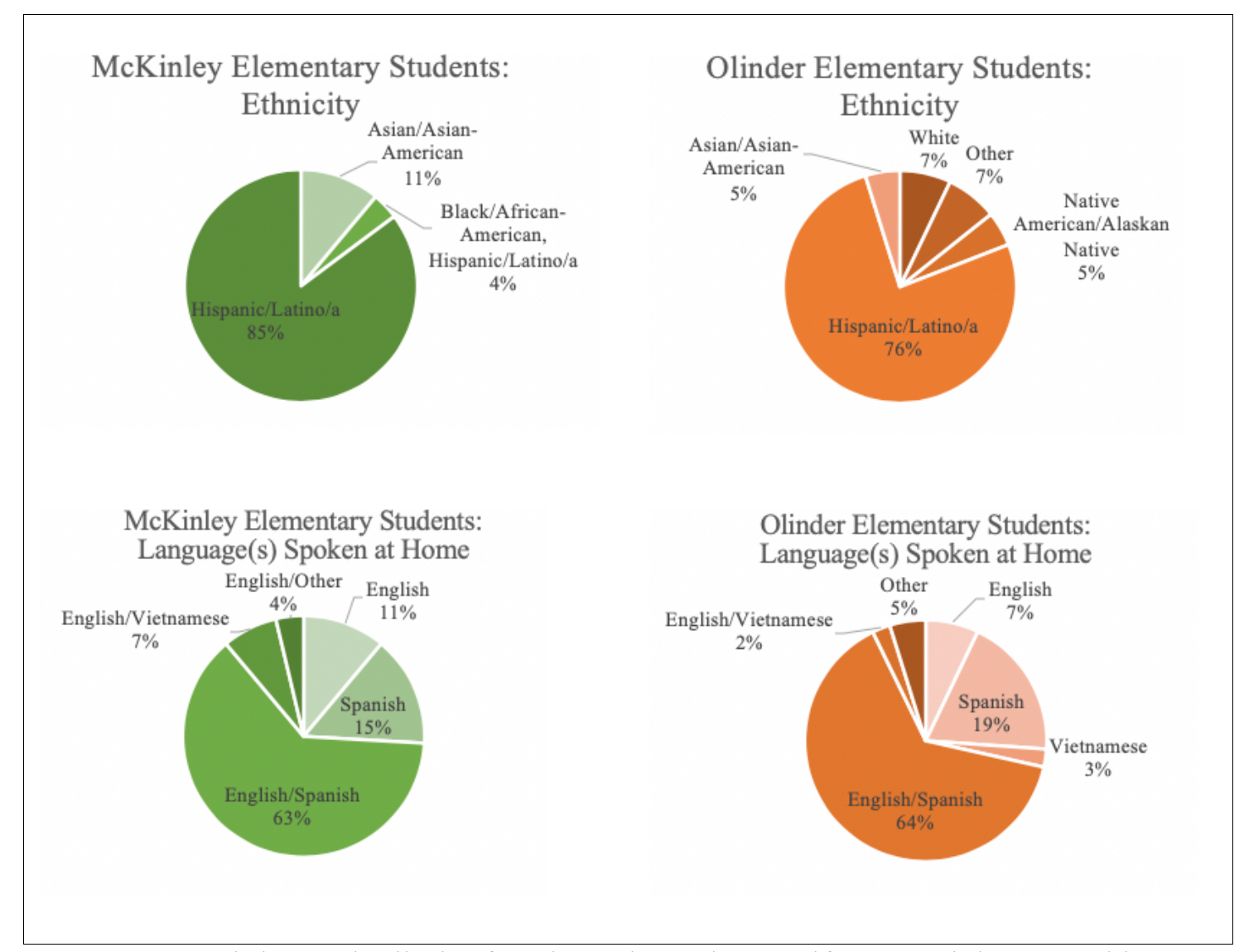

Figure 8. McKinley and Olinder fourth grade students self-reported demographic information (McKinley $\mathrm{N}=27$, Olinder $\mathrm{N}=42$ ). 
RQ1: What is the level of environmental literacy among elementary-age students in an underserved Central San José community?

Environmental literacy scores. The EL survey combined five aforementioned aspects of EL to create an overall EL score aggregated from 15 questions. Possible EL scores ranged from 15 to 75 , in which a higher score indicates a higher EL rate. Table 5 shows possible score ranges and mean scores for the study sample pre-test group.

Table 5

Environmental Literacy Pre-Test Scores by Category

\begin{tabular}{|l|l|l|l|l|l|l|}
\hline & Awareness & Knowledge & Attitude & Skill & Action & $\begin{array}{l}\text { Total } \\
\text { EL }\end{array}$ \\
\hline $\begin{array}{l}\text { Lowest possible } \\
\text { score }\end{array}$ & 3 & 3 & 3 & 3 & 3 & 15 \\
\hline $\begin{array}{l}\text { Highest possible } \\
\text { score }\end{array}$ & 15 & 15 & 15 & 15 & 15 & 75 \\
\hline $\begin{array}{l}\text { Mean score for all } \\
\text { participants }\end{array}$ & 11.52 & 6.77 & 10.81 & 9.14 & 7.92 & 46.17 \\
\hline
\end{tabular}

Note: All students, $\mathrm{N}=69$

Environmental literacy sores by student group. The pre-program EL score for McKinley students averaged $45.85(\mathrm{~N}=27)$; the lowest score recorded was 36 and the highest was 57. At Olinder Elementary, baseline EL scores averaged $46.38(\mathrm{~N}=42)$ where the lowest score was 35 and the highest score was 59.

After the GS program concluded with a trip to a local urban farm, McKinley students were again given the EL survey. This time, their mean EL score was 49.07; the lowest score was 33 and the highest was 60 . The same week, Olinder students were given the 
survey. Their average EL score was 46.76; the lowest score was 32 and the highest was 58.

To assess a difference in these scores per each group of students, an independentsamples t-test was conducted. For the pre-survey, there was no statistically significant difference in scores for McKinley students (mean=45.85, $\mathrm{SD}=5.99$ ) and Olinder students (mean $=46.38, \mathrm{SD}=6.15 ; \mathrm{t}(67)=-.35, \mathrm{p}=0.726$, two-tailed). The magnitude of differences in the means (mean difference $=-.53,95 \% \mathrm{CI}=-3.53$ to 2.47 ) was small (eta squared $=0.001$ ). The percentage of students in each class receiving each score is explored in Figure 9, which depicts scores being closely aligned. Percentage of EL scores for both schools at pre-survey is presented in Figure 9.

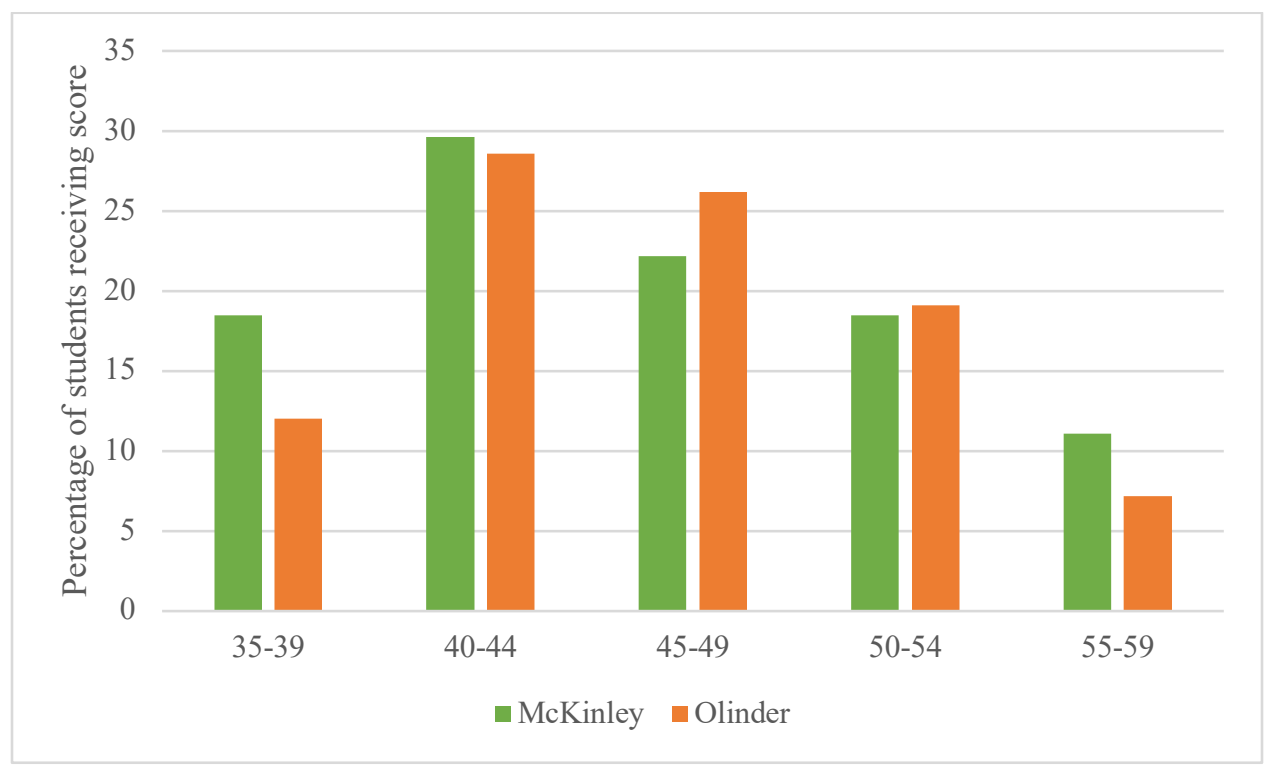

Figure 9. Percentage of EL scores received on pre-survey $(\mathrm{N}=69)$.

Both student groups showed an increase in EL scores at post-survey. McKinley students averaged an aggregate score of $49.07(\mathrm{SD}=6.55)$ while Olinder students averaged 46.76 , although these difference were not statistically significant, according to 
an independent samples t-test $(\mathrm{SD}=47.50 ; \mathrm{t}(67)=1.31, \mathrm{p}=0.194$, two-tailed $)$. The magnitude of the differences in the means (mean difference $=2.31,95 \% \mathrm{CI}=-1.21$ to 5.83 ) was moderate (eta squared $=0.02$ ). Percentage of EL scores for both schools at postsurvey is presented in Figure 10.

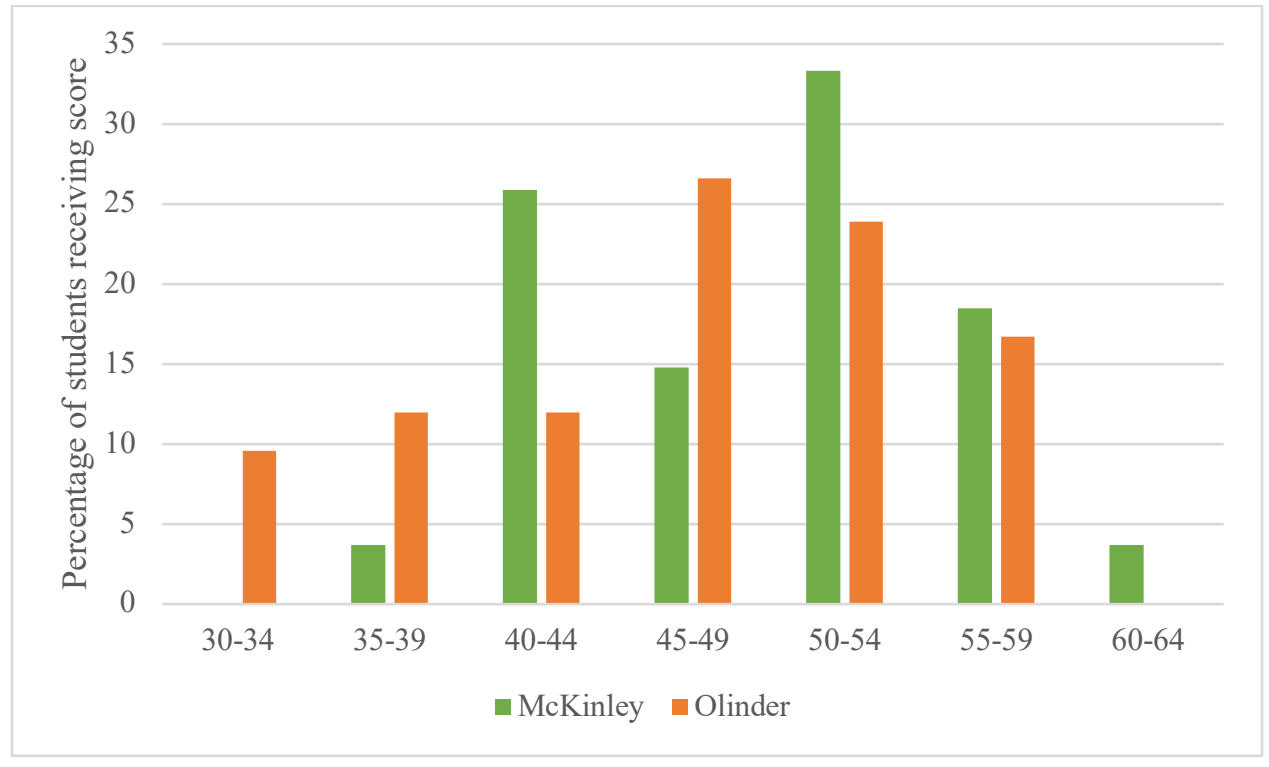

Figure 10. Percentage of EL scores received on post-survey $(\mathrm{N}=69)$. 


\section{RQ2: What impact, if any, does a garden-based environmental literacy program have on environmental literacy?}

McKinley Elementary School fourth grade students, all of whom participated in the seven-week GS program, showed a mean increase in EL score from pre- to post-survey of 3.22 points, a $7.02 \%$ increase. On a possible point range of 15 to 75 , the range of total EL scores widened from pre- to post-survey as well, with a 21-point range of submitted responses on pre-survey and a 27-point range of responses on post-survey. One additional student scored higher on post-survey than did on pre-survey.

For Olinder students, who did not participate in any specific EE programs, EL mean scores increased slightly from pre- to post-survey, by 0.38 points, a $0.82 \%$ increase. The range of received scores also increased for Olinder fourth graders, as scores submitted ranged across 24 points on pre-survey and 26 points on post-survey. Mean scores and score ranges are further outlined in Table 6.

Table 6

Pre-Survey and Post-Survey EL Score Descriptions

\begin{tabular}{llccc}
\hline McKinley & & $\begin{array}{c}\text { Lowest Score } \\
\text { (possible=15) }\end{array}$ & Mean Score & Highest Score \\
\hline$(\mathrm{N}=27)$ & Pre-Survey & 36 & 45.85 & (possible=75) \\
\hline & Post-Survey & 33 & 49.07 & 60 \\
\hline Olinder & & & & \\
\hline$(\mathrm{N}=42)$ & Pre-Survey & 35 & 46.38 & 59 \\
\hline & Post-Survey & 32 & 46.76 & 58 \\
\hline
\end{tabular}

A paired-samples t-test was conducted to evaluate the impact of the GS intervention on McKinley students' scores of EL. There was a statistically significant increase in EL scores from pre $($ mean $=45.85, \mathrm{SD}=5.99)$ to post $($ mean=49.07, $\mathrm{SD}=6.55), \mathrm{t}(26)=-2.09$, 
$\mathrm{p}=0.047$ (2-tailed). The mean increase in EL score was 3.22 with a 95\% confidence interval ranging from 6.40 to 0.05 . The shift in mean EL score can be seen in Figure 11 .

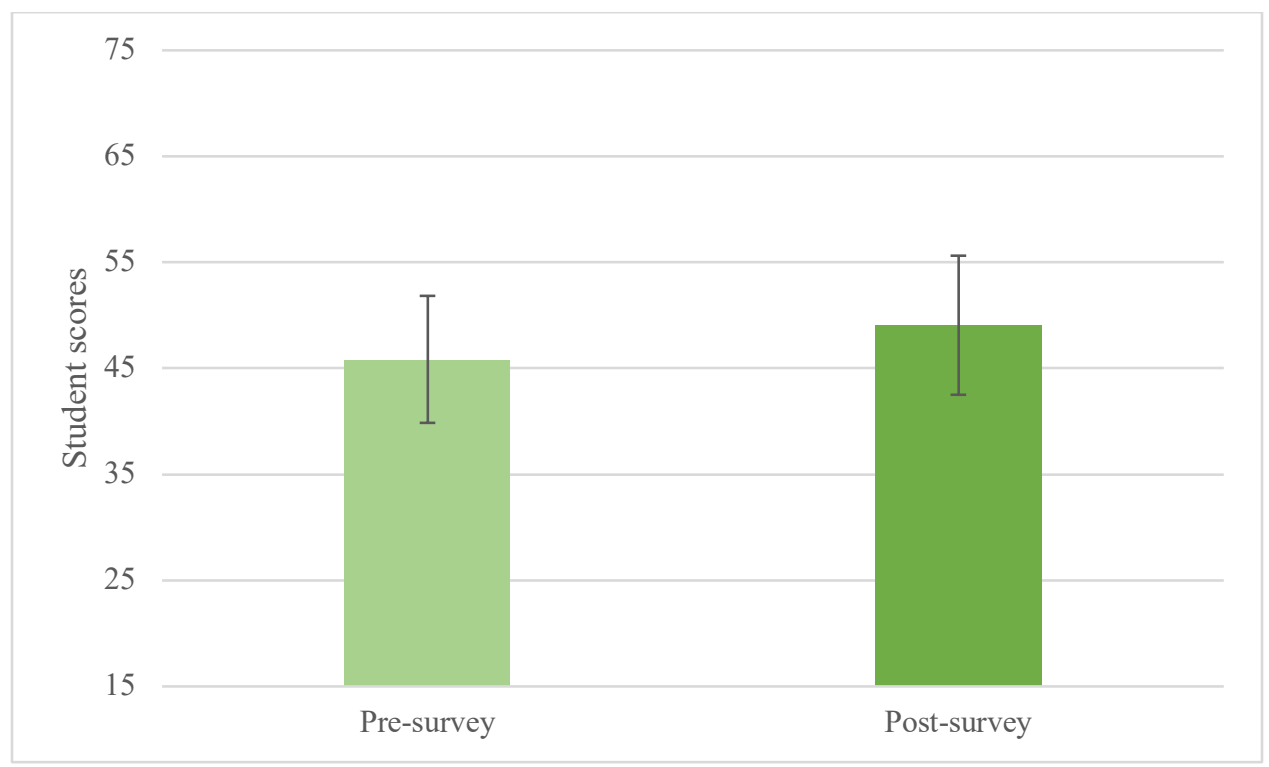

Figure 11. Change in EL mean scores for McKinley students ( $\mathrm{N}=27)$.

A paired-samples t-test was also used to evaluate the changes in EL scores among fourth grade students with no EE intervention, represented by the Olinder students. Mean EL scores only slightly increased $(+0.38)$ from pre-survey $(\mathrm{M}=46.38, \mathrm{SD}=6.15)$ to postsurvey $(\mathrm{M}=46.76, \mathrm{SD}=7.50)$ for these students over the course of the Spring 2019 semester $(\mathrm{t}(41)=0.28, \mathrm{p}=0.784$, two-tailed $)$. The Olinder students' mean EL scores can be found in Figure 12. 


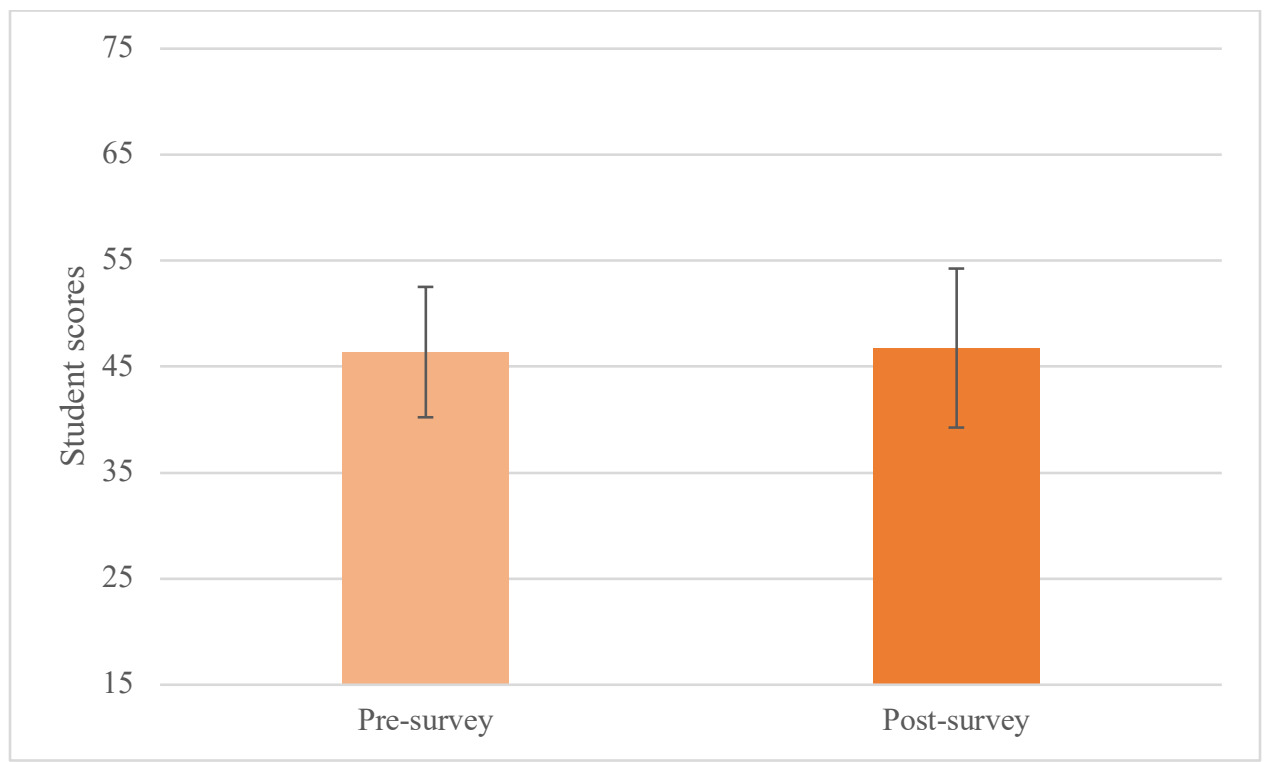

Figure 12. EL mean scores for Olinder students $(\mathrm{N}=42)$. 


\section{RQ3: If there is a change in the level of environmental literacy, which of the five aspects of EL changes most?}

Every three questions on the survey corresponded with one of five areas of EL. For McKinley students, who demonstrated a statistically significant increase in mean EL score from pre- to post-survey, awareness was the only category to increase by over a whole point and this proved to be a statistically significant increase, according to a paired samples t-test $(\mathrm{p}=0.002)$. They next largest changes were in skill and attitude, which each increased by over 0.8 points. None of the categories for Olinder students increased by a statistically significant amount, but knowledge and awareness both did show the largest increases: over 0.7 points each on average. Mean changes per category for both school groups are found in Table 7.

\section{Table 7}

EL Component Mean Changes by School

\begin{tabular}{|c|c|c|c|c|c|c|c|c|c|c|}
\hline & \multicolumn{2}{|c|}{$\begin{array}{c}\text { Awareness } \\
\text { (3-15 } \\
\text { possible pts) }\end{array}$} & \multicolumn{2}{|c|}{$\begin{array}{c}\text { Knowledge } \\
(3-15 \\
\text { possible pts })\end{array}$} & \multicolumn{2}{|c|}{$\begin{array}{l}\text { Attitude } \\
\text { (3-15 } \\
\text { possible pts) }\end{array}$} & \multicolumn{2}{|c|}{$\begin{array}{c}\text { Skill } \\
(3-15 \\
\text { possible pts) }\end{array}$} & \multicolumn{2}{|c|}{$\begin{array}{c}\text { Action } \\
(3-15 \\
\text { possible pts) }\end{array}$} \\
\hline & $\begin{array}{l}\text { Mean } \\
\text { Change }\end{array}$ & $\begin{array}{l}\mathrm{p}- \\
\text { value }\end{array}$ & $\begin{array}{l}\text { Mean } \\
\text { Change }\end{array}$ & $\begin{array}{l}\mathrm{p}- \\
\text { value }\end{array}$ & $\begin{array}{l}\text { Mean } \\
\text { Change }\end{array}$ & $\begin{array}{l}\mathrm{p} \text { - } \\
\text { value }\end{array}$ & $\begin{array}{l}\text { Mean } \\
\text { Change }\end{array}$ & $\begin{array}{l}\mathrm{p}- \\
\text { value }\end{array}$ & $\begin{array}{l}\text { Mean } \\
\text { Change }\end{array}$ & $\begin{array}{l}\mathrm{p}- \\
\text { value }\end{array}$ \\
\hline McKinley & +1.07 & .002 & +0.44 & .574 & +0.81 & .116 & +0.89 & .352 & 0 & 1.00 \\
\hline Olinder & +0.70 & .074 & +0.76 & .345 & -0.14 & .683 & +0.10 & .884 & -1.02 & .074 \\
\hline
\end{tabular}

For McKinley Elementary fourth graders, all of whom participated in the GS program, all categories of EL increased with the exception of action, which showed no change. In every category, with the exception of action, at least one student received a perfect score of 15 . On a possible score range of three to 15 , awareness post-survey scores received ranged from 11 to 15 and attitude scores received ranged from nine to 15 , 
while the other three categories also had students receiving the lowest possible score of 3 even on post-survey (Table 8).

Table 8

McKinley Students' Pre-Survey and Post-Survey Score Descriptions

\begin{tabular}{llccc}
\hline Awareness & & $\begin{array}{c}\text { Lowest Score } \\
(\text { possible=3) }\end{array}$ & Mean Score & Highest Score \\
\hline & Pre-Survey & 9 & 11.52 & (possible=15) \\
\hline \multirow{2}{*}{ Knowledge } & Post-Survey & 11 & 12.60 & 15 \\
\hline & & & & \\
\hline & Pre-Survey & 3 & 6.85 & 11 \\
\hline Attitude & Post-Survey & 3 & 7.30 & 15 \\
\hline & & & & \\
\hline \multirow{2}{*}{ Skill } & Pre-Survey & 7 & 10.89 & 15 \\
\hline & Post-Survey & 9 & 11.70 & 15 \\
\hline & & & & 15 \\
\hline Action & Pre-Survey & 3 & 8.93 & 15 \\
\hline & Post-Survey & 3 & 9.81 & 11 \\
\hline & & & & 12 \\
\hline
\end{tabular}

\section{Awareness.}

Awareness: Survey results. Awareness, defined in this study as an acknowledgement of human's positive and negative impacts on the ecosystem, was captured on the survey with three unique questions asking if students know that cars contribute to air pollution, that humans' general actions impact the natural environment, and that our garden beds create a habitat for bees and butterflies (Figure 13). Likert scale options ranged from No! to Yes! with accompanying thumbs up, down, or slanted emoticons so that the most environmentally aware scores were high (out of a possible 15) and the least 
environmentally aware students' scores were low (out of a possible 3 ).

1. Driving cars leads to increased air pollution.

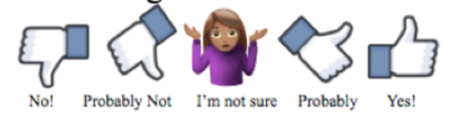

2. My actions can have a direct impact on the natural environment.

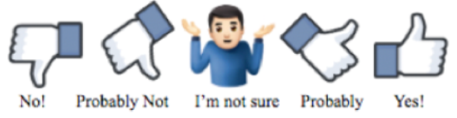

3. Growing flowers at my school creates a habitat for bees and butterflies to live.

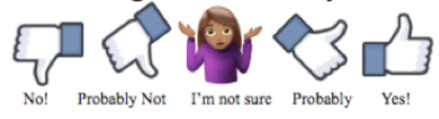

Figure 13. Awareness survey questions.

A paired-samples t-test was conducted to assess the impact of the GS program on participants' environmental awareness. There was a statistically significant increase in awareness score from pre-survey $(\mathrm{M}=11.52, \mathrm{SD}=1.50)$ to post-survey $(\mathrm{M}=12.60$, $\mathrm{SD}=1.24), \mathrm{t}(26)=-3.51, \mathrm{p}=0.002$ (two-tailed). The mean increase in awareness score was 1.07 points with a $95 \%$ confidence interval ranging from 1.70 to 0.44 .

According to results on each individual awareness question, McKinley students showed an increase in understanding of pollution causes and impacts of individuals' actions on the environment. Interestingly, McKinley students actually showed a decrease in understanding of the habitat created by their own school garden, although this question did receive a high score even on the pre-survey. Due to the overall statistically significant category increase, paired-samples t-tests were conducted to evaluate the impact of the GS program on student's awareness scores for individual questions on the EL test. There was a statistically significant increase in two of the three questions tested for the awareness variable. Awareness question one, which asked about vehicle-caused pollution, increased 
from 3.48 to 4.37 for a mean increase of $0.89(\mathrm{p}=0.001)$ on a possible score range of 1 to 5. Awareness that human actions impact the natural environment increased 0.44 points from a score of 3.15 to 3.59 , on a scale of one to five, over the course of the garden education program $(\mathrm{p}=0.007)$. Meanwhile, students' understanding of the connection between their garden and butterfly and bee habitat creation decreased slightly from a score of 4.89 to 4.63 (mean change of -0.26 ) on a scale of one to five. Table 9 highlights mean score changes for the awareness portion of the EL test.

Table 9

Changes in McKinley Students' Awareness Scores, per EL Survey

\begin{tabular}{lcccc}
\hline Question(s) & $\begin{array}{l}\text { Pre-survey } \\
\text { mean score }\end{array}$ & $\begin{array}{c}\text { Post-survey } \\
\text { mean score }\end{array}$ & Mean change & Sig (2-tailed) \\
\hline $\begin{array}{l}\text { Total } \\
\text { (range 3-15) }\end{array}$ & 11.52 & 12.60 & +1.07 & $\mathbf{. 0 0 2}$ \\
\hline $\begin{array}{l}\text { Q1: cars } \\
\text { (range 1-5) }\end{array}$ & 3.48 & 4.37 & +0.89 & $\mathbf{. 0 0 1}$ \\
\hline $\begin{array}{l}\text { Q2: actions } \\
\text { (range 1-5) }\end{array}$ & 3.15 & 3.59 & +0.44 & $\mathbf{. 0 2 5}$ \\
\hline $\begin{array}{l}\text { Q3: habitat } \\
\text { (range 1-5) }\end{array}$ & 4.89 & 4.63 & -0.26 & .090 \\
\hline
\end{tabular}

The range of EL scores for McKinley students reduced from pre- to post-survey as well. On pre-survey, scores ranged from a low of nine to a high of 15 on a possible score range of three to 15 . On post-survey, range of scores reduce to a low of 11 and a high of 15 , with one additional student receiving the highest score. Figure 14 highlights awareness survey scores, demonstrating the shift and reduction in range of scores received. 


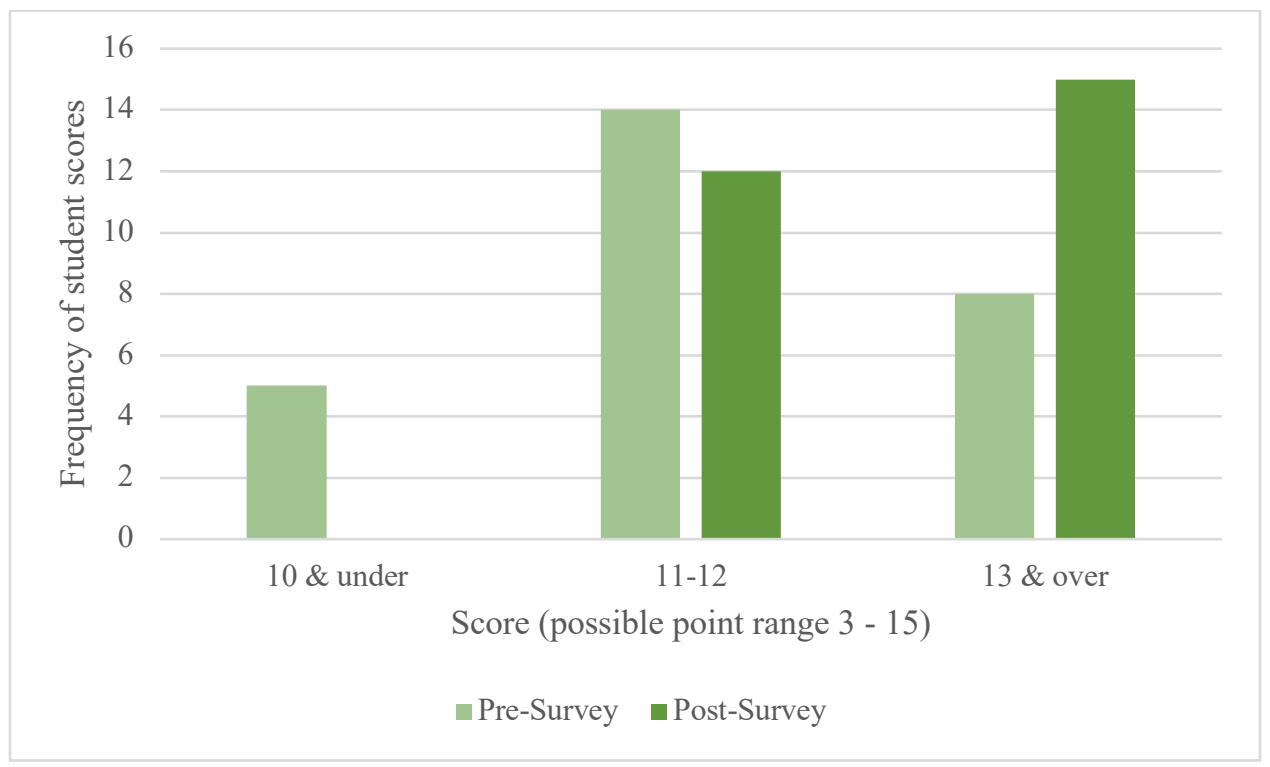

Figure 14. McKinley Elementary awareness survey scores $(\mathrm{N}=27)$.

Awareness: Journal entry results. After each garden workshop, students were asked to write or draw a journal entry with the prompt: "Today in garden workshop I did... I learned... I felt...”. Although the program lasted seven weeks, six weeks of journal entries were collected as post-surveys were administered in place of journals after the final lesson, the urban farm field trip. These entries were used to assess changes in participants and were a compliment to the written survey responses. In total 195 sets of journals were collected with a total 579 unique responses, accounting for individual responses to each of the aforementioned three prompts on each entry.

Using inductive coding, the researcher identified 114 individual journal responses that reflected awareness among McKinley garden education participants and grouped these into ten unique codes. These elements were then grouped to form three main categories, grouped together by theme. These three themes are presented in Table 10 where percentages shown are of all awareness responses. 
Table 10

Awareness Journal Entries $(N=114)$

\begin{tabular}{|c|c|c|c|c|}
\hline Group & Code & Count & Percent & Example Response \\
\hline \multirow[t]{5}{*}{ Gardening } & & 76 & $67.3 \%$ & \\
\hline & Weeds & 38 & $33.3 \%$ & $\begin{array}{l}\text { I took out the weeds that were } \\
\text { really spikey }\end{array}$ \\
\hline & Bugs & 15 & $13.2 \%$ & I learned that don't kill worms \\
\hline & Watering & 15 & $13.2 \%$ & $\begin{array}{l}\text { I learned that if you water the } \\
\text { plants way too much they might } \\
\text { die }\end{array}$ \\
\hline & Garden & 8 & $7.0 \%$ & $\begin{array}{l}\text { I learned that gardening is home } \\
\text { for animals }\end{array}$ \\
\hline \multirow[t]{4}{*}{ Conservation } & & 24 & $21.2 \%$ & \\
\hline & Pollution & 14 & $12.3 \%$ & $\begin{array}{l}\text { [Today in garden workshop, I } \\
\text { learned...] about types of pollution }\end{array}$ \\
\hline & Energy & 6 & $5.3 \%$ & $\begin{array}{l}\text { [Today in garden workshop, I } \\
\text { learned...] to not use to much } \\
\text { electricity }\end{array}$ \\
\hline & Waste & 4 & $3.5 \%$ & $\begin{array}{l}\text { [Today in garden workshop, I } \\
\text { learned...] I should recycle my } \\
\text { cans }\end{array}$ \\
\hline \multirow[t]{3}{*}{ General } & & 13 & $11.5 \%$ & \\
\hline & Environment & 11 & $9.6 \%$ & $\begin{array}{l}\text { [Today in garden workshop, I } \\
\text { learned...] learned about what's } \\
\text { good for the environment }\end{array}$ \\
\hline & General & 2 & $1.8 \%$ & $\begin{array}{l}\text { [Today in garden workshop, I } \\
\text { learned...] not to pick up flowers } \\
\text { that you just want }\end{array}$ \\
\hline
\end{tabular}

After the first garden class, student journal entries included "I learned more about the world," "I learned that there are a lot of things you can find in a garden bed," and "I learned that we can be helpful." After the final garden class, self-reflection expanded to include feelings beyond the physical context of the school garden, to the larger local entire ecosystem. For example, student participants wrote "I learned of ways to save the 
environment," "I learned about pollution and how to save energy," and "I felt good for making the environment a better place." Although survey question scores reflected a decrease in understanding that planting school garden creates a habitat for bees and butterflies, journal entries reflected an increased awareness of the positive environmental impact students create by maintaining a school garden. For example, one student wrote in one entry: "I learned that gardening is home for animals," demonstrating an awareness of the positive impact a school garden has for habitat creation.

Additionally, over the course of the garden education program, the number of journal entries coded for awareness increased: of all awareness journal responses, 14 were written in week one and 44 were written in week six. An increase in discussing human impacts on the environment indicates a positive increase in awareness. In the last two weeks of journal entry collection, $66 \%(n=76)$ of all awareness journal entries were collected. Table 11 expands on the number of journal entries coded for awareness each week. 
Table 11

Count of Awareness-Coded Journal Entries, by Week

\begin{tabular}{lll}
\hline Week & $\begin{array}{l}\text { Count of } \text { Awareness } \\
\text { Journal Entries }\end{array}$ & $\begin{array}{l}\text { Percent of } \text { Awareness } \\
\text { Journal Entries }\end{array}$ \\
\hline $\mathbf{1}$ & 14 & $12.3 \%$ \\
\hline $\mathbf{2}$ & 17 & $14.9 \%$ \\
\hline $\mathbf{3}$ & 3 & $2.6 \%$ \\
\hline $\mathbf{4}$ & 4 & $3.5 \%$ \\
\hline $\mathbf{5}$ & 32 & $28.1 \%$ \\
\hline $\mathbf{6}$ & 44 & $38.6 \%$ \\
\hline Total & 114 & $100 \%$ \\
\hline
\end{tabular}

Awareness: Observation results. Researcher observations reflect similar insights that awareness of both positive and negative actions toward the environment over the duration of the GS program increased. In week 5 while passing out a worksheet on different types of pollution, one McKinley student looked down at the figures of cars, bottles, and factories and asked his garden instructor, "Driving cars is bad for the environment?" As students continued to complete the worksheet, working in pairs or small groups, several times small debates broke out. Several of these debates centered around the impacts of public transportation; some students argued that all vehicles are bad while others argued buses can be good alternatives to cars. At the beginning of this GS lesson, general understanding of where our air pollution comes from and what can be realistic solutions to overcoming them was a point of confusion and a gap in their understanding. 
In one class that focused on water, which included watering the garden, monitoring which areas are too wet and which are too dry, and explaining the best times of the day to water, a class wrap-up discussion provided interesting insights. When asked "Why is water important?" by a garden instructor at the end of class, student-produced responses included "We would be thirsty," "We need to drink it," "We need coffee," "We need to shower," but then interestingly went on to include ecocentric responses such as "Animals need it" and "The environment needs it." While environmental awareness still largely focuses on one's own actions, an understanding of our usage of water imparted increased awareness on student participants (Figure 15).

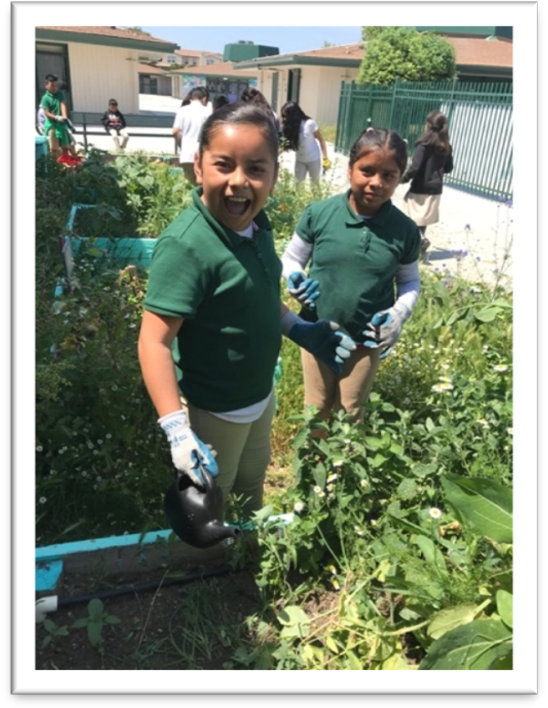

Figure 15. Students watering garden bed, March 2019.

\section{Knowledge.}

Knowledge: Survey results. Knowledge is defined in this study as a student's understanding of scientific topics. Knowledge was assessed on the EL survey with three unique questions with three multiple choice options each plus an "I'm not sure" choice 
(Figure 16). The three questions asked: "What do roots do?," "An example of a nonrenewable resource is __," and "What should you put into a compost bin?" These questions were derived from CHEAKS or were taken out of a fourth grade science textbook and each of the three unique topics was in some capacity touched upon during the garden workshop series.

4. What do roots do?

a) Make food for the plant through sunlight

b) Move nutrients to all parts of a plant

c) Absorb water and nutrients from soil

d) I'm not sure

5. An example of a nonrenewable resource is:
a) Sunlight
b) Trees
c) Petroleum
d) I'm not sure

6. What should you put into a compost bin?
a) Juice pouches
b) Newspaper
c) Leftover hot dogs
d) I'm not sure

Figure 16. Knowledge survey questions.

A paired-samples t-test was conducted to evaluate the impact of the GS program on participants' environmental knowledge. Although there was a mean increase ( 0.44 points $)$ in score from pre-survey $(\mathrm{M}=6.85, \mathrm{SD}=2.60)$ to post-survey $(\mathrm{M}=7.29, \mathrm{SD}=3.31)$, it was not statistically significant $(\mathrm{t}(26)=0.570, \mathrm{p}=0.574)$.

There were no statistically significant differences for any question in this section of the survey although the mean score for each question showed a slight increase. At presurvey, no McKinley students got a perfect score, and on post-survey two students (7.4\%) 
got all three knowledge questions correct. Figure 17 highlights frequencies of knowledge scores received, demonstrating similarity in pre- to post-survey with an increase in highest score received.

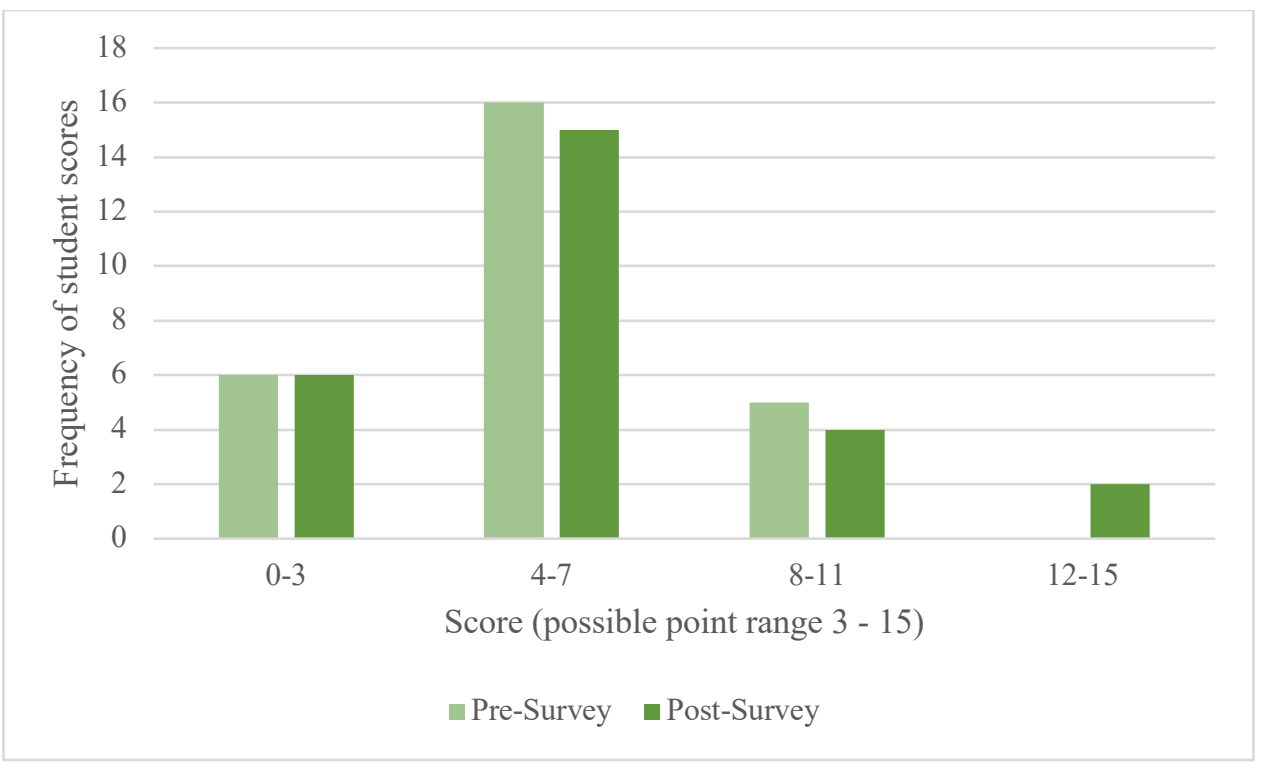

Figure 17. McKinley Elementary knowledge survey scores (N=27).

GS participants demonstrated an increase understanding of root function as four more students $(14.8 \%)$ answered this question correctly from pre- to post-survey. Three more students (11.1\%) correctly named a nonrenewable resource from pre- to post-survey, although this totaled only five of the 27 students. Interestingly, five (18.5\%) fewer students who could identify what can be composted decreased from pre- to post-survey. Table 12 illustrates the number of students who answered each question correctly (received score of 1). 
Table 12

Number of Knowledge Questions Answered Correctly (N=27)

\begin{tabular}{llll}
\hline & & $\begin{array}{l}\text { Number of students } \\
\text { answering correctly }\end{array}$ & $\begin{array}{l}\text { Percentage of students } \\
\text { answering correctly }\end{array}$ \\
\hline $\begin{array}{l}\text { Pre- } \\
\text { Survey }\end{array}$ & Q1: roots & 11 & $40.7 \%$ \\
\hline & Q2: resources & 2 & $7.4 \%$ \\
\hline $\begin{array}{l}\text { Post- } \\
\text { Survey }\end{array}$ & Q1: roots & 16 & $48.1 \%$ \\
\hline & Q2: resources & 5 & $59.3 \%$ \\
& Q3: compost & 8 & $18.5 \%$ \\
\hline
\end{tabular}

Knowledge: Journal entry results. After each garden workshop, students were asked to write or draw a journal entry with the prompt: "Today in garden workshop I did... I learned... I felt...”. Although the program lasted seven weeks, six weeks of journal entries were collected as post-surveys were administered in place of journals after the final lesson. These entries were used to assess changes in participants complimented by the survey responses.

Using inductive coding analysis, the researcher identified 59 individual journal responses that reflected knowledge among McKinley garden education participants and grouped these into six unique codes. These elements were then grouped to form six main categories, grouped together by theme. These six themes are presented in Table 13 where percentages shown are of all knowledge responses. 
Table 13

Knowledge Journal Entries ( $N=65)$

\begin{tabular}{lccl}
\hline Code & Count & Percent & Example Response \\
\hline Food & 17 & $25.8 \%$ & we learned what a food chain is! \\
\hline Plants & 16 & $24.2 \%$ & $\begin{array}{l}\text { [Today in garden workshop, I } \\
\text { learned...] that leaves absorb sunlight }\end{array}$ \\
\hline Gardening & 14 & $21.2 \%$ & $\begin{array}{l}\text { [Today in garden workshop, I } \\
\text { learned...] weeds aren't good for soil }\end{array}$ \\
\hline Bugs & 10 & $15.2 \%$ & I learned worms can't see \\
\hline General & 6 & $9.1 \%$ & $\begin{array}{l}\text { [Today in garden workshop, I } \\
\text { learned...] the seasons }\end{array}$ \\
\hline Compost & 2 & $3.0 \%$ & $\begin{array}{l}\text { [Today in garden workshop, I } \\
\text { learned...] what you can compost in } \\
\text { the dirt }\end{array}$
\end{tabular}

Student journal entries do reflect some level of knowledge increase, with some students reflecting on topics specifically taught in the lesson plans while others mention new discoveries they made on their own. Over the course of the workshop series, fourteen unique facts about roots were in response to the prompt, "Today in garden workshop, I learned...". Participant answers included "that you have to rip out the roots to pick flowers," "what roots absorb," and "that roots are weak." These comments directly reflect topics taught by their garden instructors, such as that you need to take the roots when pulling weeds and that you need to be careful when handling roots to transplant seedlings into raised beds. Other responses reflected scientific observation 
made by garden participants. For example, one student was using a magnifying glass in the garden and suddenly realized in the light, the glass formed rainbows back on her hand. This was something she then walked around sharing with her classmates. In her journal that day, she wrote that she "did that you can put a [magnifying] glass in the sun." Another student reflection that "when it rains more bugs come out" was a consequence of a workshop right after a rain, in which many students enquired about why they could easily find so many worms where in dry, hot days, they could not.

Knowledge: Observation results. Researcher observations showed some increase in knowledge, particularly in topical areas specifically addressed throughout the program, despite showing no statistical significance in survey results. Interestingly, survey results showed a decline in knowledge regarding what can be put into a compost bin, but observations actually indicated some understanding. Composting and plant life cycles were addressed in week one, with little to no knowledge of composting demonstrated by students initially. By week four, when food cycles were taught, one McKinley student offered "composting" as a piece of the waste management portion of our food cycles. That same lesson, one participant found peanut shells someone had thrown into the bed and asked if she could put them into the compost bin instead.

Another interesting observation reflected many students' confusion surrounding topics that are typically mastered below their fourth-grade level. On week two, when seasonality and planting times were discussed, students completed worksheets that required answering questions by specifically naming months and/or seasons. Many students could not name the four seasons, which months constituted which seasons, or the 
difference between months and seasons. By the end of the lesson, students were offering responses such as "Fruits and vegetables can taste good, but if you buy them out of season, they will be less fresh.”

In general, students were extremely inquisitive. When they found an unfamiliar bug, they ask their garden teachers what kind it is and if it is poisonous. They wanted to know the names of the plants, what they can eat, and why bugs were on the stems of tall weeds, why bugs are good for the garden. While at times, students were non-responsive during the lecture portion of the class involves, students demonstrated active learning behavior during the outdoor garden portion of class (Figure 18).

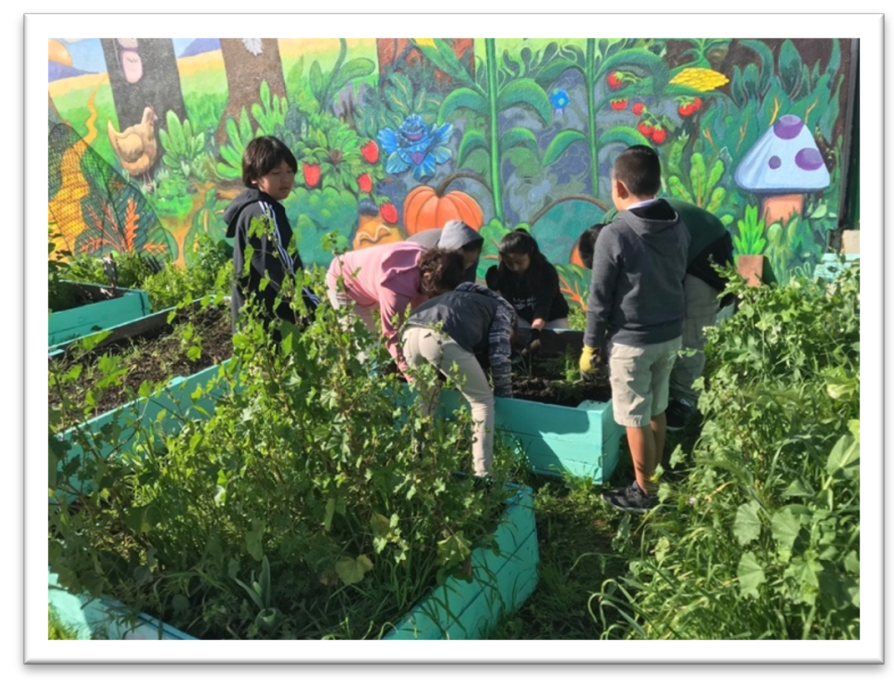

Figure 18. Students working together in garden beds, May 2019.

\section{Attitude.}

Attitude: Survey results. Personal feelings concerning the environment and its accompanying challenges were captured via the attitude portion of the survey. Within the parameters of the survey, students were asked their feelings about three unique scenarios 
to capture their changing environmental attitudes: knowing that others recycle (positive), that companies test on animals (negative), and pollution's effects on the environment (negative) (Figure 19). Using Likert scale options from Angry to Excited, student responses were scored from one to five on each question, with one showing low and five showing high pro-environmental attitudes. Questions that favored a negative response (companies testing on animals, pollution's effects on the environment), were recoded so that the most negative response (Angry) was given the highest point value and the most positive response (Excited) was given the lowest point value. Those scoring a three for the attitude section demonstrated unfavorable attitudes toward the environment while those scoring fifteen demonstrated favorable attitudes toward the environment.

7. When people recycle used bottles, cans, and paper, I feel:

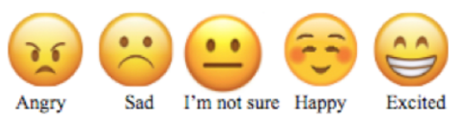

8. When I think about companies testing products on animals, I feel:

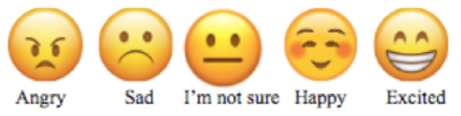

9. When I think about what pollution does to the environment, I feel:

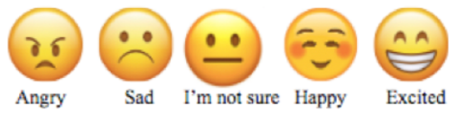

Figure 19. Attitude survey questions.

A paired-samples t-test was conducted to assess the impact of the GS program on participants' environmental attitudes. While there was an increase in mean score from pre-survey $(\mathrm{M}=10.89, \mathrm{SD}=2.15)$ to post-survey $(\mathrm{M}=11.70, \mathrm{SD}=1.65)$, this increase was not statistically significant $(\mathrm{t}(26)=-1.63, \mathrm{p}=0.116$ (two-tailed). The mean increase in 
attitude score was +0.81 points with a $95 \%$ confidence interval ranging from -1.84 to 0.21 .

According to results on each individual attitude question, McKinley students showed an increase in scores for questions regarding animal testing (statistically significant) and pollution effects, and actually showed a slight mean decrease in attitudes toward recycling behaviors. Attitudes against companies testing on animals increased a statistically significant amount, from a score of 3.52 to $4.11(\mathrm{~N}=27)$ for a mean increase of $+0.60(\mathrm{SD}=1.50, \mathrm{t}(26)=-2.05, \mathrm{p}=.050$ (two-tailed)). Regarding attitudes against pollution's effects on the environment, a slight mean increase $(+0.29)$ was also demonstrated as pre-survey results showed a score of 3.44 while post resulted in 3.70 , although this also did not alone prove to be statistically significant $(\mathrm{t}(26)=-1.13$, $\mathrm{p}=0.270$ ). Attitudes toward knowing others recycle actually showed a slight decrease in mean score $(-0.21)$ from pre-survey $(\mathrm{M}=3.81, \mathrm{SD}=0.86)$ to post-survey $(\mathrm{M}=3.60$, $\mathrm{SD}=1.06$ ), and this was not a statistically significant change $(\mathrm{t}(41)=1.14, \mathrm{p}=0.262$ (twotailed)). Table 14 highlights mean score changes for the attitude portion of the EL test. 
Table 14

Changes in McKinley Students' Attitude Scores, per EL Survey.

\begin{tabular}{lllll}
\hline Question(s) & $\begin{array}{l}\text { Pre-survey } \\
\text { mean score }\end{array}$ & $\begin{array}{l}\text { Post-survey } \\
\text { mean score }\end{array}$ & Mean change & Sig (2-tailed) \\
\hline $\begin{array}{l}\text { Total } \\
\text { (range 3-15) }\end{array}$ & 10.89 & 11.70 & +0.81 & .116 \\
\hline $\begin{array}{l}\text { Q1: animal } \\
\text { testing } \\
\text { (range 1-5) }\end{array}$ & 3.52 & 4.11 & +0.60 & .050 \\
\hline $\begin{array}{l}\text { Q2: pollution's } \\
\text { effects } \\
\text { (range 1-5) }\end{array}$ & 3.44 & 3.70 & & \\
\hline $\begin{array}{l}\text { Q3: recycling } \\
\text { behaviors } \\
\text { (range 1-5) }\end{array}$ & 3.81 & & +0.29 & .270 \\
\hline
\end{tabular}

The range of scores received by McKinley students reduced from pre- to post-survey as well. On pre-survey, scores ranged from a low of seven to a high of 15 on a possible range of three to 15 . On post-survey, ranges of scores reduced to a low of nine to a high of 15. Figure 20 highlights the frequencies of attitude survey scores received. 


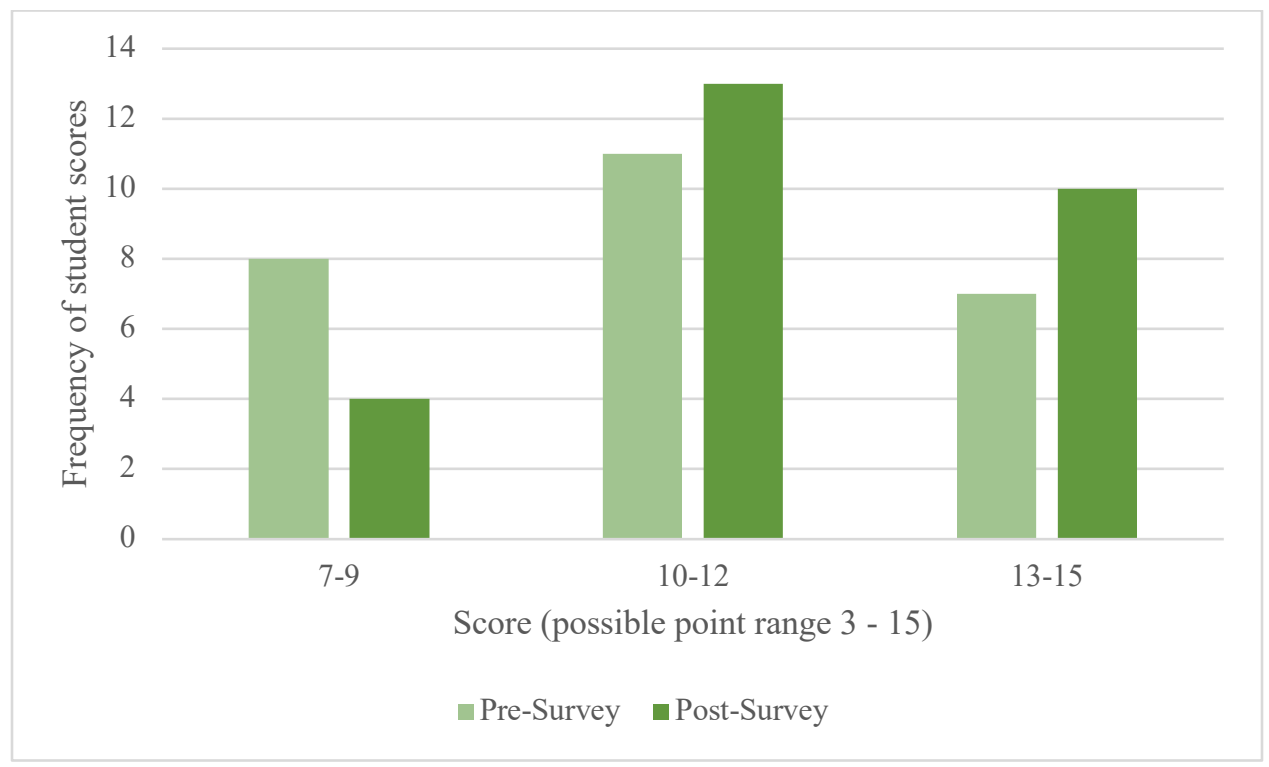

Figure 20. McKinley Elementary attitude survey scores $(\mathrm{N}=27)$.

Attitude: Journal entry results. While all three of these topics were covered sometime throughout the garden education program, it coincides with journal reflections that attitudes toward animal testing and pollution demonstrated the greatest change, as these topics were discussed much more frequently. Within all free entries, recycling was only mentioned one time, while animal harm was mentioned thirteen times and pollution was mentioned fifteen.

In total, 191 journal entries were completed under the "I felt" journal header. These were then coded to reflect positive, negative, or neutral attitudes toward the environment and the GS program (Table 15). One trend observed from McKinley students' reflective journal entries is an increase in positive affect toward the environment from beginning to end of program. After the first lesson, under the "I felt" journal header, 17 students reflected positive experiences while five wrote negatively about their day in garden class 
$(\mathrm{N}=36)$. However, after the last lesson, 30 students reflected positive attitudes toward their day in garden class while only none wrote negatively $(\mathrm{N}=36)$.

Table 15

Attitudes Recorded in Participant Journal Entries

\begin{tabular}{|c|c|c|c|c|c|c|}
\hline Week & $\begin{array}{c}\text { Positive } \\
\text { Affect }\end{array}$ & $\begin{array}{c}\text { Neutral } \\
\text { Phrases }\end{array}$ & $\begin{array}{c}\text { Negative } \\
\text { Affect }\end{array}$ & Total & $\begin{array}{c}\text { Positive } \\
\text { (as a percentage of } \\
\text { weekly total) }\end{array}$ & $\begin{array}{c}\text { Negative } \\
\text { (as a percentage of } \\
\text { weekly total) }\end{array}$ \\
\hline 1 & 17 & 14 & 5 & 36 & $47.2 \%$ & $13.8 \%$ \\
\hline 2 & 24 & 5 & 8 & 37 & $64.9 \%$ & $21.6 \%$ \\
\hline 3 & 13 & 1 & 1 & 15 & $86.7 \%$ & $6.6 \%$ \\
\hline 4 & 26 & 4 & 3 & 33 & $78.8 \%$ & $9.1 \%$ \\
\hline 5 & 27 & 6 & 1 & 34 & $79.4 \%$ & $2.9 \%$ \\
\hline 6 & 30 & 6 & 0 & 36 & $83.3 \%$ & $0.00 \%$ \\
\hline
\end{tabular}

Attitudes captured in students' journal responses reflected feelings of responsibility, belonging, and pride. Many students wrote comments such as, "I felt great and learned some amazing things," "[I felt] amazing I was happy I got to plant a pea seedling," or "I felt happy when I was outside because I got to use tools." Students felt both positive reactions toward creating the habitat in their garden: "I felt great that I was touching and saving worms" and negative reactions toward negative actions: "I felt bad because people kill worms" (Figure 21). Students also recognized the positive consequences their work in the garden created, writing entries such as, "[I felt] good for making the environment a better place," "[I felt] happy for helping the environment," and "I felt really good because I was helping the garden beds." In comparison, examples of negatively coded journal entries include, "I felt annoyed," "I felt nervous because of the worms," or "I felt gross 
because the fertilizer was stinky." Examples of neutral coded journal entries include, "I felt ok," "I felt a worm," or "I felt dirt."

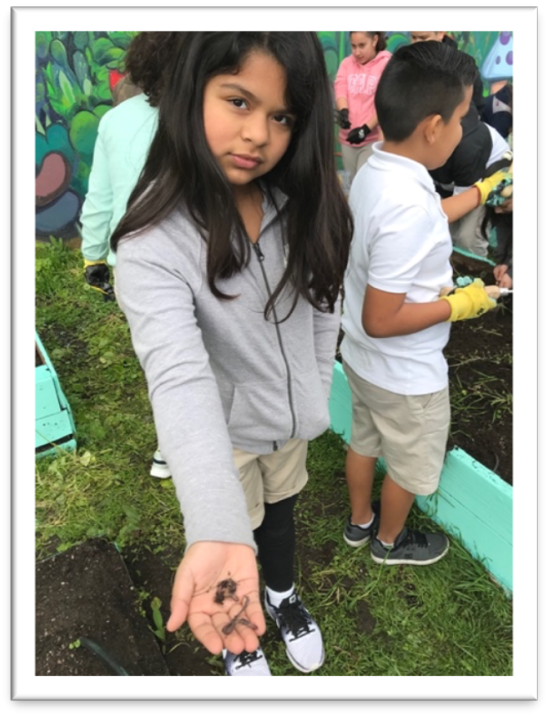

Figure 21. GS participant shows off worms found in garden, April 2019.

Attitude: Observation results. Researcher observations reflect decreases in fear and aversion alongside increases in pride, eagerness, and ownership over the duration of the intervention. On week one, one girl did not want to leave the classroom to go to the garden and when asked why, said because she was afraid of bugs. At the very end of the lesson, she approached one of her garden educators and said, "I learned worms are important. I was scared of them, but then I touched them.” Dislike of the outdoors was also observed in the amount of space students occupied during time in the garden. It was not until week four that students spread themselves across the entirety of the garden, pulling weeds from all beds. The amount of space students took up on their own was monitored at each workshop, with students remaining only surrounding their assigned beds on week one. Additionally, researcher observations show an increase in ownership 
of garden beds. Students were overheard referring to the garden bed as "ours" or a spot where they planted seeds as "our corner."

Furthermore, researcher observations reveal an increase in pride, eagerness, and a sense of accomplishment. As the workshop series progressed, students were more excited to leave their classroom for their garden, asking what activities they would be doing that day. Students were eager to show their garden instructors weeds they pulled in pairs or teams, roots they identified, or bugs they found. During week six, two students pulling weeds called out, “Are we doing a good job?" They were excited about the work they were doing and eager to show off their accomplishments (Figure 22). One interesting observation occurred during week two's fruit and vegetable taste test: when asked to taste new foods, many students overly dramatized their dislike, even spitting it out on their plates or rushing to the sink to get a drink of water. During week four, a garden instructor pointed out snap peas and green onions that were ready to harvest. Students were very eager to taste them and pass them around to their classmates, even going out of their way to show their primary teacher. This demonstrated a large change from week two, emphasizing the importance of self-grown food and the students' increased willingness to taste food grown themselves. 


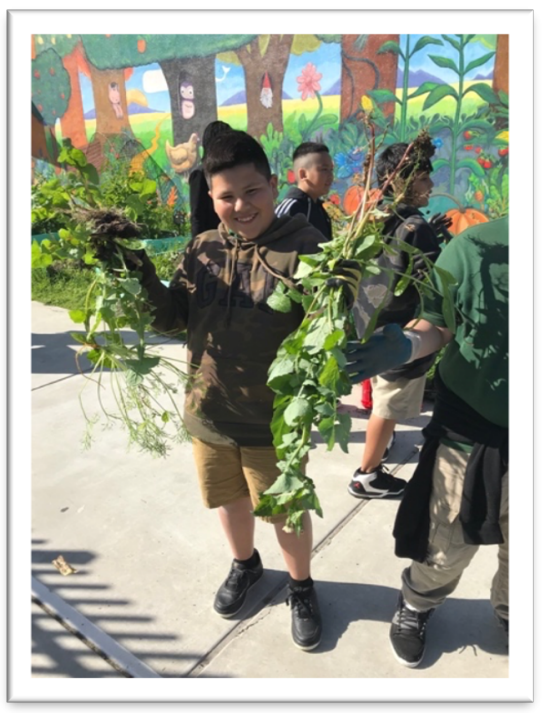

Figure 22. Student holds up weeds picked from garden, April 2019.

Skill.

Skill: Survey results. Skill is demonstrated on this EL survey by assessing knowledge of actions that individuals can perform that affect the environment. This crucial step of EL does not necessarily ensure that the skills are being actively employed by respondents, but more so question responses indicate the students' general level of understanding concerning what actions can be helpful or harmful toward the environment. This aspect of EL was captured through three multiple choice questions asking how water can be saved, how waste can be reduced, and how energy can be saved (Figure 23). 
10. Water can be saved by:

a) Turning off the faucet when I wash my hands

b) Taking a bath instead of a shower

c) Using a different cup each time I need a drink

d) I'm not sure

11. Waste can be reduced by:

a) Using paper towels instead of cloth towels at home

b) Walking instead of driving

c) Separating my food scraps into compost

d) I'm not sure

12. One way to save energy is:

a) Using the dryer instead of hang-drying my clothes

b) Opening the refrigerator door while I decide what to eat

c) Using less air conditioning

d) I'm not sure

Figure 23. Skill survey questions.

A paired-samples t-test was conducted to evaluate the impact of the GS program on participants' environmental skill. McKinley students' mean skill score increases from 8.93 to 9.81 from pre- to post-survey, a mean increase of +0.88 , although this does not prove to be statistically significant $(\mathrm{t}(26)-=.095, \mathrm{p}=.352$ (two-tailed)). The mean increase in skill score was +0.89 points with a $95 \%$ confidence interval ranging from $1-2.81$ to 1.04 .

There were no statistically significant differences for any question in this section of the survey according to a paired samples t-test, although each question did demonstrate a slight increase in number of students answering correctly (Table 16). Twenty of the 27 (74.1\%) students answered skill on saving water question correct, just a one student increase from pre-survey. Two more students got the skill reducing waste question correct from pre- to post-survey, but still only six students $(22.2 \%)$ of students were able 
to answer this correctly. The question regarding skills on saving energy showed the largest increase, from 17 students $(63.0 \%)$ answering correctly at pre-survey to 20 students (74.1\%) answering correctly at post-survey.

Table 16

Changes in McKinley Students' Skill Scores, per EL Survey

\begin{tabular}{llll}
\hline & & $\begin{array}{l}\text { Number of students } \\
\text { answering correctly }\end{array}$ & $\begin{array}{l}\text { Percentage of students } \\
\text { answering correctly }\end{array}$ \\
\hline Pre-Survey & Q1: water & 19 & $70.4 \%$ \\
\hline & Q2: waste & 4 & $14.8 \%$ \\
\hline Post-Survey & Q1: water & 20 & $63.0 \%$ \\
\hline & Q2: waste & 6 & $74.1 \%$ \\
\hline & Q3: energy & 20 & $22.2 \%$ \\
\hline
\end{tabular}

The number of students receiving each score on pre-survey and post-survey is explored in Figure 24, which depicts scores being closely aligned. One fewer student received the lowest possible score, but no additional students received the highest possible score in this section. 


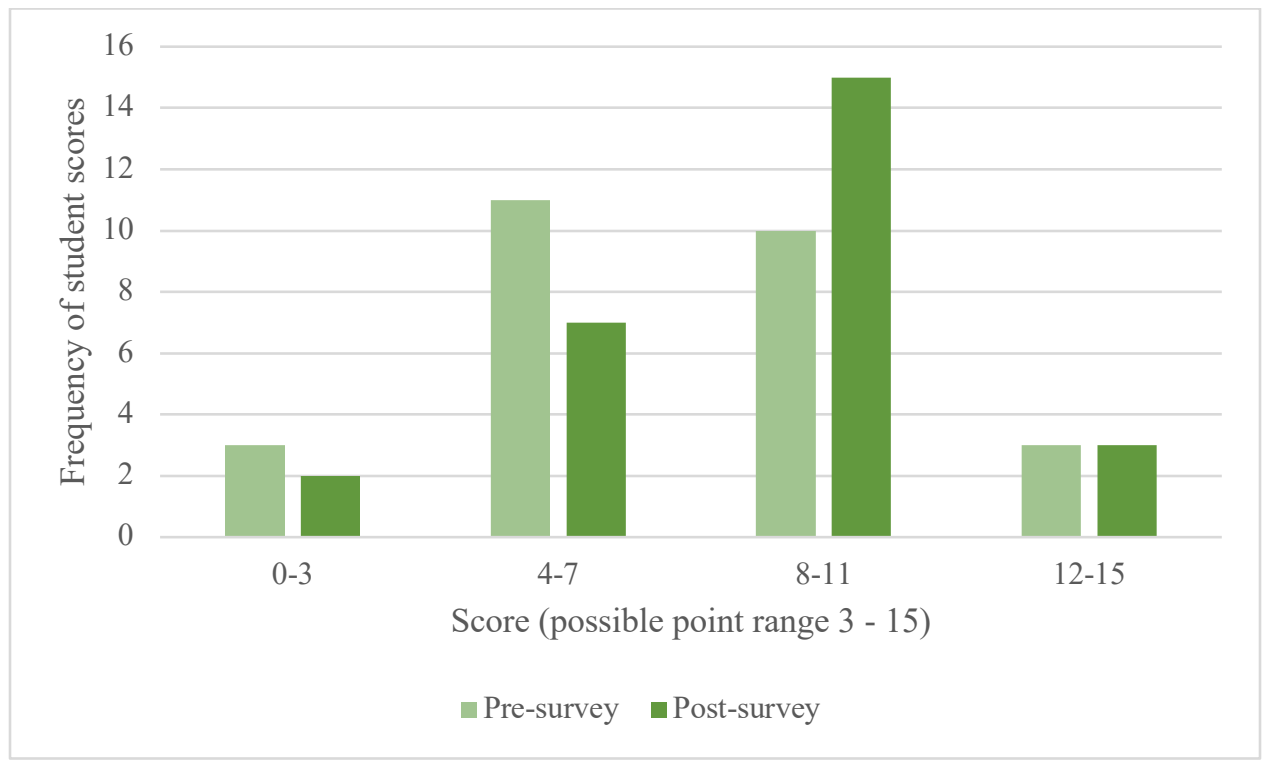

Figure 24. McKinley Elementary skill survey scores (N=27).

Skill: Journal entry results. GS participants' journal entries reflect an increase in skill as many students were able to articulate actions they learned about during the program. In the context of gardening, students reflected a lot of acquired skills, such as learning how to identify and pull weeds, that too much or too little watering will cause a seedling to die, and how to plant seeds and transfer seedlings.

Using inductive analysis, the researcher identified 17 individual journal responses that reflected skill among McKinley garden education participants and grouped these into eight unique codes. These elements were then grouped to form three main categories, grouped together by theme. These three themes are presented in Table 17 where percentages shown are of all responses. 
Table 17

Skill Journal Entries (N=17)

\begin{tabular}{|c|c|c|c|c|}
\hline Group & Code & Count & Percent & Example Response \\
\hline \multirow[t]{5}{*}{ Gardening } & & 10 & $62.5 \%$ & \\
\hline & Planting & 6 & $37.5 \%$ & I learned how to plant a flower \\
\hline & Weeding & 2 & $12.5 \%$ & I learned how to pull out roots \\
\hline & Gardening & 1 & $6.3 \%$ & $\begin{array}{l}\text { [Today in garden workshop, I } \\
\text { learned...] what not to do in a garden }\end{array}$ \\
\hline & Tools & 1 & $6.3 \%$ & $\begin{array}{l}\text { [Today in garden workshop, I } \\
\text { learned...] to use shovels properly }\end{array}$ \\
\hline \multirow[t]{4}{*}{ Conservation } & & 5 & $31.3 \%$ & \\
\hline & Energy & 2 & $12.5 \%$ & I learned how to save light \\
\hline & Pollution & 2 & $12.5 \%$ & I learned how to prevent pollution \\
\hline & Water & 1 & $6.3 \%$ & I learned how not to waste water \\
\hline General & & 1 & $6.3 \%$ & $\begin{array}{l}\text { I learned to try something before } \\
\text { judging it }\end{array}$ \\
\hline
\end{tabular}

While skill typically reflects understanding what pro-environmental actions are and how to perform them, in the context of EL, most journal entries captured here reflected stills learned in gardening specifically. In the context of journal entries mentioning "I learned," students acknowledge not that they did or did not perform each action, but that they are aware of how to do it or its consequences. Journal entries that qualified for skill had an emphasis on students explaining that they knew how to do something that was pro-environmental. Gardening skills make up $62.5 \%$ of total skill journal entries coded, while skills gained toward conservation behaviors only made up 31.3\% of journal entries. 
Skill: Observation results. McKinley students were observed with some understanding of pro-environmental skills, but most reflected-on skills learned about gardening, not necessarily about how to act toward the environment as a whole. An interesting observation was during week six's lesson, when students were taught about water usage, including the best time of day to water plants to avoid excess evaporation. Due to intern availability schedules, usually garden instructors simply finish watering the beds after the lesson is over, so typically in the middle of the school day. After this lesson on water, the garden instructors turned on the sprinklers, to which one student returned and asked, “Aren't you not supposed to do that?” This student exhibited retention of proenvironmental behavior and willingness to ask adults why they were not also demonstrating this sustainable behavior. At a fruit and vegetable tasting lesson, one student was overheard telling another, "I'm going to tell my mom to get bell peppers!" After excitement for trying a new healthy food, this student demonstrated ability to pass this information along to his family at home, an indicator of potential future behavior change.

Another interesting observation is that students mentioned having little to no experience gardening at the beginning of the program, which was very clear once activities began outside. When watering the raised beds, some spots were drenched with water while others remained dry, causing instructors to consistently be monitoring water can usage (Figure 25). For example, seeds that were left to germinate in paper cups while students were on spring break were transferred to the raised outdoor beds. There was much confusion observed: students needed constant guidance on digging a big enough 
hole, did not know if the cup should be left inside the raised bed as well, or were concerned when soil from inside their germinated cup fell loose. It was clear students had never done a task like this before, thus demonstrating the importance of garden education.

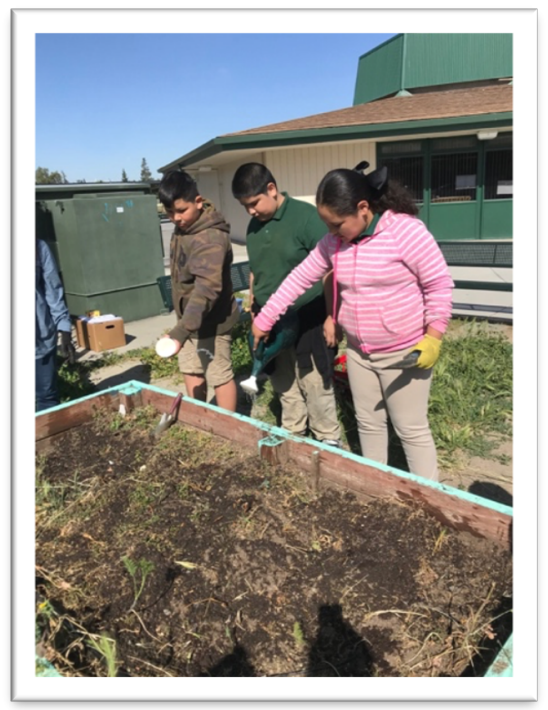

Figure 25. Students watering raised bed, May 2019.

Action.

Action: Survey results. Action is determined on this EL survey as a specific proenvironmental task that has actually been performed by the survey taker. Action was captured on this survey with three unique questions asking of frequency of several proenvironmental behaviors. Based on CHEAKS, these questions are each written in the past or present tense, indicating that these are actions the students already partake in, not actions they hope to do or know about. The first question stated students have talked with their parents about how to help with environmental problems (positive), the second stated that students leave the refrigerator open (negative), and the third stated that students have 
asked others what they can do to help reduce pollution (positive) (Figure 26). Frequency options ranged from Never to Always with accompanying images, so that each individual question had a possible score range of one to five, and in total pro-environmental actions were high (out of a possible 15) and the least pro-environmental actions were low (out of a possible 3). The question that favored a negative response (leaving the refrigerator door open) was recoded so that the most negative response (Never) was given the highest point value and the most positive response (Always) was given the lowest point value. Those scoring a three for the action section demonstrated unfavorable actions regarding environmentalism while those scoring fifteen demonstrated favorable actions regarding the environment.

13. I have talked with my parents about how to help with environmental problems.

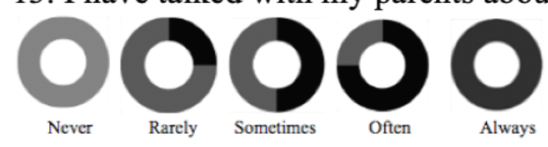

14. I leave the refrigerator open while I decide what to get out.

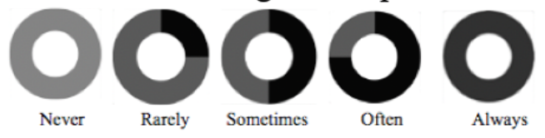

15. I have asked others what I can do to help reduce pollution.

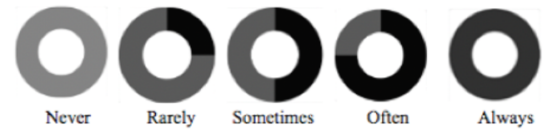

Figure 26. Action survey questions.

A paired-samples t-test was conducted to assess the impact of the GS program on participants' environmental action. There was actually no change in mean score from presurvey $(\mathrm{M}=7.67, \mathrm{SD}=2.30)$ to post-survey $(\mathrm{M}=7.67, \mathrm{SD}=2.54)$. 
Overall, McKinley students showed no difference in action mean scores from pre- to post-survey. Paired samples t-tests were conducted to assess any changes in individual questions for action on the EL survey. Mean scores toward asking others about pollution reduction showed no change, while mean scores regarding not leaving the refrigerator open increased by $13.85 \%$ pre- to post-survey, and mean scores on asking parents about helping with environmental problems actually decreased by $14.81 \%$ pre- to post-survey. None of these changes were statistically significant, according to a paired samples t-test (Table 18).

Table 18

Changes in McKinley Students' Action Scores, per EL Survey (N=27)

\begin{tabular}{lllll}
\hline Question(s) & $\begin{array}{l}\text { Pre-survey } \\
\text { mean score }\end{array}$ & $\begin{array}{l}\text { Post-survey mean } \\
\text { score }\end{array}$ & $\begin{array}{l}\text { Mean } \\
\text { change }\end{array}$ & $\begin{array}{l}\text { Sig (2- } \\
\text { tailed) }\end{array}$ \\
\hline $\begin{array}{l}\text { Total } \\
\text { (range 3-15) }\end{array}$ & 7.66 & 7.66 & No change & 1.00 \\
\hline $\begin{array}{l}\text { Q1: parents } \\
\text { (range 1-5) }\end{array}$ & 2.70 & 2.30 & -0.40 & .204 \\
\hline $\begin{array}{l}\text { Q2: energy } \\
\text { (range 1-5) }\end{array}$ & 2.96 & 3.37 & +0.41 & .292 \\
\hline $\begin{array}{l}\text { Q3: pollution } \\
\text { (range 1-5) }\end{array}$ & 2.00 & 2.00 & No change & 1.00 \\
\hline
\end{tabular}

No students received a perfect score for the action portion of the EL survey, and the range of scores widened by a point on either side from pre- to post-survey. On postsurvey, the range of scores received widened to include the lowest possible. The ranges of action scores received are depicted in Figure 27. 


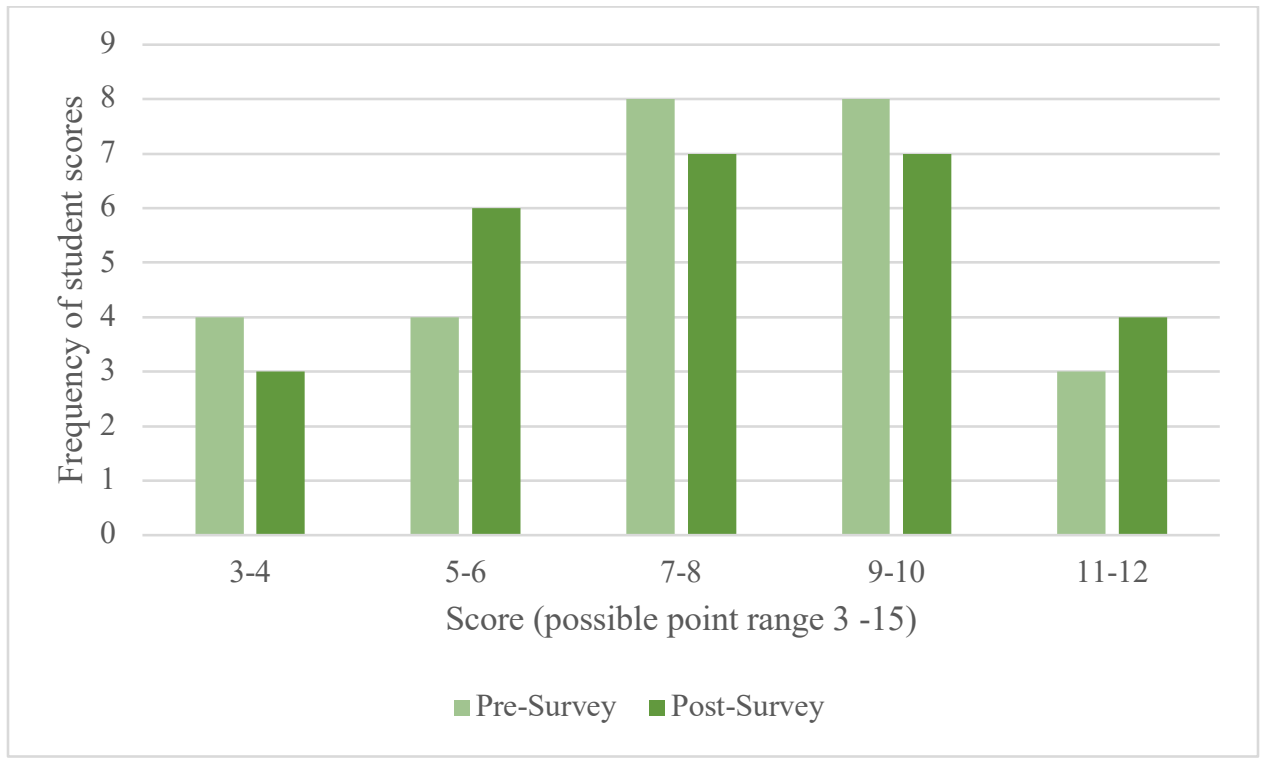

Figure 27. McKinley Elementary action survey scores $(\mathrm{N}=27)$.

Action: Journal entry results. Using inductive analysis, the researcher identified 62 individual journal responses that reflected action among McKinley garden education participants and grouped these into six unique codes. These elements were then grouped to form four main categories, grouped together by theme. These three themes are presented in Table 19 where percentages shown are of all responses. 
Table 19

Action Journal Entries (N=62)

\section{Group Code Count Percent Example Response}

\begin{tabular}{|c|c|c|c|c|}
\hline Gardening & & 49 & $79.0 \%$ & \\
\hline & Planting & 39 & $62.9 \%$ & $\begin{array}{l}\text { [Today in garden workshop, I did...] I } \\
\text { planted some peas. Picture of pea plant } \\
\text { on vine. }\end{array}$ \\
\hline & Digging & 7 & $11.3 \%$ & $\begin{array}{l}\text { [Today in garden workshop, I did...] I } \\
\text { put soil in the plants }\end{array}$ \\
\hline & Bugs & 3 & $4.8 \%$ & $\begin{array}{l}\text { [Today in garden workshop, I did...] } \\
\text { save worms and bugs }\end{array}$ \\
\hline Food & & 11 & $17.7 \%$ & $\begin{array}{l}\text { [Today in garden workshop, I did...] I } \\
\text { ate snap peas. }\end{array}$ \\
\hline Pollution & & 1 & $1.6 \%$ & $\begin{array}{l}\text { [Today in garden workshop, I did...] } \\
\text { scooped up the paper [that was littering } \\
\text { the garden bed]! }\end{array}$ \\
\hline General & & 1 & $1.6 \%$ & $\begin{array}{l}\text { I felt helpful because I helped pick up } \\
\text { gloves }\end{array}$ \\
\hline
\end{tabular}

Throughout the duration of the garden workshop, a majority of actions captured by students were based on their just completed gardening workshops, and therefore few reflected true pro-environmental behavior as defined by this study. It is still important however to capture self-reported actions of these students as they acknowledged the actions performed during that day's lesson that contributed to the overall wellbeing of the garden.

Action: Observation results. As mentioned for action journal entries, most action observations constituted solely garden-based behaviors as actions elsewhere were outside the scope of this research method. At the onset of the program, students demonstrated a lot of aggression and violence: for example, digging up planted beds again or throwing 
dirt at each other. By week six however, students were observed understanding the concepts of what needs to be and can be done in a garden. While at weeks one and two, students were timid to explore and asked what could be done, by the end of the program, they were task-driven and wanted to include their teachers in their demonstration of newly gained skills. Week six observations included students being self-sufficient, creating teams independently and tasks with little guidance, and engaging in behaviors that supported plant health (Figure 28).

One notable observation was at the last lesson when a pair of boys were rough and rowdy and not listening to their garden instructors, until it was time to explore the garden. Upon instruction that it was free-range time for observation amongst the beds, one of the boys called his friends over exclaiming, "I found a ladybug!" They were immediately engaged and focused, excited to be in the garden and kneeling down to look for more bugs and asking their garden instructors questions about the bugs they were finding. Observations such as this were common: that once outside, students were task-driven, engaged, and applied. 


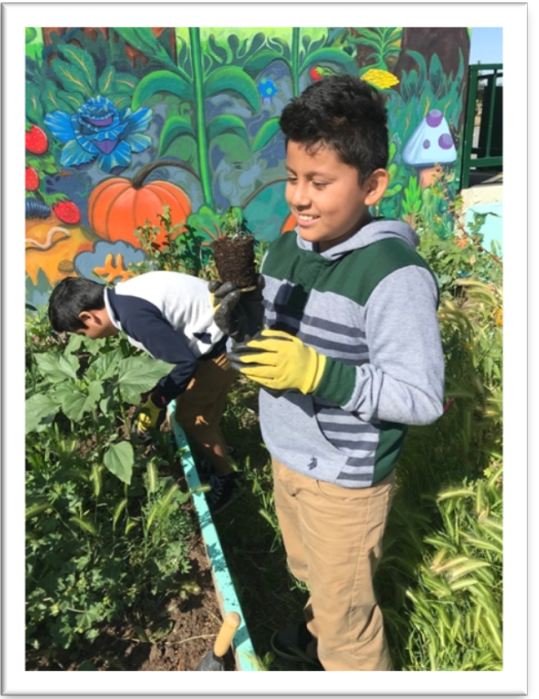

Figure 28. Student transferring germinated seedling to garden bed, May 2019. 


\section{Discussion}

This study tested fourth graders at two different Title 1 schools, half of whom received the GS garden education program over the course of the Spring 2019 semester. Likert scale and multiple-choice question surveys were distributed to all students at both the beginning and end of the semester to determine changes in all five aspects of the EL chain: awareness, knowledge, attitude, skill, and action. The results of this study support the assertion that an increase in EL in children is associated with a hands-on outdoor educational opportunity, which includes in-class lessons and field trip.

As EL is not generally tested and research is lacking on students' EL, there is not currently an accepted baseline of EL rates, especially for this demographic of elementary school children (McBeth \& Volk, 2010; Ruggiero \& Aydeniz, 2015). On an EL survey modeled after CHEAKS, with possible scores ranging from a low of 15 to a high of 75 , all fourth-grade students in this study averaged a score of 46.17 at their initial testing, with scores highest in awareness and attitude and lowest in action and knowledge. This indicates the students scored a 51.95\% in an aggregate of all EL categories. McBeth and Volk (2010), who validated the MSELS assessment tool among $6^{\text {th }}-8^{\text {th }}$ grade students, classified their students who received a 59\% on survey as moderate to high EL. Based on this comparison, this study population could be considered low to moderate in these scores that fell just below $52 \%$.

Due to the lack of existing research on EL, particularly in children this young and in this demographic, it is difficult to know if this is consistent nationwide. In literature that does exist, EL rates remain low to moderate due to the traditional classroom setting and 
teachers' EE knowledge or resources. In typical school settings, EE is treated as a standalone subject, which may limit its impact and allow it to be excluded as a separate field of knowledge (Moroye \& Ingman, 2013). In addition, teachers have reported not having enough time or enough EL-related lesson plans to adequately integrate EE in their classrooms (Stevenson, Carrier, \& Peterson, 2014). Gruenewald and Manteaw (2007) also substantiate the conflict between the post-NCLB school structure and the goals of $\mathrm{EE}$ in the inability to create adequate EL education opportunities. According to a National Public Radio poll, $86 \%$ of teachers believe climate change topics should be taught in schools, but 55\% say they do not include these in their own lessons. Of these, $65 \%$ indicated the reason why is because it is outside of their own subject area, while $17 \%$ indicated they do not know enough about it themselves and another $17 \%$ said they do not have the materials needed to teach this subject (Kamenetz, 2019). In addition, elementary school teachers report simply not having the time to teach grade-level science, let alone EE, due to the focus on increasing math and reading comprehension scores (A. Wicklander, personal communication, September 16, 2018).

Results of this study indicate that as a whole, EL increased a statistically significant amount for those students who took part in the seven-week outdoor garden education program. McKinley Elementary fourth grade students, all of whom participated in GS, showed a statistically significant increase in EL scores, with a pre-survey mean score of 45.85 and a post-survey mean score of 49.07 , for a mean score increase of +3.22 points on a 60-point range. Interestingly, McKinley students' mean score increased, but so did the range of all scores received: at pre-survey, McKinley students' scores ranged from 36 
to 57 (range of 21 points), while at post-survey, scores ranged from 33 to 60 (range of 27 points). While the mean moved up, a few students actually demonstrated potential confusion by scoring lower on post-survey. At the same time, the highest score received also increased from pre- to post-survey, indicating that more students demonstrated overall EL understanding. This positive change in EL is not completely surprising, as garden-based education programs have been found to increase program participants' understanding of and appreciation for natural ecosystems as well as increased willingness to engage in pro-environmental behavior (Desmond et al., 2004; Ozer, 2007; Zelenika, Moreau, Lane, \& Zhao, 2018).

On the other hand, for Olinder Elementary students, there was no statistically significant increase. These students, who did not partake in any specific EE programs over the course of their semester, had a score increase of only 0.38 points, with a presurvey mean score of 46.38 and a post-survey mean score of 46.76 . Olinder students' score range also increased: at pre-survey, Olinder students' scores ranged from 35 to 59 (range of 24 points), while at post-survey, scores ranged from 32 to 58 (range of 26 points). In contrast to McKinley students' scores from pre- to post-survey, the highest score received by Olinder students actually decreased by one point and is lower than McKinley students' highest score.

When comparing these two groups of students between each other, there is no statistically significant difference between McKinley and Olinder pre-surveys or between McKinley and Olinder post-surveys. It is interesting to note that no statistically 
significant difference between school groups at pre-survey demonstrates consistency of EL rates in a variety of student populations.

With McKinley students demonstrating a statistically significant increase from pre- to post-survey, it likewise interesting to assess the changes in each of the five distinct EL categories. Each step in the five-stage EL chain is crucial for development of environmentally literate students (Hungerford \& Volk, 1990). For McKinley students, each category increased, with the exception of action, which had no change pre- to postsurvey. On a 12-point range of possible scores for each category, three being the lowest and 15 being the highest, only awareness (11.52) and attitude (10.89) initially started with a score above the halfway point (9). Knowledge (6.85), skill (8.93) and action (7.67) all had a pre-survey mean score below the halfway point (9). The low scores in these categories demonstrate a general confusion regarding these topics. Interestingly, awareness, as the first step in the EL chain, had the highest pre-survey score, while action, the last step in the EL chain, had the lowest pre-survey score.

Only awareness showed a statistically significant increase on the EL survey. This small but significant change signifies the catalyst for overall EL score change. As the first stage in developing environmentally literate citizens, there was a change expected in this category, if any, due to the possible sequencing of EL components. This was also the only category of the five that increased by over a whole survey point (1.07), which proved to be a large enough change to affect overall mean EL score. Additionally, this category could have shown the largest mean score change because of its age-appropriate nature: as the first step in EL, it was the category that successfully increased. 
Additionally, although the third awareness question, regarding the understanding that students are creating habitats for bees and bugs with their garden, decreased slightly, this is most likely due to its already high score: out of a possible 5, the pre-survey mean score was 4.89 , indicating that students already understood the positive environmental impacts of a school garden. With a more challenging question regarding awareness of human impacts on the environment, we may have seen a larger mean change in the overall category.

As the first EL category, awareness showing the largest change in mean score follows alongside many previous writings and definitions of EL that describe the importance of understanding of the interaction between humans and the natural environment as a step in becoming environmentally literate. Roth describes the awareness stage of EL progression as "Perception of human/nature interactions and consequences in general or around a particular issue" (1992, p. 26) and lists it as the first stage of EL. Previous literature also suggests that a positive increase in environmental awareness is correlated with students participating in school garden programs (Brynjegard, 2001; Chawla, 2007; Hilgers, Haynes, \& Olson, 2008). Coyle (2005) indicates that in general, environmental awareness is high nationwide, but that knowledge, general understanding of environmental science, is low, which coincides with findings in this study in that awareness scores were highest and knowledge scores were lowest.

Despite being closely related to awareness, knowledge showed much lower scores (pre-survey 6.85, post-survey 7.30) and a smaller mean score increase ( +0.44 points). In fact, despite knowledge technically being the predominant focus of the GS program, this 
category had the smallest score increase, 0.44 points, and had the lowest post-survey score, 7.30. Within the knowledge section, the most McKinley students (16, 59.2\%) answered "What do roots do?" correctly at post-survey. Knowledge of root function was the only question that over half of the students were able to answer correctly. This coincides with the large amount of root knowledge demonstrated in journal entries. Additionally, much of the hands-on work in the GS program was done around identifying and observing roots, resulting in many student-prompted questions and conversations. Interestingly, only eight students were able to correctly identify what should be placed into a compost bin by post-survey, despite having an on-site compost bin. Four $(6.7 \%$ of all knowledge responses) journal responses specifically mentioned learning what roots do, while only two (3.0\%) journal response mentioned learning what can be composted. While nonrenewable and renewable resources were discussed briefly within a workshop lesson, based on its lack of attachment to a hands-on lesson, it seems reasonable that so few students $(5,18.5 \%)$ were able to correctly identify a nonrenewable resource on the post-survey. The inability to correctly answer this question, which was extracted directly from CHEAKS, supports the survey's criticism that questions can be too difficult and above a child's direct control or interaction (Evans et al., 2007). The low environmental knowledge found in this study is consistent among findings from other environmental educators: Charles Saylan, co-founder and CEO of Ocean Conservation Society, explains despite the rise in environmentalism, still only $20 \%$ of the general public could really be considered scientifically literate (Saylan \& Blumstein, 2011). However, McBeth and Volk (2009) contrast the findings of this research: they measured environmental 
knowledge as the highest-scoring category in distribution of the MSELS to middle school students, followed closely by positive environmental attitudes. Despite the educationbased intervention in this research, knowledge change among these program participants remains relatively low.

Next, although attitude mean score increase was not statistically significant according to survey results, this category was one that showed significant change through journal entries and observations. While in general, some survey questions showed little or no increase due to the fact that the pre-survey score was already high, the questions regarding knowing that others recycle and that pollution impacts the environment both started just above a 50\% score: recycling mean score at pre-survey was 3.81 and pollution mean score at pre-survey was 3.52 (possible points range of $1-5$ ). However, attitudes toward testing on animals had a mean score of 4.11 on post-survey, out of a potential five points, and this was the only individual question in the attitude portion of the EL survey that had a statistically significant change from pre- to post-survey. This increase in almost a full point in score is interesting in that specifically the topic of companies testing on animals was talked about least of all attitude question topics during GS lectures (other survey question topics were recycling and pollution). Toward the end of the program, students did complete a worksheet that included companies testing on animals, which must have stood out to many. In addition, one of the largest attitudinal changes found via journal entries was regarding bugs that took home in the garden beds. The interest and empathy that developed toward these bugs could also account for the statistically significant increase in this particular survey question. Sobel (1996) mentions 
the importance that children first develop positive environmental affect and that this provides the foundation for motivation to engage in pro-environmental behavior.

A major attitude observation by the researcher is that a reduction in fear and an increase in appreciation and intrigue in the garden bed was apparent due to the close interaction with nature offered in the GS program. In the first week of garden education, students reflected feelings of fear, displeasure, and apathy toward their participation in outdoor education. Students wrote phrases such as I felt... "gross because the fertilizer was stinky," "weird and nasty," and "good but [I was] scared of [redacted student name] was chasing us with worms." Throughout the duration of the program, many positive feelings toward the garden program itself, each other, and the environment appeared. Students journaled phrases such as "I felt great that I was touching and saving worms," "I felt great and learned some amazing things," "I felt bad because people kill worms," "I felt amazing. I was happy because I got to plant a pea seedling," and "I felt happy because I was helping the environment.” In studying EE experiences, Stevenson et. al (2013) found that EE that includes an outdoor component has a positive effect on learners' attitudes. These attitudinal changes support Louv's (2005) nature deficit disorder argument in that typical outdoor exposure among children today is very limited, resulting in fear and dislike for the outdoors, which was found at the beginning of the EE intervention. However, over the course of the GS program, study participants used time spent in the garden to develop an appreciation of and fascination with nature, in addition to a reduction in unease and dislike for nature. The qualitative data collection methods 
suggest that pro-environmental attitude actually had an important increase over the duration of the GS program.

Next, after the statistically significant increase in awareness, skill had the greatest mean score increase of almost a full point $(+0.89)$, although this change did not prove to be statistically significant. It is interesting that the skill survey question on reducing waste by composting had more students answering incorrectly ( 21 students) than did correctly (7 students) on post-survey, as opposed to the other two skill questions, which each had 20 students $(74.1 \%, \mathrm{~N}=27)$ answering correctly. The students did have an on-site compost bin, which was used in lessons and frequently turned and observed by students. However, students were clearly still confused at the purpose of a compost bin in reducing waste as only six $(22.2 \%)$ of students could correctly identify that separating food scraps into compost was an effective way to reduce waste on post-survey. While some aforementioned observations indicate that students were interested in utilizing the compost bin, the complicated topic of waste management and the short duration of the program, which did not allow for usage of the product of the compost bin, may account for the fact that understanding of why to use composting was missed. Additionally, the use of the vocabulary waste in the survey question may have been confusing for study participants, who are more familiar with terms such as trash or garbage. Also, 19 students (70.4\%) were able to correctly answer that turning off the faucet while washing hands was a good way to reduce water usage at pre-survey, demonstrating some initial understanding of this skill before the onset of the program. McBeth and Volk (2010) showed with their MSELS distribution that many students lack the problem-solving skills 
necessary to combat environmental issues in their local ecosystem, which coincides with the low skill scores found in this research.

The culminating component of EL, action, showed no change on this survey. Like for skill, it is possible that the length of the program and the restricted timing of collecting data could both account for inability to track changes in action. The low mean score changes for other categories of EL, perhaps indicate, as the last step in the EL chain, action would likely not increase. This finding coincides with preexisting EL research emphasizing the importance of demonstrating changes in each of the five pieces of EL in order to truly become an environmentally literate citizen (Hungerford \& Volk, 1990). When the National Science Teachers Association made its first comments on EE, it stated that a foundation of environmental knowledge is necessary in forming adults who are capable of performing environmentally appropriate actions (1985). This parallels the findings of this research that a lack of change in some of these other EL categories leaves action with the inability to increase. Roth (1992) mentions that at the nominal EL stage, students develop awareness toward their environment and an attitude of respect and concern for nature, but the only behaviors taken part are within family, school, or youth organizations aimed at maintaining environmental quality and responding behaviors. With a larger increase in the knowledge and skill categories, perhaps a change in action would have been seen. Despite original theories of EE indicating that knowledge was the greatest factor to behavior change (Kollmuss \& Ageyman, 2002), these results indicate that knowledge may not be as important of a step, further emphasizing the importance of the other categories mentioned by EL. The final stage of the EL continuum, operational 
EL, is perhaps only possible when categories come together to result in action performed (Roth, 1992).

In general, GS program participants did show a statistically significant increase in EL rates. The low increase in attitudes and consistency in action on the EL survey is surprising, as time spent outdoors has shown to increase pro-environmental attitudes and behaviors in children (Stevenson et al., 2013). After awareness, the only single category that showed a statistically significant increase, skill and attitude increased by the largest amount. It is similarly interesting to note that knowledge, the predominant focus on the GS program itself, increased the slightest, by only 0.44 points. After the statistically significant mean score change for awareness, the largest changes in mean score from presurvey to post-survey were for skill $(+0.89)$ and attitude $(+0.81)$ out of a 12 possible point range. However, these findings emphasize the necessity for a variety of data collection methods, as well as brings into question the validity of relying solely on standardized testing for students at this age and reading comfortability level. Although by the survey accounts, only awareness increased a statistically significant amount, student journal entries and researcher observations indicate an important increase in attitude as well.

Although some literature (Coyle, 2005; Roth, 1992) suggests there is a degree of sequencing in the steps of EL to creating environmentally literate citizens who are able to participate in pro-environmental behavior, the findings from this research suggest that there may not be a consecutive timeline necessary in changing some of these steps. Although awareness, the first EL stage, was the only component that showed a statically significant increase in quantitative data collection methods, attitude, the third category, 
also showed significant increase in qualitative data collection methods. Additionally, all categories demonstrated some change over time via journal entries and researcher observations. It is possible that the impact of the outdoor experience creates a dynamic learning opportunity in that change does not occur step-by-step down the EL chain. By simply taking students who are not regularly able to explore nature in their urban environment outside and seeing what happens, there is room for change in a variety of different aspects of EL. Figure 29 summarizes components of EL originally proposed in this study: instead of sequential attributes, here the lightest green indicates areas of change identified by this research while the darkest green still indicates that action is the pinnacle EL step. 


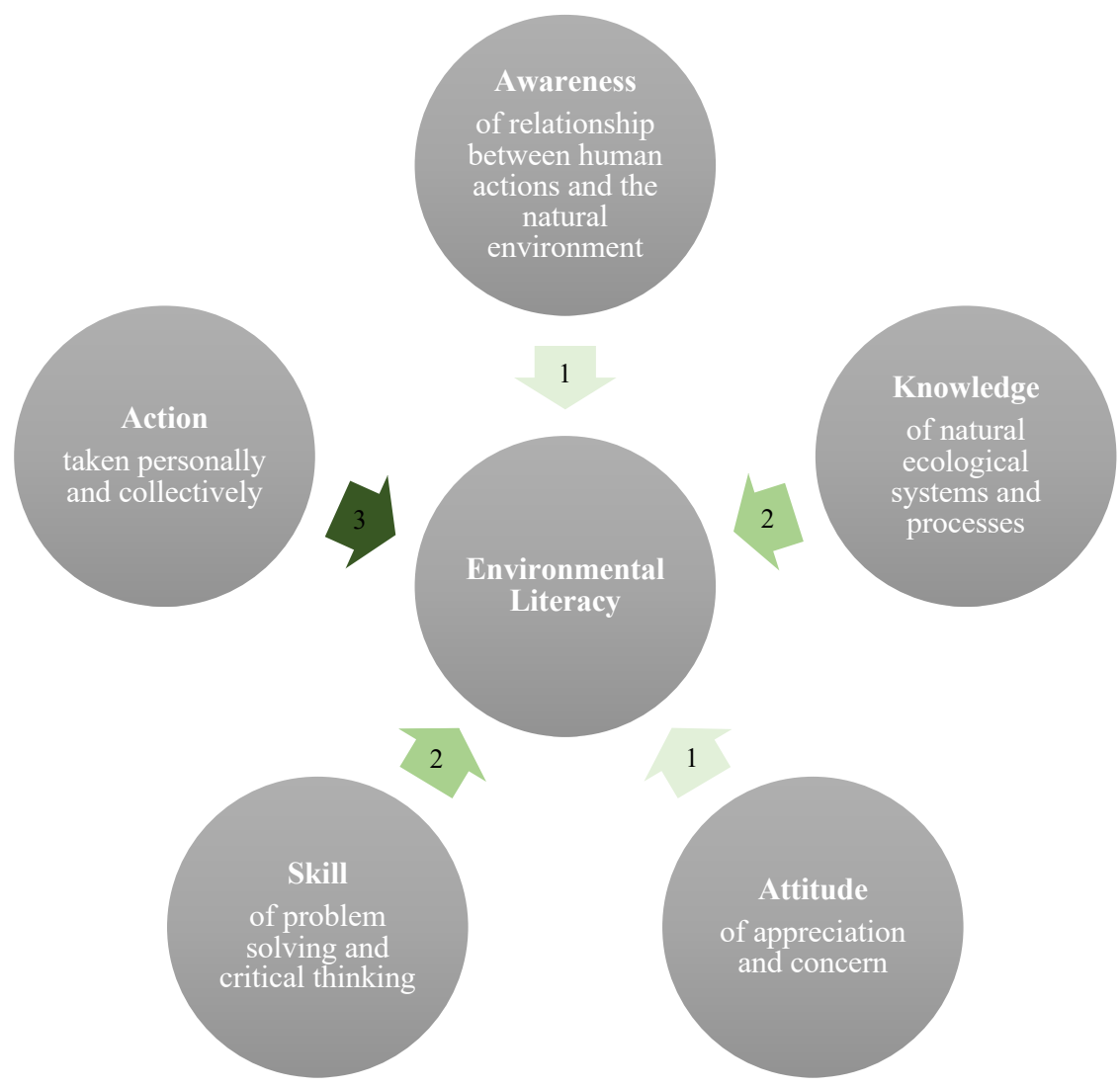

Figure 29. EL components.

In attributing the change found in EL scores, the most impactful component therefore of this EE program is the outdoor portion. As each hour-long class consisted of an approximately 25 minutes of lecture with an activity, craft or worksheet, and then 25 minutes of time in the garden beds, this program may not have had the same significant impacts if it were conducted solely based on lecture and activities. Many aspects of the GS program were of interest to the researcher, including having college interns as role models in the classroom, introduction of a new teacher, lesson-based activities such as crafts and food taste-tests, and in general an introduction to science. However, the most important piece of the GS program for changing EL was the fact that the students were 
able to spend time outside. In most EL categories, topics discussed most in student journal entries were garden based. Of awareness journals, $66.7 \%$ were about gardening; for knowledge, $60.6 \%$ were about gardening, plants, or bugs; for skill, $62.5 \%$ were about gardening; and for action, 79.0\% were about gardening. Additionally, researcher observations such as a reduction in fear of bugs, an increase of ownership and pride for work accomplished, increased focus and ability to perform tasks to completion, and a retention of knowledge specific to activities such as watering and taste-testing harvested foods, all come from time spent in the garden beds.

The field trip to the six-acre urban farm proved to be an effective culmination for the GS program, as students were able to see the larger impact their gardening work can make. The Environmental Educator at the field trip to Veggielution Community Farm mentioned the strategy she calls "Earthing," in which she makes children simply stick their hands into the dirt. "The soil really grounds young people and totally calms them down," she explains, evident by the way she adds pulling weeds, digging holes, and planting seeds to her curriculum (J. Barba, personal communication, December 13, 2018). Without the nature-based aspect of the EE program, it is unlikely to have found the same positive impacts on students' EL. 


\section{Implications \& Recommendations}

While extensive research exists on the impacts of garden education programs in schools, this research is the first to assess changes specifically in EL. Additionally, this study used a unique research demographic in a Latinx, underserved community.

The implications of this research are that the school garden-based education movement is effective in increasing EL in schoolchildren, particularly in environmental awareness and attitudes, in addition to the ongoing list of positive physical, emotional, and cognitive consequences. However, additional program factors would be needed to raise additional EL factors, such as environmental knowledge, skills, and actions. To create environmentally literate students, further research is needed that includes increased program length, embedded class curriculum, and data collection of action outside of the program itself.

With these implications in mind, below are recommendations for future research to continue to contribute to this body of literature:

\section{Recommendation 1: Lengthen EE Program \& Integrate with Existing Curriculum}

While this program demonstrated changes in EL among program participants, a longer program may provide the opportunity to more closely pinpoint changes in students. Long-term EE program research is rare as programs are expensive to monitor and facilitate. The GS program currently only lasts six to seven weeks each semester due to time taken to recruit, train, and background check student interns.

In addition, the length of the program not only affected the content taught, but also the amount of time actually spent outside. More time spent in the garden per workshop 
might have further influences on the journal and observation changes. The need for more time spent outdoors is particularly indicative for this study population: previous research found that while time spent outdoors has a positive impact on EL, Hispanic students had EL scores that were both lower and that increased more slowly than those of their peers (Stevenson et al., 2013).

While may pro-environmental behaviors, skills, attitudes, and knowledge take time to curate in participants, a longer program would provide better insight into the effectiveness of the EE method. Specifically within the realm of hands-on garden education programs, rewards reaped within the context of raised-bed gardens takes weeks to months to identify. Much of the work these students did in planting, caretaking, and composting, could not truly be recognized until long past the timeline of this program.

The uniqueness of the garden-based education program also separates itself from the rest of the school day, thus limiting the opportunities to tie GS lessons into ongoing Math and ELA classes. For example, students were reading Esparanza Rising, a story which takes place in a California camp for Mexican farm workers. While garden educators influenced vocabulary brought up by the students from their reading throughout the program, this would have been an ideal opportunity to tie in garden-based education with critical thinking through their reading exercises. Additionally, EL could be comprehensively tied into subjects that constitute more of each teacher's time, such as practicing math skills by measuring growth of plants over time or practicing ELA skills by reading environmental texts. Time and resources are common barriers to teaching EE as a part of the regularly assigned coursework, and thus changes must be made in the way 
curriculum standards are set, instructional focus in determined, and interdisciplinary integration is used.

In lengthening the GS program, the weekly lessons should couple closely with the progression of the students' semester so that general curriculum needs are addressed in the time the GS program takes up each week. The GS Project Coordinator can work in conjunction with the primary teacher in aligning lesson plans to complement each other, instead of running the GS program as an academically siloed experience for students. In the future, a full-time Project Coordinator position as well as internship positions for the academic year instead of per semester could decrease "down time" between semesters to allow a longer program. Without these gaps in program planning and coordination, classrooms could participate in the GS program across the entirety of a semester instead of for the six to seven week period. To accommodate for some of these financial burdens as a consequence of a longer program, the Project Coordinator could develop and teach a permanent set of lesson plans, instead using interns as classroom management support, thereby reducing the number of interns needed and the number of hours interns worked. Another solution follows CUC's experiential education model closely: by pairing the GS program with an existing class for undergraduates studying EE, urban agriculture, or teaching, SJSU students can practice lesson plan development, classroom management, and public speaking by engaging with their coursework in the GS classrooms. In general, treating the garden-based program as education intertwined with consistent weekly school schedules may further increase EL rates in students. 


\section{Recommendation 2: Collect Data Outside the EE Workshops \& Create More Nuanced Assessment Mechanism for Reflection}

One major limitation of this study was that only actions during the actual garden education program were observed. A more comprehensive study should capture observations long-term and outside of the program itself. Future research should look to capture data beyond the workshops themselves: what the participants know and do at home, in their traditional classroom, etc. In addition, several students would share stories of lessons learned that they then taught their parents, gardening history they shared with grandparents, healthy recipes practiced at home, etc. By allowing data collection to go beyond the timeframe of the workshops themselves, a researcher may be able to capture further insight into changes in knowledge, attitudes, actions, etc.

Additionally, allowing students to keep journals beyond just the garden education time slot would be helpful in capturing more applicable data to everyday environmentalism. So many of the journal responses only collected what the students thought in that exact moment, therefore missing the effect the lessons learned in garden workshop has on their outside perspective. For example, students submitted reflections such as, "[Today in garden workshop, I felt...] good and cold and it was raining," “[Today in garden workshop, I learned...] nothing," or "[Today in garden workshop, I

did...] I sat with my friend because it was raining, I was sick and didn't want to get more sick." While these insights are relevant, they are not helpful in the overarching theme of changes in EL. 


\section{Recommendation 3: Further Develop Holistic Assessment Measures Method Beyond the Traditional Written Survey}

While changes could be observed via journal entries or researcher observations, awareness was the only EL category to show a statistically significant increase via use of the surveys. Surveys alone are not enough to capture changes in some of these difficult or abstract categories, nor does survey data alone tell the complete story. By combining data collection methods, additional insights in participant changes and unique aspects of the program were captured.

Attitude is a great example of a Likert-scale survey alone not capturing changes in children. While many students' journal entries reflected more positively toward their garden workshop classes and the environment in general, these attitudinal changes were not reflected within their survey scores. As aforementioned, researcher observations indicated a decrease in fear of the garden beds and an increase in empathy and ownership over the course of the GS program, although the EL survey reflected no statistically significant difference across the same time frame.

Another indication of this is knowledge and skill gained around composting. Composting was only addressed on the survey under knowledge and actually decreased from pre to post-survey. However, visual observations indicated that students did actually have an increased understanding of the process of composting, as indicated for example by the observation of one student asking her garden instructors if she can compost her leftover fruits and vegetables despite being told to throw them in the classroom trashcan. The survey as a tool may not be the most effective way to gather data on knowledge increases due to the specific, closed-ended questions that do not allow students to project 
all that they have learned. Additionally, some of these larger, more abstract concepts, such as why composting is important or why some items can be composted while others cannot, may be too large for understanding in a seven-week period and too abstract to condense to one multiple choice question on a survey. An alternate solution to data collection methods for topics such as these are assignments and tasks observed by researchers, such as setting out items to compost and observing the frequency with which students can correctly place a compostable item into the bin.

Another interesting observation is that this age or reading level may not necessarily capture true responses. For example, in the awareness multiple-choice question asking to identify the nonrenewable resource from four options. Interestingly, when administering the pre-survey, several students asked what a nonrenewable resource was, demonstrating that this question may have been advanced for their level of science education. This question, directly adopted from CHEAKS, may be one that correlated to its critique of being too advanced for accurate completion by an elementary school student (Evans et al., 2007). Additionally, as I circled Olinder classroom collecting completed survey packets, one boy stopped me to ask what "petroleum" meant. I glanced down at his paper, noticing that he had circled this, the correct answer, on his survey sheet. Although he had answered correctly, his answer did not reflect understanding of the concept or vocabulary. The questions selected for this survey were chosen for general knowledge, not necessarily a consequence of what was taught in the lessons.

Survey data, or standardized testing in general, may not be a valid representation of knowledge gained or changes made, as many of the categories tested in this research 
increased in journal or observation results, but were not statistically significant via survey. While some questions on the survey were explicitly reviewed as a part of the program (what do roots do), others were not. The survey here is not necessarily a tool to assess effectiveness of this specific program, but instead to assess changes in general EL. Some information was extrapolated to see if attitudes/actions, etc. go beyond the scope of gardening. Therefore, while some categories may have changed beyond the scope of the questions' asking, they were not able to be captured using these tools. In order to gather a true sense of EL rates among children, especially of this demographic and reading ability, holistic assessment measures of EL should be developed.

Beyond the traditional survey, a narrative pre- and post-survey could be used in the future to collect a larger grasp on students' understanding changes. For example, including open-ended questions in addition to the multiple choice and Likert scales, or having students write or draw what they know about the environment or gardening beforehand provides a specific insight into knowledge gained. Additionally, many students show difficulty in writing, but feel confident in speaking about their experiences. The addition of oral surveys may overcome some of the literacy challenges as well. 


\section{Conclusion}

Despite differences in application and measurement, the goals of EE are constant: creating citizens who can act appropriately toward the environment by using critical thinking, problem solving, and knowledge-backed decisions. EE prepares elementaryaged children to become global citizens capable of pro-environmental behavior backed by the understanding of the consequences of their decisions, a foundation of scientific information regarding the Earth's function, feelings of concern and empathy toward the ecosystem around them, and the tools to complete favorable actions. Many studies have shown the importance of outdoor experiences during childhood, as well as the positive impacts of garden-based education programs in elementary schools for students.

By first developing an EL assessment tool, the baseline level of elementary-aged students in this underserved, Central San José community was determined to be lowmoderate. There was no difference between students at the onset of the Spring 2019 semester, demonstrating consistent EL levels and EE opportunities available, despite students being in two different school districts.

In this research, a garden-based experiential education opportunity demonstrated EL increases among participants after completion of such a program. While this program may not be enough to produce children who are outright environmentally literate, it was shown to increase the EL level a statistically significant amount, which could not be said for the similar elementary-aged control group during the same time frame.

In California, SB720 enforces the need for students to have access to EE opportunities in order to develop EL. While having the time and resources to incorporate 
EE into regular curriculum can be a challenge for many educators, this study indicates that a garden-based experiential education opportunity is an effective strategy to increase EL in elementary school-aged children. The GS program is both equitable and easy to replicate, as demonstrated by its success in an urban, Title 1 elementary school.

A garden-based EE program is specifically sufficient in increasing environmental awareness and attitudes for elementary-aged children. Awareness of interactions between humans and the natural environment is the first stage in the EL continuum, and as such this category showed a slight, but significant increase for students in the garden education program. Additionally, this intervention was sufficient in increasing environmental attitudes, as demonstrated through students' journals and researcher observations. This unique outdoor education program offered students the opportunity to spend time face-toface with nature in their own urban environment. This outdoor time resulted in reduced rates of fear and increased rates of empathy and excitement.

Based on the changing of these two categories, the sequencing of the EL categories may not be as important as previous literature suggests. Action still holds as the pinnacle EL stage and the end-goal of developing environmentally literate students. There was not a change in action possibly because there was not a change in all preceding categories. This research does not give insight into when knowledge or skill categories develop in learners. It is possible, instead, that simply by taking children who previously do not have access to EE, or even a lot of science education or access to outdoor experiences, and placing them in a nature-based experiential education program, several categories have the opportunity to change at once, instead of developing in a consecutive chain. 
Therefore, the outdoor experiences of this program showed to be the most impactful aspect of the overall EE program. While each GS workshop consisted of in-class lectures, worksheets, and activities, portions spent in the raised bed garden provided the most opportunities for change in these critical areas, as well as the widest opportunity to observe attitude, behavior, and understanding changes. Outdoor experiences were comprised of time spent working, making observations, and having free time in the raised bed garden as well as on the culminating experience at a local six-acre farm. Of particular interest was the reduction in fear and dislike for an increase in appreciation and excitement regarding the garden, particularly of worms and bugs, among children who may not frequently have the opportunity to explore an outdoor environment. This research proved to be effective in combating some of the negative consequences of nature deficit disorder by reducing barriers to outdoor experiences.

The underserved community from which these students reside does not typically allow much outdoor time. Many students in the GS program walk to schools from nearby apartment complexes, stay on campus for long hours at after school programs run by partner organizations, and even have their daily recess on a blacktop. The GS program was originally developed for students in these schools in order to give them the opportunity to not only understand where food comes from, but also to have time in their day cut out specifically to play outside and to learn science. At the onset of this program, I witnessed nature deficit disorder in many students: they were uninterested in going outside, afraid to put their hands in the beds because of what may lie below the soil, and unable to focus on the task at hand. 
Researchers and environmental educators need a holistic approach to understanding changes that take place among learners in such an intervention. Future research should include a longer EE program and more nuanced data collection methods to further assess changes in developing EL in elementary school children. While survey data did express an overall increase in EL, particularly for awareness, researcher observations and student journal entries also captured changes among participants in other aspects of EL, particularly in attitude. Data collection methods for EE programs should capture the transfer of lesson ideas beyond time spent in the GS workshops as well as evidence in some of these more obscure topics like attitude and behavior change. While EE programs can be difficult to study due to their expense or sample size, an on-site school garden allows for a relatively easy program and study method.

To be effective, EE needs to be integrated across disciplines, incorporated into curriculum, and tied into hands-on, nature-based experiences. Schools could provide opportunities for more students to be involved in on-site raised bed gardens, including incorporating science lab work, facilitating afterschool garden clubs, or hosting guest environmental educators. Students need the opportunity to experience the outdoors in a comfortable, close environment in addition to learning new vocabulary, concepts, and about pro-environmental behaviors. This hands-on outdoor EE program proved to be effective in increasing EL in elementary-aged participants in just seven weeks; therefore, I am hopeful that with continued program development and EL research, a future of environmentally literate learners is obtainable. 


\section{References}

Adkins, C., \& Simmons, B. (2002). Outdoor, experiential, and environmental education: converging or diverging approaches? ERIC Clearinghouse on Rural Education and Small Schools. (ED467713).

Agee, J. L. (2002). A child's garden of standards: Linking school gardens to California education standards, grades two through six. California Department of Education.

Aguilar, O. M., Waliczek, T. M., \& Zajicek, J. M. (2008). Growing environmental stewards: The overall effect of a school gardening program on environmental attitudes and environmental locus of control of different demographic groups of elementary school children. HortTechnology, 18(2), 243-249.

Allington, R. L., \& Johnston, P. H. (2002). Reading to learn: Lessons from exemplary fourthgrade classrooms. Guilford Press.

Barker, J., \& Weller, S. (2003). “Is it fun?” Developing children centered research methods. International Journal of Sociology and Social Policy, 23(1/2), 33-58.

Benson, J., \& Hocevar, D. (1985). The impact of item phrasing on the validity of attitude scales for elementary school children. Journal of Educational Measurement, 22(3), 231240.

Bhattacherjee, A. (2012). Social science research: Principles, methods, and practices $\left(2^{\text {nd }}\right.$ ed.). Global Text Project.

Bixler, R. D., Floyd, M. F., \& Hammitt, W. E. (2002). Environmental socialization:

Quantitative tests of the childhood play hypothesis. Environment and Behavior, 34(6), 795-818.

Burros, M. (2009, March 19). Obamas to plant vegetable garden at White House. New York Times, pp. 20.

Byrne, J., \& Wolch, J. (2009). Nature, race, and parks: Past research and future directions for geographic research. Progress in Human Geography, 33(6), 743-765.

Brynjegard, S. (2001). School gardens: Raising environmental awareness in children. ERIC Documentation Reproduction Service (ED452085).

California Department of Education (2019). 2017-18 School accountability report card, McKinley Elementary. https://sarconline.org. 
California Department of Education (2019). 2017-18 School accountability report card, Selma Olinder Elementary. https://sarconline.org.

California League of Conservation Voters (2012, October 4). California league of conservation voters education fund releases results of new statewide poll on California latino voters' environmental values [Press Release].

California Native Garden Foundation. (2018) About CNGF. http://cngf.org/about/

Cammack, C., Waliczek, T. M., \& Zajicek, J. M. (2002). The green brigade: The psychological effects of a community-based horticultural program on the selfdevelopment characteristics of juvenile offenders. HortTechnology, 12(1), 82-86.

Campbell, D. T., \& Stanley, J. C. (1963). Experimental and quasi-experimental designs for research. Handbook of Research on Teaching, 171-246.

Chall, J. S. (1983). Learning to read: The great debate. New York, NY: McGraw-Hill.

Chavez, D. J. (2012). Latinos and outdoor recreation. Outdoor recreation trends and futures: a technical document supporting the Forest Service 2010 RPA Assessment (p. 74-77). Gen. Tech. Rep. SRS-150. Asheville, NC: US Department of Agriculture Forest Service, Southern Research Station.

Chawla, L. (1999). Life paths into effective environmental action. The Journal of Environmental Education, 31(1), 15-26.

Chawla, L. (2007). Childhood experiences associated with care for the natural world: A theoretical framework for empirical results. Children Youth and Environments, 17(4), 144-170.

CommUniverCity SJSU. (n.d.) What we do. https://cucsj.org/about-us/what-we-do.

Coyle, K. (2005). Environmental literacy in America. National Environmental Education \& Training Foundation.

Creswell, J. W., \& Clark, V. L. P. (2017). Designing and conducting mixed methods research. Sage Publications.

Cronin-Jones, L. L. (2000). The effectiveness of schoolyards as sites for elementary science instruction. School Science and Mathematics, 100(4), 203-211.

Davis, J. (1998). Young children, environmental education, and the future. Early Childhood Education Journal, 26(2), 117-123. 
Desmond, D., Grieshop, J., \& Subramaniam, A. (2004). Revisiting garden-based learning in basic education. International Institute for Educational Planning/Food and Agriculture Organization.

Dewey, J. (1923). Democracy and education: An introduction to the philosophy of education. Macmillan.

Duerden, M. D., \& Witt, P. A. (2010). The impact of direct and indirect experiences on the development of environmental knowledge, attitudes, and behavior. Journal of Environmental Psychology, 30(4), 379-392.

Elder, J. L. (2003). A field guide to environmental literacy: Making strategic investments in environmental education. Environmental Education Coalition.

Emma Prusch Farm Park Foundation. (n.d.). Foundation Projects. http://www.pruschfarmpark.org/prusch-park-foundation.html.

Environmental education: environmental principles and concepts, Cal. Senate Bill 720, Chapter $374 \S 51227.3$ (2018).

Environmental Literacy Task Force. (2015). A blueprint for environmental literacy. California Department of Education.

Evans, G. W., Brauchle, G., Haq, A., Stecker, R., Wong, K., \& Shapiro, E. (2007). Young children's environmental attitudes and behaviors. Environment and Behavior, 39(5), 635658 .

Fisman, L. (2005). The effects of local learning on environmental awareness in children: An empirical investigation. The Journal of Environmental Education, 36(3), 39-50.

Frumkin, H. (2005). Guest editorial: health, equity, and the built environment.

Google. (n.d.) [Google Maps of San José - McKinley Elementary and Olinder Elementary]. Retrieved June 20, 2018 from https://www.google.com/maps/@37.3408393,121.8698817,16z

Gough, N. (1990). Healing the earth within us: Environmental education as cultural criticism. Journal of Experiential Education, 13(3), 12-17.

Griffith, G., \& Scharmann, L. (2008). Initial impacts of No Child Left Behind on elementary science education. Journal of Elementary Science Education, 20(3), 35-48. 
Gruenewald, D. A., \& Manteaw, B. O. (2007). Oil and water still: How no child left behind limits and distorts environmental education in US schools. Environmental Education Research, 13(2), 171-188.

Hall, L., Hume, C., \& Tazzyman, S. (2016, June). Five degrees of happiness: Effective smiley face likert scales for evaluating with children. Proceedings of the 15th International Conference on Interaction Design and Children, 311-321.

Hilgers, K. R., Haynes, C., \& Olson, J. (2008). Assessing a garden-based curriculum for elementary youth in Iowa: Parental perceptions of change. HortTechnology, 18(1), 18-23.

Hong, A., \& Anderson, D. H. (2006). Barriers to participation for Latino people at Dodge Nature Center. The Journal of Environmental Education, 37(4), 33-44.

Hudson, S. J. (2001). Challenges for environmental education: Issues and ideas for the 21 st century. AIBS Bulletin, 51(4), 283-288.

Hungerford, H. R., \& Volk, T. L. (1990). Changing learner behavior through environmental education. The Journal of Environmental Education, 21(3), 8-21.

Johnson, B., \& Manoli, C. C. (2010). The 2-MEV scale in the United States: a measure of children's environmental attitudes based on the theory of ecological attitude. The Journal of Environmental Education, 42(2), 84-97.

Kamenetz, A. (2019, April 22). Most teachers don't teach climate change; 4 In 5 parents wish they did. NPR.

Klemmer, C. D., Waliczek, T. M., \& Zajicek, J. M. (2005). Growing minds: The effect of a school gardening program on the science achievement of elementary students. HortTechnology, 15(3), 448-452.

Kohlstedt, S. G. (2008). A better crop of boys and girls: The school gardening movement, 1890-1920. History of Education Quarterly, 48(1), 58-93.

Kollmuss, A., \& Agyeman, J. (2002). Mind the gap: why do people act environmentally and what are the barriers to pro-environmental behavior?. Environmental Education Research, 8(3), 239-260.

Krosnick, J. A., \& Alwin, D. F. (1987). An evaluation of a cognitive theory of response-order effects in survey measurement. Public Opinion Quarterly, 51(2), 201-219.

Lautenschlager, L., \& Smith, C. (2007). Understanding gardening and dietary habits among youth garden program participants using the theory of planned behavior. Appetite, $49(1)$, 122-130. 
Leeming, F., Dwyer, W., Porter, B., \& Cobern, M. (1993). Outcome research in environmental education: A critical review. The Journal of Environmental Education, 24(4), 8-21.

Leeming, F. C., Dwyer, W. O., \& Bracken, B. A. (1995). Children's environmental attitude and knowledge scale: Construction and validation. The Journal of Environmental Education, 26(3), 22-31.

Lineberger, S. E., \& Zajicek, J. M. (2000). School gardens: Can a hands-on teaching tool affect students' attitudes and behaviors regarding fruit and vegetables?.

HortTechnology, 10(3), 593-597.

Louv, R. (2005). Last child in the woods: Saving our kids from nature deficit disorder. Algonquin Books of Chapel Hill.

Marcinkowski, T. (1991). The relationship between environmental literacy and responsible environmental behavior in environmental education. Methods and Techniques for Evaluating Environmental Education. UNESCO.

Martin, S. C. (2003). The influence of outdoor schoolyard experiences on students' environmental knowledge, attitudes, behaviors, and comfort levels. Journal of Elementary Science Education, 51-63.

Mauthner, M. (1997). Methodological aspects of collecting data from children: Lessons from three research projects. Children \& Society, 11(1), 16-28.

McBeth, W., \& Volk, T. L. (2010). The National Environmental Literacy Project: A Baseline Study of Middle Grade Students in the United States. The Journal of Environmental Education, 41(1), 55-67.

Mellor, D., \& Moore, K. A. (2013). The use of scales with children. Journal of Pediatric Psychology, 39(3), 369-379.

Miller, M. R., Giesbrecht, G. F., Müller, U., McInerney, R. J., \& Kerns, K. A. (2012). A latent variable approach to determining the structure of executive function in preschool children. Journal of Cognition and Development, 13(3), 395-423.

Morgan, P. J., Warren, J. M., Lubans, D. R., Saunders, K. L., Quick, G. I., \& Collins, C.E. (2010). The impact of nutrition education with and without a school garden on knowledge, vegetable intake and preferences and quality of school life among primaryschool students. Public Health Nutrition, 13(11), 1931-1940.

Moroye, C. M., \& Ingman, B. C. (2013). Ecological mindedness across the curriculum. Curriculum Inquiry, 43(5), 588-612. 
Morris, J., Neustadter, A., \& Zidenberg-Cherr, S. (2001). First-grade gardeners more likely to taste vegetables. California Agriculture, 55(1), 43-46.

Moseley, C. (2000). Teaching for environmental literacy. The Clearing House, 74(1), 23.

National Environmental Education and Training Foundation. (1997). Annual Report. Washington (DC): NEETF.

National Resources Defense Council (2016, October). NRD report: Latinos are especially hard-hit by climate change. [Press Release] Retrieved from https://www.nrdc.org/media/2016/161013.

No Child Left Behind Act of 2001, Pub. L. No. 107-110, § 115, Stat. 1425 (2002).

Ozer, E. J. (2007). The effects of school gardens on students and schools: Conceptualization and considerations for maximizing healthy development. Health Education \& Behavior, $34(6), 846-863$.

Parks, Recreation, and Neighborhood Services. (n.d.) Community Gardens Program. City of San José. http://www.sanjoseca.gov/index.aspx?NID=599.

Pearson, A. R., Schuldt, J. P., Romero-Canyas, R., Ballew, M. T., \& Larson-Konar, D. (2018). Diverse segments of the US public underestimate the environmental concerns of minority and low-income Americans. Proceedings of the National Academy of Sciences, 115(49), 12429-12434.

Portney, L. G. (2020). Foundations of clinical research: Applications to evidence-based practice. FA Davis.

Public Policy Institute of California (2007). Latino attitudes and the environment. [Press Release]. Retrieved from https://www.ppic.org/content/pubs/jtf/JTF_LatinoAttitudesEnvironmentJTF.pdf.

Reissman, C.K. (1993) Narrative analysis. London: Sage Publications.

Roberts, N. S. (2013). Mixed race or mixed up? Making progress and breaking down barriers. In D. Dustin \& K. Schwab (Eds.), Just leisure: Addressing social and environmental justice in parks, recreation and tourism (p. 27-34). Urbana, IL: Sagamore.

Rosenfeld, A., \& Wise, N. (2010). The over-scheduled child: Avoiding the hyper-parenting trap. St. Martin's Griffin.

Roth, C. E. (1968). On the road to conservation. Massachusetts Audubon, 38-41. 
Roth, C. E. (1992). Environmental literacy: Its roots, evolution and directions in the 1990s. ERIC Clearinghouse for Science, Mathematics, and Environmental Education. (ED348235).

Ruggiero, K.M., \& Aydeniz, M. (2015, October 15-18). Assessing environmental literacy in the United States: A meta-analysis. [Conference presentation]. North American Association for Environmental Education, Annual International Conference, San Diego, CA.

Russell, C. L., \& Bell, A. C. (1996). A politicized ethic of care: Environmental education from an ecofeminist perspective. Women's Voices in Experiential Education, 172-181.

Saint Victor School. (2019). Giving for the Garden. https://www.stvictorschool.org/givingfor-the-garden.

Sanera, M. (2008). The problem with environmental education today: Is the tail wagging the dog. Dearborn, MI: Free Market Forum.

Saylan, C., \& Blumstein, D. (2011). The failure of environmental education (and how we can fix it). Univ of California Press.

Skelly, S. M., \& Zajicek, J. M. (1998). The effect of an interdisciplinary garden program on the environmental attitudes of elementary school students. HortTechnology, 8(4), 579583.

Sobel, D. (1996). Beyond ecophobia. Great Barrington, MA: Orion Society.

Stevenson, K. T., Carrier, S. J., \& Peterson, M. N. (2014). Evaluating strategies for inclusion of environmental literacy in the elementary school classroom. Electronic Journal of Science Education, 18(8), n8.

Stevenson, K. T., Peterson, M. N., Bondell, H. D., Mertig, A. G., \& Moore, S. E. (2013). Environmental, institutional, and demographic predictors of environmental literacy among middle school children. PLoS One, 8(3), e59519.

Steward, I. T., Purner, E. K., \& Guzmán, P. D. (2013). Socioeconomic disparities in the provision of school gardens in Santa Clara County, California. Children Youth and Environments, 23(2), 127-153.

Strife, S., \& Downey, L. (2009). Childhood development and access to nature: A new direction for environmental inequality research. Organization \& Environment, 22(1), 99122. 
Tanner, T. (1980). Significant life experiences: A new research area in environmental education. The Journal of Environmental Education, 11(4), 20-24.

Tilbury, D. (1995). Environmental education for sustainability: Defining the new focus of environmental education in the 1990s. Environmental Education Research, 1(2), 195212.

Tranter, P. J., \& Malone, K. (2004). Geographies of environmental learning: an exploration of children's use of school grounds. Children's Geographies, 2(1), 131-155.

United Nations Educational, Scientific, and Cultural Organization (1997, December 8-12). Educating for a sustainably future: A transdisiplinary vision for concerted action. International Conference on Environment and Society: Education and Public Awareness for Sustainability, Thessalokike, Greece.

Valentine, G., \& McKendrck, J. (1997). Children's outdoor play: Exploring parental concerns about children's safety and the changing nature of childhood. Geoforum, 28(2), 219-235.

Veggielution (2019). Our Farm. http://www.veggielution.org/our-farm.

Wells, N. M., \& Lekies, K. S. (2006). Nature and the life course: Pathways from childhood nature experiences to adult environmentalism. Children Youth and Environments, 16(1), $1-24$.

Zelenika, I., Moreau, T., Lane, O., \& Zhao, J. (2018). Sustainability education in a botanical garden promotes environmental knowledge, attitudes and willingness to act. Environmental Education Research, 24(11), 1581-1596. 


\section{APPENDIX}

Name:

Teacher:

I am: (circle one)
a) Female
b) Male
c) Don't want to say

Language my family speaks at home: (circle all that apply)
a) English
b) Spanish
c) Vietnamese
d) Other

What is your ethnicity, race, or origin? (circle all that apply)
a) Asian, Asian-American (Vietnamese, Thai, Laotian Chinese, Japanese)
b) Black, African-American
c) Hispanic or Latino/a (Mexican, Guatemalan, Salvadoran)
d) Native American or Alaskan Native
e) Native Hawaiian or Pacific Islander
f) White 
1. Driving cars leads to increased air pollution.

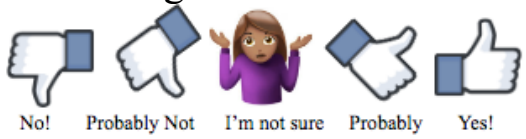

2. My actions can have a direct impact on the natural environment.

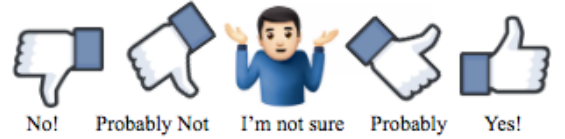

3. Growing flowers at my school creates a habitat for bees and butterflies to live.

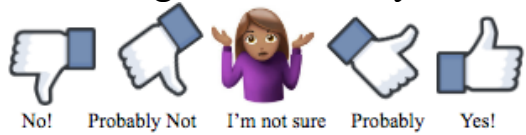

4. What do roots do?
a) Make food for the plant through sunlight
b) Move nutrients to all parts of a plant
c) Absorb water and nutrients from soil
d) I'm not sure

5. An example of a nonrenewable resource is:
a) Sunlight
b) Trees
c) Petroleum
d) I'm not sure

6. What should you put into a compost bin?
a) Juice pouches
b) Newspaper
c) Leftover hot dogs
d) I'm not sure

7. When people recycle used bottles, cans, and paper, I feel:

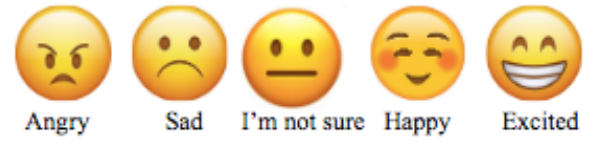

8. When I think about companies testing products on animals, I feel:

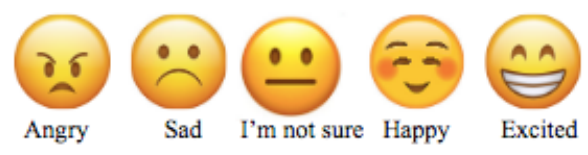


9. When I think about what pollution does to the environment, I feel:
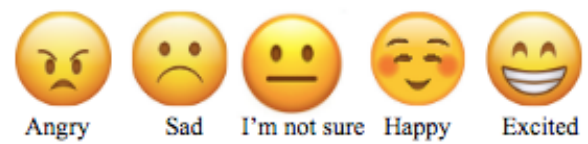

10. Water can be saved by:
a) Turning off the faucet when I wash my hands
b) Taking a bath instead of a shower
c) Using a different cup each time I need a drink
d) I'm not sure

11. Waste can be reduced by:
a) Using paper towels instead of cloth towels at home
b) Walking instead of driving
c) Separating my food scraps into compost
d) I'm not sure

12. One way to save energy is:
a) Using the dryer instead of hang-drying my clothes
b) Opening the refrigerator door while I decide what to eat
c) Using less air conditioning
d) I'm not sure

13. I have talked with my parents about how to help with environmental problems.

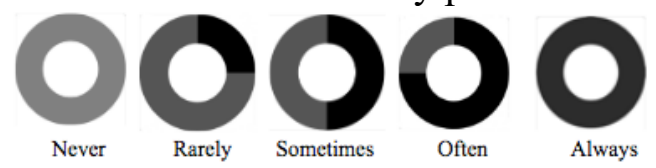

14. I leave the refrigerator open while I decide what to get out.

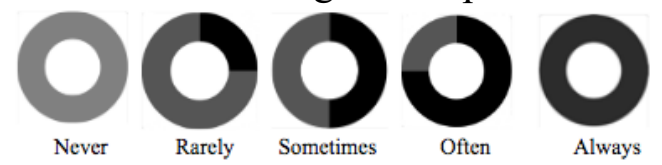

15. I have asked others what I can do to help reduce pollution.

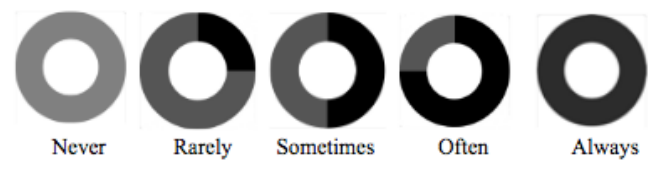

